Universidad de Lima

Facultad de Comunicación

Carrera de Psicología

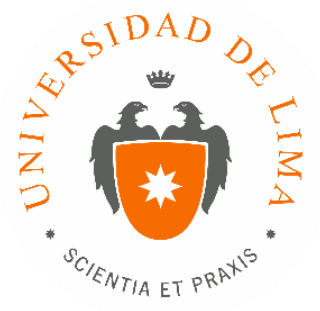

\title{
ADULTO DE 49 AÑOS CON TRASTORNO BIPOLAR TIPO II Y TRASTORNO POR DÉFICIT DE ATENCIÓN E HIPERACTIVIDAD (TDAH)
}

Tesis para optar el Título Profesional de Licenciado en Psicología

\section{Karen Márquez Benza}

20080615

\author{
Asesor \\ Paola Lindo Bárcena
}

Lima - Perú

Marzo del 2016 


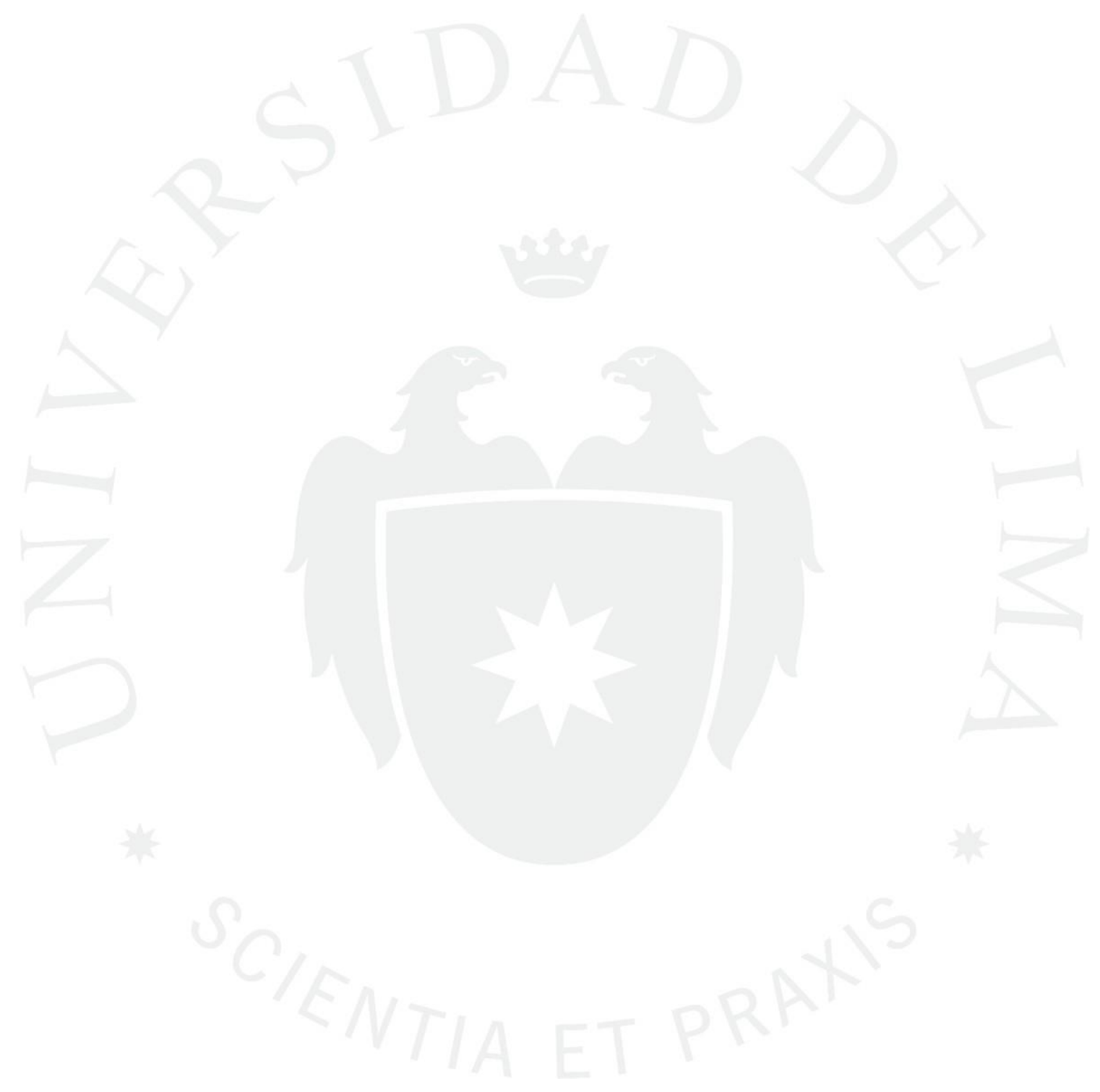




\section{ADULTO DE 49 AÑOS CON TRASTORNO BIPOLAR TIPO II Y TRASTORNO POR DÉFICIT DE ATENCIÓN E HIPERACTIVIDAD (TDAH)}




\section{RESUMEN}

Esta investigación consiste en la exploración de un estudio de caso único de un varón de 49 años diagnosticado con TDAH y trastorno bipolar tipo II. A través de la investigación se identifica la sintomatología del TDAH y trastorno bipolar tipo II a lo largo de la historia del evaluado mediante la anamnesis. También se describe el perfil neuropsicológico del paciente para corroborar su rendimiento cognitivo actual. Luego de la revisión de la sintomatología actual y el perfil neuropsicológico hallado, se propone una intervención pertinente según los resultados encontrados.

Palabras clave: TDAH en adulto, trastorno bipolar tipo II, depresión, comorbilidad, neuropsicología, tratamiento.

\footnotetext{
ABSTRACT

This research consists in the exploration of a unique case study of a male subject of 49 years of age, diagnosed with ADHD and bipolar disorder type II. This research allows to identify the ADHD and bipolar disorder type II symptomatology through the patient's history via the anamnesis. It also describes the subject's neuropsychological profile to verify his current cognitive performance. After revising the current symptomatology and the neuropsychological profile that were found, a pertinent intervention based on the results is proposed.
}

Key words: Adult ADHD, bipolar disorder type II, comorbidity, neuropsychology, treatment. 


\section{TABLA DE CONTENIDO}

CAPÍTULO I: PLANTEAMIENTO DEL PROBLEMA ........................................1

1.1 Descripción del Problema................................................................. 1

1.2 Justificación y Relevancia ............................................................

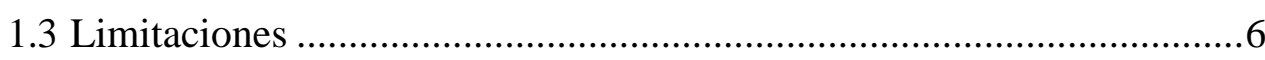

CAPÍTULO II: MARCO TEÓRICO ….............................................................................7

2.1 Trastorno por Déficit de Atención e Hiperactividad .........................7

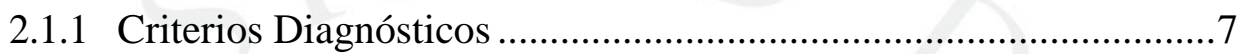

2.1.2 Prevalencia del trastorno por déficit de atención e hiperactividad en la

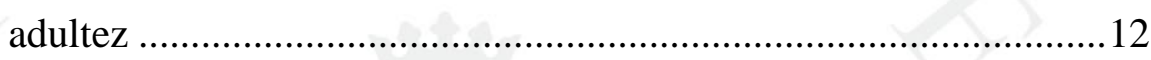

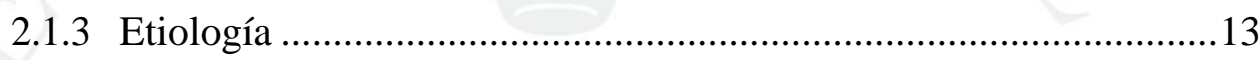

2.1.4 Características clínicas en la adultez ...........................................14

2.1.5 Trastorno Comórbidos......................................................................18

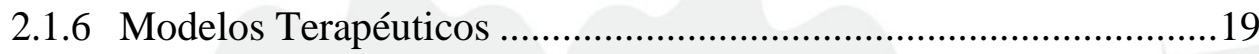

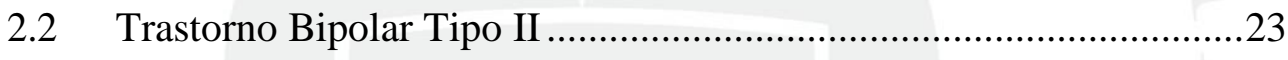

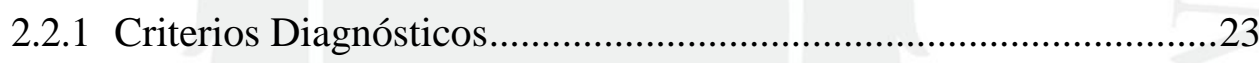

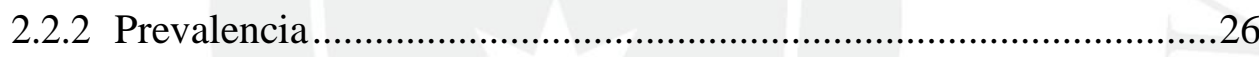

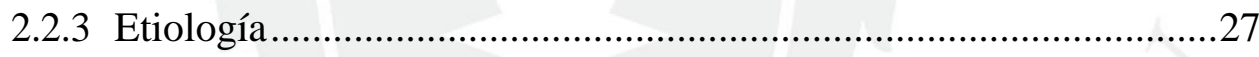

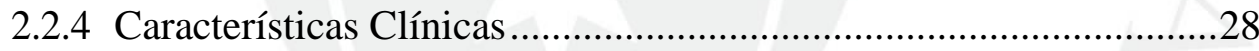

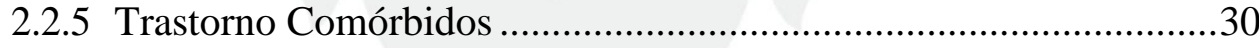

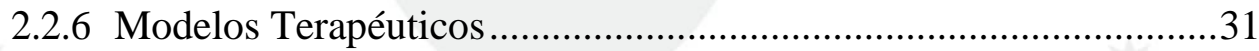

2.3 Neuropsicología de los trastornos psiquiátricos ................................33

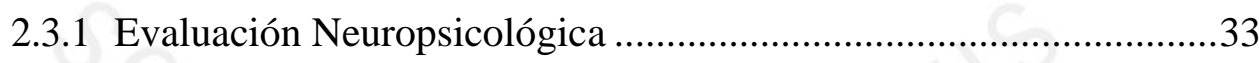

2.3.2 Características Neuropsicológicas Alteradas en el TDAH ..............38

2.3.3 Características Neuropsicológicas en el Trastorno Bipolar Tipo II.40

2.4 Diagnóstico Diferencial del Trastorno por Déficit de Atención y el

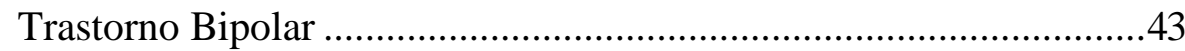

2.4.1 Diferencias Clínicas .....................................................................43

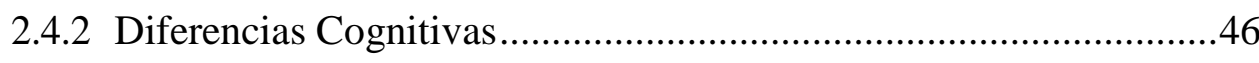

CAPÍTULO III: OBJETIVOS ......................................................................48

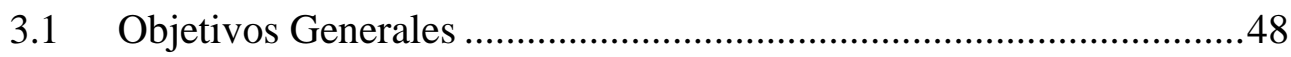




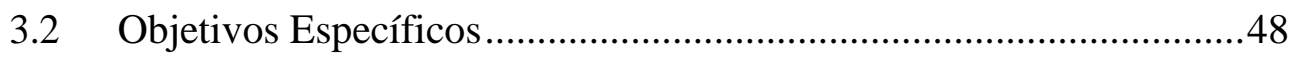

CAPÍTULO IV: MÉTODO .................................................................................49

4.1 Tipo y Diseño de Investigación........................................................49

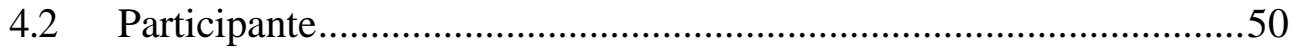

4.3 Técnicas de Recolección de Datos .......................................................53

4.4 Procedimiento de Recolección de Datos ...........................................64

CAPÍTULO V: RESULTADOS .......................................................................66

5.1 Anamnesis 66

5.2 Presentación de los resultados de cada técnica de recolección de

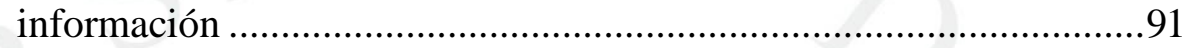

5.2.1 Escala de Inteligencia de Wechsler WAIS-IV .............................91

5.2.2 Evaluación Neuropsicológica Breve en Español- NEUROPSI.......95

5.2.3 Batería Neuropsicológica de Funciones Ejecutivas y Lóbulos Frontales

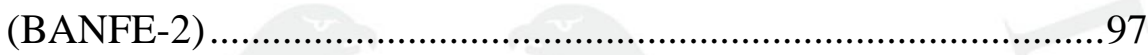

5.2.4 Escala de Memoria de Wechsler WMS- IV ....................................... 102

5.2.5 Test of Variables of Attention (T.O.V.A) ...................................... 106

CAPÍTULO VI: DISCUSIÓN .........................................................................................109

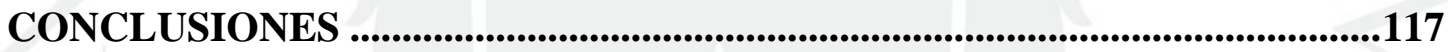

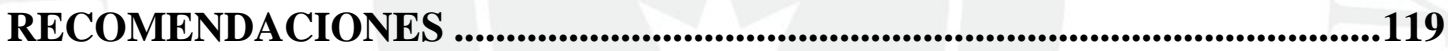

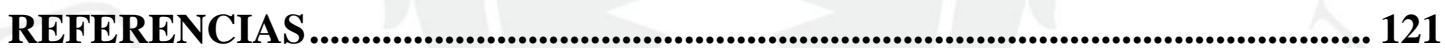




\section{ÍNDICE DE TABLAS}

Tabla 2.1 Dificultades en las funciones ejecutivas presentes en personas con TDAH ..16

Tabla 2.2 Características clínicas de a bipolaridad tipo II ............................................28

Tabla 2.3 Características clínicas en la fase de depresión mayor ...................................29

Tabla 2.4 Áreas de evaluación neuropsicológica sugeridas por cada autor......................34

Tabla 2.5 Síntomas comunes y diferenciales entre el TDAH y el trastorno bipolar.......45

Tabla 4.1 Tratamiento farmacológico por fechas y su evolución .....................................52

Tabla 4.2 Proceso de evaluación por sesión, objetivo y actividad evaluativa .................55

Tabla 5.1 Puntajes obtenidos tras la aplicación del WAIS IV ...................................... 92

Tabla 5.2 Perfil de puntuaciones compuestas del WAIS IV .......................................93

Tabla 5.3 Puntuaciones por área del NEUROPSI.................................................... 96

Tabla 5.4 Puntuación total y diagnóstico del NEUROPSI ............................................97

Tabla 5.5. Puntuaciones del BANFE por área y subprueba.......................................... 99

Tabla 5.6 Puntuaciones Totales del BANFE................................................................. 101

Tabla 5.7 Puntajes del WMS- IV por subtest......................................................... 103

Tabla 5.8 Perfil de puntuaciones compuestas del WMS- IV ...................................... 104

Tabla 5.9 Puntuaciones del TOVA por área ............................................................... 107 


\section{ÍNDICE DE FIGURAS}

Figura 5.1 Perfil de puntuaciones compuestas del WAIS IV .....................................923

Figura 5.2 Perfil de puntuaciones compuestas del WMS- IV .......................................104 


\section{ÍNDICE DE ANEXOS}

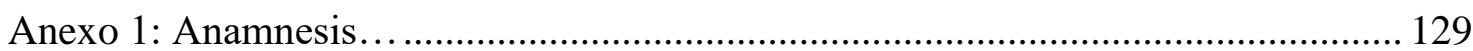

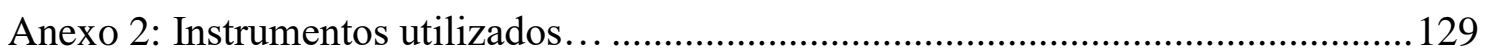

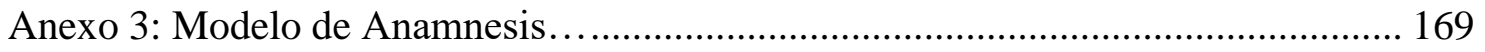

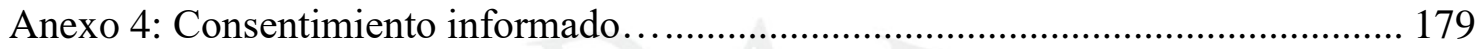

Anexo 5: Plan terapéutico para la depresión.................................................................. 180

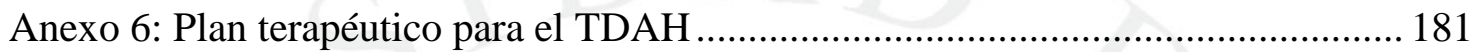




\section{INTRODUCCIÓN}

Por muchos años el estudio y diagnóstico del trastorno por déficit de atención (TDAH) se basó exclusivamente en la población infantil. Sin embargo, en la actualidad, su abordaje en la población adulta está adquiriendo cada vez mayor importancia. Es así como, ya se cuenta con criterios diagnósticos que posibilitan su detección en la edad adulta y existe un número creciente de investigaciones en torno a ello.

Además de los síntomas provenientes de esta patología, es común observar que el TDAH esté asociado con otros trastornos. Es así como las personas que lo tienen presentan altas probabilidades de comorbilidad. Estos trastornos comórbidos, si no son identificados y abordados con efectividad, pueden repercutir aún más en la calidad de vida de la persona. El trastorno bipolar tipo II es una alteración anímica que se observa en una reducida parte de la población y que es difícilmente identificable, sobre todo si existe un TDAH de por medio, debido a la similitud de algunos de sus síntomas.

Para el presente estudio de caso se abordó el caso de Adrián, un adulto de 49 años diagnosticado con TDAH y trastorno bipolar tipo II. Por lo anteriormente expuesto, este caso resulta relevante como contribución científica, siendo su objetivo general la identificación de los síntomas del trastorno por déficit de atención y trastorno bipolar tipo II por medio de anamnesis para observar la sintomatología a lo largo de la vida del evaluado. Asimismo, debido a que el TDAH es considerado un trastorno del neurodesarrollo y que el trastorno bipolar presenta causas biológicas, también se planteó un enfoque neuropsicológico para identificar las características y consecuencias relacionadas a tales patologías. Finalmente, luego de observar la sintomatología clínica y neuropsicológica actual, se propondrá un plan de intervención basado en el cuadro actual. 


\section{CAPÍTULO I: PLANTEAMIENTO DEL PROBLEMA}

\subsection{Descripción del Problema}

El diagnóstico del trastorno por déficit de atención e hiperactividad (TDAH) ha experimentado cambios en los últimos años. Esta patología estuvo basada por mucho tiempo en criterios diagnósticos planteados por especialistas en la psiquiatría infantil por lo que su estudio se ha concentrado principalmente en la población infantil y adolescente. Recién con la quinta edición del Manual Diagnóstico y Estadístico de los Trastornos Mentales (APA, 2014) se han incorporado criterios adaptados para la población adulta, que si bien se mantienen como sus principales síntomas la inatención y/o la hiperactividad-impulsividad, difieren en términos de cantidad y en la forma en que se expresan en la vida de la persona.

El TDAH, cuya prevalencia mundial se estima es del 5\% en niños y el $2.5 \%$ en adultos (APA, 2014), es considerado un trastorno del neurodesarrollo, lo que implica necesariamente la existencia de un compromiso en ciertas funciones neurocognitivas. Se sabe que en este grupo de personas es común observar dificultades en los procesos mnésicos y en las funciones ejecutivas. Este último concepto incluye procesos cognitivos tales como la capacidad de organizar, integrar y manipular información del entorno, las cuales ayudan a crear, anticipar, planear y abstraer información. Además, también regulan procesos menores como la atención sostenida, selectiva y dividida, la memoria de trabajo y el lenguaje, entre otros. Mientras que en el plano conductual y emocional se caracteriza por la incapacidad para trazar metas y dificultades en la autorregulación emocional, respectivamente. (Bombín, 2014). Por su lado Barkley (2015) indica que estas características neurocognitivas también podrían interferir en los objetivos terapéuticos, pues la adquisición de nuevas habilidades (propuestas en la terapia) podría verse influenciada por la dificultad para organizar, recordar y motivarse.

Por todas estas dificultades que implica el TDAH, en la edad adulta puede traer consigo consecuencias tales como un bajo rendimiento laboral, 
un mayor número de conflictos interpersonales, mayor probabilidad de desempleo, uso de sustancias y mayor riesgo de intentos suicidas (APA, 2014). Además, el TDAH aumenta las probabilidades de desarrollar características psicológicas disfuncionales como baja autoestima, desregulación emocional y baja autoeficacia; asimismo incrementa el riesgo de trastornos del ánimo comórbidos, tales como depresión, ansiedad o un trastorno bipolar (Barkley, 2015).

A pesar de que el TDAH es una patología que ha sido muy estudiada y las investigaciones que la abordan van en aumento, su diagnóstico aún presenta diversas dificultades. Una de ellas es el diagnóstico diferencial con el trastorno bipolar tipo II debido a la similitud de sus síntomas (Barkley, 2015; Klassen Katzman y Choka, 2015). Además, es importante resaltar que pueden presentarse síntomas emocionales y cognitivos residuales entre episodios en el trastorno bipolar, que podrían solapar síntomas del TDAH. Tales similitudes sintomáticas podrían provocar dificultad en el diagnóstico, así como la elección de un tratamiento adecuado. Michelini y colaboradores (2016) señalan que ante la dificultad para diferenciar los aspectos clínicos, el aspecto neurocognitivo ayudaría a esclarecer la diferenciación de las patologías, por ejemplo, en el trastorno bipolar las investigaciones muestran un mayor número de funciones cognitivas afectadas que en el TDAH.

El trastorno bipolar tipo II, cuya prevalencia a nivel mundial es del $0.3 \%$ (APA, 214) tiene como principal característica la oscilación de los estados anímicos, entre la hipomanía y la depresión mayor. El episodio hipomaniaco se caracteriza por un estado anímico elevado anormal en el que la energía y la actividad se ven incrementados. Aunque, cabe resaltar, que en muchas ocasiones los individuos no llegan a identificarlo ya que no produce una alteración negativa significativa. Por otro lado, el episodio depresivo se caracteriza por una pérdida del placer y un estado de ánimo deprimido que repercute de manera significativa en el área laboral, social y familiar (APA, 2014). Además, también se ha encontrado que el funcionamiento cognitivo en las personas con trastorno bipolar se encuentra afectado en áreas como la memoria verbal, la velocidad de procesamiento, las inhibición y las funciones ejecutivas (Mora, Portella, Forcada, Vieta y Mur, 2013). 
Padecer de un trastorno bipolar puede tener repercusiones importantes a nivel social ya que dificulta la autonomía de la persona, aumenta los problemas en las relaciones interpersonales y aumenta la probabilidad de tener problemas financieros, entre otros (Mora, Portella, Forcada, Vieta y Mur, 2013). De igual manera, este trastorno también repercute a nivel psicológico. Bender, Alloy, Sylvia, Urosevic y Abramson (2010) consideran que esta enfermedad es desestabilizadora y estresante, lo cual aumenta las posibilidades de sufrir eventos vitales. Asimismo, Caballo, Salazar y Carrobles (2011) sugieren una alta comorbilidad del trastorno bipolar con otros problemas psicológicos. Por ejemplo, las personas con trastorno bipolar tienen 35 veces más probabilidad de sufrir un trastorno por ansiedad que la población normal. Esto indicaría que aproximadamente entre $65 \%$ y el $90 \%$ de los bipolares van a sufrir trastornos de ansiedad.

Como se puede observar, ambas patologías implican alteraciones a nivel social, emocional y neurocognitivo. Si bien las dos primeras áreas se encuentran bien definidas, las investigaciones que tratan el aspecto neurocognitivo tienen resultados que difieren entre sí (Barkley, 2015; Latalova, 2011; Tirapú, 2012). Por ejemplo, Braham (2012) indica que en el TDAH ciertas funciones mejoran con la edad, mientras que González (2013) y Adler (2015) señalan que las alteraciones cognitivas se mantienen a lo largo de la vida de la persona. En el trastorno bipolar las características neuropsicológicas varían según las características personales (Latalova, 2011); sin embargo, otros autores indican la presencia de patrones de alteraciones cognitivas (Mora, 2013; López, 2011). Este aspecto centrado en las variables cognitivas, en el que aún no se han definido características claras para ambas patologías, es abordado por una rama creciente en la ciencia del comportamiento que se basa en las neurociencias y hoy en día es denominada neuropsicología.

Hasta no hace mucho tiempo las ciencias comportamentales como la psicología y las ciencias biológicas como la neurología, se encontraban totalmente separadas, creciendo en paralelo y sin la menor pretensión porque una se inmiscuya en el campo de la otra. Sin embargo, al cada vez ser más obvia la innegable interrelación entre el comportamiento y el funcionamiento del sistema nervioso, estas dos ramas científicas no pudieron seguir 
manteniéndose al margen una de la otra. Es por ello que surgió una ciencia dedicada al estudio de la organización cerebral de los procesos cognitivocomportamentales y de sus alteraciones denominada neuropsicología (Ardila $\&$ Rosselli, 2007). Si bien en un inicio esta rama se encontraba relegada al estudio de la relación entre lesiones cerebrales y el comportamiento (Tirapú y Muñoz, 2004), actualmente su campo de estudio se ha extendido notablemente en los últimos años hacia áreas como problemas del desarrollo infantil, los fenómenos relacionados al envejecimiento, el análisis demencias y la neuropsicología de las psicopatologías (Ardila \& Rosselli, 2007).

Esta necesidad de relacionar la conducta humana con el funcionamiento cerebral le ha concedido una gran importancia a los aportes provenientes de la evaluación neuropsicológica, actividad en la que entre sus objetivos principales se encuentra la descripción de los trastornos mentales en términos del funcionamiento cognitivo (Tirapú y Muñoz, 2004).

Es dentro de este panorama, en el que la neuropsicología comienza a ganar un mayor protagonismo en el aporte al cuerpo de conocimientos sobre la conducta humana y en el que se ha descubierto que en ciertas psicopatologías hay una influencia importante del componente neurocognitivo, donde cobra gran importancia preguntarnos sobre los aspectos neuropsicológicos subyacentes de las psicopatologías. Es por ello que la presente investigación tiene el objetivo de analizar el aspecto neuropsicológico de un paciente con trastorno por déficit de atención y trastorno bipolar tipo II.

Por lo tanto, sería pertinente plantearnos las siguientes preguntas: ¿qué síntomas neurocognitivos se encuentran presentes en un paciente que presenta TDAH y un trastorno bipolar Tipo II? y ¿cuáles han sido los síntomas predominantes del TDAH y trastorno bipolar tipo II presentes a lo largo de la historia del examinado?

\subsection{Justificación y Relevancia}

El principal aporte de la presente investigación es la contribución, a nivel teórico y práctico, de datos que ayuden a una mejor apreciación de las 
características y/o repercusiones relacionadas a las dos patologías que presenta el evaluado: TDAH y trastorno bipolar II.

La importancia del estudio del TDAH radica en que, además de ser una patología con una incidencia importante a nivel mundial, durante mucho tiempo solo fue estudiada en la población infantil, por lo que este estudio contribuye a la descripción de cómo se expresa el TDAH en la adultez. Mientras que el estudio del trastorno bipolar tipo II, si bien su incidencia a nivel mundial es baja, se sustenta mediante el desafío que plantea su diagnóstico debido a la dificultad que implica identificar los episodios hipomaniacos (APA, 2014). Además, el estudio de ambas patologías en conjunto es un aporte teórico importante debido al reto relacionado a su diagnóstico diferencial (Klassen et al. 2010). Es así como aportar datos que faciliten una diferenciación de los síntomas de ambas patologías también resulta en un aporte práctico al contribuir a una mayor precisión diagnóstica y, en consecuencia, un mejor abordaje terapéutico.

Ahora bien, en lo que respecta a la decisión de optar por una perspectiva neurocognitiva en el abordaje de ambas patologías, esta se basa no solo en el hecho de que las variables neurocognitivas juegan un rol importante tanto en la etiología como en el desarrollo del TDAH y el trastorno bipolar (Barkley, 2015; García-Blanco, 2014), sino también en el hecho de que la psicología debe ir asumiendo el discurso de los modelos que explican el funcionamiento cerebral para lograr un mayor entendimiento y abordaje de las patologías (Tirapú, 2004). Es aquí donde la evaluación neuropsicológica, esto es, la exploración del cerebro mediante el estudio del producto conductual (Lezak, 2004), adquiere un papel protagonista en la descripción de los trastornos mentales en términos del funcionamiento cognitivo (Tirapú, 2004). Específicamente en la psicología clínica, los resultados de la evaluación neuropsicológica pueden ser de gran utilidad en la comprensión de la conducta del paciente, pronosticar su aptitud para cumplir el tratamiento establecido, determinar la necesidad de supervisión y establecer una medición base para después evaluar posibles cambios (Pérez y Vásquez, 2012). Así también, la evaluación neuropsicológica puede contribuir a perfilar nuevas estrategias técnicas de intervención y estrategias de tratamiento más individualizadas, así como la evaluación de la eficacia de las 
mismas (Tirapú 2004). Entonces, recopilando lo expuesto con anterioridad, busca aportar información al cuerpo creciente, pero aún insuficiente, de conocimientos que se tienen sobre las neurociencias aplicadas a la psicología, es decir, la neuropsicología.

Por otro lado, respecto al diseño de investigación elegido, el estudio de caso único, su elección radica en que esta metodología implica una mayor atención y profundización en las características de ambas patologías, así como en las particularidades del paciente. Es por ello que la información recabada, aunque a expensas de una mayor capacidad de generalización, implica una mayor minuciosidad que puede servir como punto de partida para ahondar en características poco estudiadas del TDAH y el trastorno bipolar.

Finalmente, cabe resaltar la falta de investigaciones que abordan trastornos comórbidos. Pues si bien, se han realizado estudios de caso de ambas patologías de manera individual, no se han realizado en personas que las presentan en comorbilidad. Es más, al ser el TDAH un trastorno con una alto riesgo de presentar trastornos del ánimo comórbidos (Barkley, 2015), la realización de este estudio adquiere mayor importancia. Es así como se busca, no solo la descripción de las características del TDAH y el trastorno bipolar por separado, sino también su expresión como patologías coexistentes.

\subsection{Limitaciones}

Uno de los principales problemas en el Perú, en lo que respecta a la evaluación psicológica, es la escasez de pruebas con adaptadas a la población peruana. Por tal razón, una primera limitación es que las pruebas administradas al participante del estudio se encuentran baremadas en el extranjero. En consecuencia, los resultados obtenidos deben tomarse con cautela, ya que los puntajes son comparados con el desempeño de personas pertenecientes a otros medios. Sin embargo, Lezak, Howieson y Loring (2004) afirman que, a pesar de que las pruebas neuropsicológicas no se encuentren adecuadamente estandarizadas, el valor clínico supera la debilidad estadística. Es por ello que, adicionalmente al valor cuantitativo, también se observará el aspecto cualitativo de las pruebas administradas. 
Además de los resultados obtenidos en las evaluaciones, también es de gran importancia la entrevista clínica. Respecto a ello, se considera como limitación la veracidad de la información brindada por el evaluado, pues esta podría verse afectada por su variabilidad emocional y/o por la deseabilidad social.

Adicionalmente, otro posible obstáculo para el presente estudio es el consumo de sustancias que el paciente ha presentado a lo largo de su historia y que podrían repercutir en los resultados neuropsicológicos como una variable interviniente. Sin embargo, tomando en cuenta que el consumo de sustancias es una característica con altas probabilidades de incidencia en las personas con ambas patologías, la presente investigación busca describir el estado actual del paciente considerándola como una característica más de su patología.

Del mismo modo, la medicación prescrita por su médico psiquiatra (Bupropión 300 mg, Litio 900 mg, Benzodiacepina 0.5 mg y Quetiapina 25 mg) puede considerarse como una limitación, ya que estos fármacos podrían generar interferencia en los resultados neuropsicológicos. Algunos autores han encontrado que ciertos medicamentos utilizados para tratar el trastorno bipolar pueden producir efectos colaterales en las funciones cognitivas (Pachet y Winsiewski, 2003; Solé, Martínez y Vieta, 2012), así como también se ha encontrado que los efectos secundarios de algunos de estos medicamentos sobre la cognición son mínimos o inexistentes (Chevassus et al., 2013; Solé, Martínez y Vieta, 2012). Sin embargo, esta condición es difícilmente modificable para la evaluación, puesto que el retirar la medicación podría resultar perjudicial para su salud mental y se estarían infringiendo normas éticas.

\section{CAPÍTULO II: MARCO TEÓRICO}

\subsection{Trastorno por Déficit de Atención e Hiperactividad}

\subsubsection{Criterios Diagnósticos}


Anteriormente, el diagnóstico del TDAH en la adultez se encontraba limitado por los criterios propuestos en los manuales de diagnóstico debido a que estos se basaban en la psiquiatría infantil. Una evidencia de ello es una investigación que buscó analizar el grado de conocimiento de los psiquiatras, neurólogos y especialistas sobre el TDAH en las diferentes etapas de la vida (niñez, adolescencia y adultez). Los resultados indicaron que la valoración en la adultez reflejó un menor grado de conocimientos en comparación con las demás etapas, pues dicho trastorno se encontraba menos definido en la edad adulta (Quintero, Balanzá-Martínez, Correas y Soler, 2013). Recién a partir del 2014, con la publicación del DSM-5, se proponen criterios aplicables a adolescentes mayores y adultos. Es así como los criterios que se deben cumplir para el diagnóstico del TDAH son los siguientes:

A. Patrón persistente de inatención y/o hiperactividad-impulsividad que interfiere con el funcionamiento o el desarrollo, que se caracteriza por (1) y/o (2):

1. Inatención: Seis (o más) de los siguientes síntomas se han mantenido durante al menos 6 meses en un grado que no concuerda con el nivel de desarrollo y que afecta directamente las actividades sociales y académicas/laborales [Nota: Los síntomas no son sólo una manifestación del comportamiento de oposición, desafío, hostilidad o fracaso en la comprensión de tareas o instrucciones. Para adolescentes mayores y adultos (17 y más años de edad), se requiere un mínimo de cinco síntomas]:

a. Con frecuencia falla en prestar la debida atención a detalles o por descuido se cometen errores en las tareas escolares, en el trabajo o durante otras actividades (p. ej., se pasan por alto o se pierden detalles, el trabajo no se lleva a cabo con precisión).

b. Con frecuencia tiene dificultades para mantener la atención en tareas o actividades recreativas (p. ej., tiene dificultad para mantener la atención en clases, conversaciones o la lectura prolongada). 
c. Con frecuencia parece no escuchar cuando se le habla directamente (p. ej., parece tener la mente en otras cosas, incluso en ausencia de cualquier distracción aparente).

d. Con frecuencia no sigue las instrucciones y no termina las tareas escolares, los quehaceres o los deberes laborales (p. ej., inicia tareas pero se distrae rápidamente y se evade con facilidad).

e. Con frecuencia tiene dificultad para organizar tareas y actividades (p. ej., dificultad para gestionar tareas secuenciales; dificultad para poner los materiales $\mathrm{y}$ pertenencias en orden; descuido $\mathrm{y}$ desorganización en el trabajo; mala gestión del tiempo; no cumple los plazos).

f. Con frecuencia evita, le disgusta o se muestra poco entusiasta en iniciar tareas que requieren un esfuerzo mental sostenido (p. ej., tareas escolares o quehaceres domésticos; en adolescentes mayores y adultos, preparación de informes, completar formularios, revisar artículos largos).

g. Con frecuencia pierde cosas necesarias para tareas o actividades (p. ej., materiales escolares, lápices, libros, instrumentos, billetera, llaves, papeles del trabajo, gafas, móvil).

h. Con frecuencia se distrae con facilidad por estímulos externos (para adolescentes mayores y adultos, puede incluir pensamientos no relacionados).

i. Con frecuencia olvida las actividades cotidianas (p. ej. hacer las pñp\{huiuui mtareas, hacer las diligencias; en adolescentes mayores y adultos, devolver las llamadas, pagar las facturas, acudir a las citas).

2. Hiperactividad e Impulsividad: Seis (o más) de los siguientes síntomas se han mantenido durante al menos 6 meses en un grado que no concuerda con el nivel de desarrollo y que afecta directamente a las actividades sociales y académicas/laborales [Nota: Los síntomas no son sólo una manifestación del comportamiento de oposición, desafío, hostilidad o fracaso para comprender tareas o instrucciones. Para adolescentes mayores y 
adultos (a partir de 17 años de edad), se requiere un mínimo de cinco síntomas]:

a. Con frecuencia juguetea con o golpea las manos o los pies o se retuerce en el asiento.

b. Con frecuencia se levanta en situaciones en que se espera que permanezca sentado (p. ej., se levanta en la clase, en la oficina o en otro lugar de trabajo, o en otras situaciones que requieren mantenerse en su lugar).

c. Con frecuencia corretea o trepa en situaciones en las que no resulta apropiado. (Nota: En adolescentes o adultos, puede limitarse a estar inquieto.)

d. Con frecuencia es incapaz de jugar o de ocuparse tranquilamente en actividades recreativas.

e. Con frecuencia está "ocupado," actuando como si "lo impulsara un motor" (p. ej., es incapaz de estar o se siente incómodo estando quieto durante un tiempo prolongado, como en restaurantes, reuniones; los otros pueden pensar que está intranquilo o que le resulta difícil seguirlos).

f. Con frecuencia habla excesivamente.

g. Con frecuencia responde inesperadamente o antes de que se haya concluido una pregunta (p. ej., termina las frases de otros; no respeta el turno de conversación).

h. Con frecuencia le es difícil esperar su turno (p. ej., mientras espera en una cola).

i. Con frecuencia interrumpe o se inmiscuye con otros (p.ej., se mete en las conversaciones, juegos o actividades; puede empezar a utilizar las cosas de otras personas sin esperar o recibir permiso; en adolescentes y adultos, puede inmiscuirse o adelantarse a lo que hacen otros).

B. Algunos síntomas de inatención o hiperactivo-impulsivos estaban presentes antes de los 12 años. 
C. Varios síntomas de inatención o hiperactivo-impulsivos están presentes en dos o más contextos (p. ej., en casa, en la escuela o en el trabajo; con los amigos o parientes; en otras actividades).

D. Existen pruebas claras de que los síntomas interfieren con el funcionamiento social, académico o laboral, o reducen la calidad de los mismos.

E. Los síntomas no se producen exclusivamente durante el curso de la esquizofrenia o de otro trastorno psicótico y no se explican mejor por otro trastorno mental (p. ej., trastorno del estado de ánimo, trastorno de ansiedad, trastorno disociativo, trastorno de la personalidad, intoxicación o abstinencia de sustancias).

Dependiendo de los síntomas detectados y los criterios previamente expuestos que cumple el paciente, se debe especificar el tipo de la presentación actual:

- Presentación combinada: Si se cumplen el Criterio A1 (inatención) y el Criterio A2 (hiperactividad-impulsividad) durante los últimos 6 meses.

- Presentación predominante con falta de atención: Si se cumple el Criterio A1 (inatención) pero no se cumple el Criterio A2 (hiperactividad-impulsividad) durante los últimos 6 meses.

- Presentación predominante hiperactiva impulsiva: Si se cumple el Criterio A2 (hiperactividad-impulsividad) y no se cumple el Criterio A1 (inatención) durante los últimos 6 meses.

También debe especificarse si se encuentra en remisión parcial. Esto es, cuando previamente se cumplían todos los criterios, no todos los criterios se han cumplido durante los últimos 6 meses, y los síntomas siguen deteriorando el funcionamiento social, académico o laboral. Finalmente, se debe especificar la gravedad actual: 
- Leve: Pocos o ningún síntoma están presentes más que los necesarios para el diagnóstico, y los síntomas sólo producen deterioro mínimo del funcionamiento social o laboral.

- Moderada: Síntomas o deterioros funcionales presentes entre "leve" y "grave".

- Grave: Presencia de muchos síntomas aparte de los necesarios para el diagnóstico o de varios síntomas particularmente graves, o los síntomas producen deterioro notable del funcionamiento social o laboral.

El DSM-5 (APA, 2014) indica que el TDAH tiene su inicio en la primera infancia; no obstante, el diagnóstico antes de los 4 años resulta complejo ya que se debe diferenciar los síntomas propios de la patología con el comportamiento normal del niño. En la niñez suelen ser comunes los síntomas de hiperactividad y la inatención se ve reflejada en el bajo rendimiento académico. Mientras que en la adolescencia/adultez, si bien la inatención permanece, las conductas hiperactivas se reducen para dar paso a conductas más antisociales y también se observan otros síntomas como la inquietud, la impaciencia, la impulsividad y las dificultades en la planificación.

\subsubsection{Prevalencia del trastorno por déficit de atención e hiperactividad en la adultez}

Si bien se estima que aproximadamente el $5 \%$ de niños y el 2.5 $\%$ de adultos padecen TDAH a nivel mundial (APA, 2014), los estudios que han tratado de estimar la prevalencia del TDAH en la población general han encontrado distintos resultados. Por su parte, Barkley (2012) halla una prevalencia aproximada del $5 \%$ en una extensa muestra representativa de adultos en Estados Unidos. Mientras que un estudio de adultos con TDAH realizado en diferentes países obtuvo las siguientes estimaciones: Bélgica (4.1\%), Colombia (1.9\%), Francia (7.3\%), Alemania (3.1\%), Italia (2.8\%), México (1.9\%), Países bajos (5.0\%) y 
España (1.2\%) (Fayyad y colaboradores citados en Barkley, 2015). Según Polanczyk, De Lima, Horta, Biederman y Rohde (2007), los factores que pueden afectar este tipo de estimaciones y que explican la disparidad de los resultados son el método utilizado para el diagnóstico, la definición del TDAH, los criterios de disfuncionalidad y la locación geográfica del estudio. Por otro lado, en el Perú la prevalencia del TDAH en niños es aproximadamente $5 \%$ y en adultos de $4 \%$ (Velásquez y Molina, 2014).

\subsubsection{Etiología}

Según estudios recientes, el componente genético parece ser el mayor predictor de la presencia de esta patología. En esta línea, Fernández, Fernández, Calleja, Muñoz y López (2012) indican que el TDAH es un trastorno complejo, el cual puede ser causado por factores ambientales en un $20-30 \%$ y explicado en un $70-80 \%$ por componentes genéticos. Asimismo, existen evidencias sólidas acerca de que es una alteración genética, en la cual se modifica el funcionamiento de la dopamina, la principal causa del TDAH (Roselli, Matute, y Ardila, 2010). En cuanto al estudio de neuroimagen estructural y funcional en niños y adultos con TDAH, se encontró que las personas con dicha patología suelen presentar alteraciones en la corteza prefrontal derecha, núcleos basales (sobre todo en el núcleo caudado), cuerpo calloso y cerebelo (Semrud y Teeter, 2011).

Por otro lado, Barkley (2015) realizó una revisión de diferentes investigaciones encontrando que, así como los factores genéticos, también existen factores del neurodesarrollo que contribuyen en mayor medida a la presencia del TDAH. Estos pueden ser causados por complicaciones durante el embarazo o en el parto, por daños cerebrales y por la exposición ante toxinas e infecciones. 


\subsubsection{Características clínicas en la adultez}

La característica principal del TDAH es la inatención y/o la hiperactividad-impulsividad que obstaculizan el desenvolvimiento del individuo en su entorno. Estas interferencias se manifiestan a lo largo de la niñez, la adolescencia y la adultez; sin embargo, influyen y se expresan de manera distinta dependiendo de la etapa. Es así como en el periodo preescolar la principal característica es la hiperactividad, mientras que en el curso de la primaria se observan más síntomas de inatención reflejados en un bajo rendimiento académico. En la adolescencia, los síntomas de hiperactividad disminuyen y se traducen en una sensación interna de nerviosismo, inquietud o impaciencia. Finalmente en la adultez, la inquietud, la inatención y la impulsividad son los síntomas más frecuentes. Asimismo, otras características asociadas que apoyan el diagnóstico en la edad adulta son la baja tolerancia a la frustración, la irritabilidad y la labilidad emocional (APA, 2014).

Según Barkley (2015), el déficit de autorregulación emocional (DESR - Deficient emotional self-regulation) debe ser considerado como un síntoma central puesto que está muy presente en personas diagnosticadas con TDAH. Este déficit incluye una alteración en la automotivación y activación dirigida hacia un objetivo, dificultades para moderar las reacciones emocionales ante eventos desencadenantes e impulsividad emocional (EI - Emotional Impulsivity). Esta última sería la característica más llamativa e implica una dificultad para inhibir las emociones que resulta en una primera reacción emocional negativa y rápida en respuesta a ciertos eventos. Todo esto genera en la persona problemas para moderar la expresión de sus emociones, trabas para ser aceptados socialmente y dificultades para dirigir la conducta hacia un objetivo alternativo. La presencia del DESR y el EI se observa en las escalas de autoreporte aplicadas a las personas con TDAH, quienes reportan con frecuencia síntomas como impaciencia, baja tolerancia a la frustración, sobrerreacción, excitabilidad e irritabilidad (Barkley, Murphy y Fischer citados en Barkley, 2015). 
Una investigación buscó examinar los síntomas del DESR en una muestra de 206 adultos con TDAH y 123 adultos sin la patología. Los resultados indicaron que la deficiencia en la autorregulación emocional fue más común en las personas con TDAH y que el 55\% de estas personas reportaron un DESR de mayor severidad que el grupo control. Además, el DESR fue asociado con alteraciones en el funcionamiento marital, accidentes automovilísticos y arrestos (Surman et al., 2013). Mientras que en otro estudio se encontró que la labilidad emocional es un predictor significativo del deterioro en la vida diaria, independientemente de las dos dimensiones del TDAH (Skirrow y Asherson, 2013). Todo esto siguiere una gran relevancia de los síntomas afectivos en las personas que presentan esta patología.

También es importante resaltar el concepto de funciones ejecutivas, ya que su desempeño suele verse afectado en los adultos con TDAH. Ardilla y Ostrosky (2012) definen las funciones ejecutivas como las encargadas de la capacidad para organizar, integrar y manipular información de su entorno, las cuales ayudan a crear, anticipar, planear y abstraer. También indican que estas no se consideran funciones cognitivas individuales, sino un constructo que contiene un grupo de habilidades reguladoras de otras habilidades y conductas. Según Barkley (2012), estas funciones son las necesarias tanto para elegir metas, como para crear y mantener las acciones hacia las metas. Es por ello que dificultades en las funciones ejecutivas pueden ocasionar reducción en la productividad, ineficiencia, incumplimiento de plazos de tiempo, errores por descuido, olvidos y pérdida de cosas como resultados de la desorganización; características que son comúnmente presentadas en los adultos con TDAH.

Además, Bombin et al. (2014) clasifican a las funciones ejecutivas según las áreas en las que se expresa. Así, en el nivel cognitivo, las funciones ejecutivas integran funciones cognitivas "superiores" tales como la planificación, abstracción, capacidad de análisis y pensamiento lógico. Pero también se encargan de la regulación de otros procesos menores tales como la atención sostenida, selectiva y dividida, memoria de trabajo, lenguaje, entre otras. En el plano 
conductual, las funciones ejecutivas son las encargadas de que la persona organice sus conductas hacia una meta, en las cuales incluye capacidades para crear objetivos y planearlos. Si existe una alteración en dicho nivel, se pueden observar dificultades en la activación e inhibición conductual. Mientras que en el área emocional, las funciones ejecutivas se evidencian en el funcionamiento de la regulación emocional, por lo que su alteración podría resultar en labilidad, irritabilidad o aplanamiento emocional. Adicionalmente, Ardilla y Ostrosky (2012) mencionan que este control ejecutivo también permite que el individuo reconozca las situaciones inesperadas en las que se deben generar planes alternativos ante hechos imprevistos; igualmente, permite la inhibición de conductas inapropiadas para mantener una interacción adecuada con otras personas.

Duda (2011), tomando las seis funciones ejecutivas propuestas por Brown (2005), ejemplifica las dificultades que puedan presentar las personas con TDAH:

Tabla 2.1

Dificultades en las funciones ejecutivas presentes en personas con TDAH

Función Ejecutiva $\quad$ Actividades

Organizar: Llevar una agenda, mantener cosas en orden.

Priorizar: Decidir que se debe hacer primero, distinguir entre lo urgente y lo importante.

Activación Activarse para trabajar: Levantarse de la cama en las mañanas, hacer lo debido (estar viendo televisión y saber que hay que trabajar, pero no empezar a hacerlo), ejecutar lo que se ha decidido.

Focalizar la atención: Prestar atención a lo Enfoque importante, observar detalles.

Mantener la atención: Atención sostenida. 


\begin{tabular}{ll} 
& Alternar la atención: Capacidad de pasar de un \\
& tema a otro. \\
& Regular el estado de alerta: Mantenerse despierto \\
en situaciones que no son motivadoras. \\
Mantener el esfuerzo: Persistir en tareas que \\
impliquen esfuerzo para complementarse \\
satisfactoriamente. \\
Procesar la velocidad: Realizar una tarea en el \\
tiempo establecido. \\
Manejar la frustración: Inhibir impulsos, para \\
escuchar la voz interna y para dirigir el \\
comportamiento. \\
Modular emociones: Reaccionar adecuadamente al \\
estímulo. \\
Utilizar la memoria de trabajo: Recordar lo \\
necesario durante el tiempo suficiente, no poder \\
continuar una conversación por no recordar lo que se \\
quería decir. \\
Acceder a la memoria: Retener información \\
importante. \\
Memoria \\
Monitoreo: tener en cuenta variables que \\
acompañan la conducta por ejemplo: riesgos. \\
Reconocer causas del éxito o fracaso para luego \\
aplicarlo en el futuro. Manejar el tiempo \\
adecuadamente. \\
Autorregulación: Esperar cuando es necesario. \\
\hline
\end{tabular}

Otras características a resaltar en esta población, son las referidas al ámbito académico y laboral. Así, la educación recibida en estas personas, se caracteriza por la presencia de dificultades en la etapa escolar debido a problemas conductuales y un desempeño académico disminuido. Las estimaciones indican que entre el $16 \%$ y el $40 \%$ de personas con TDAH han repetido un año escolar y el $43 \%$ ha recibido clases de refuerzo adicionales fuera del horario escolar. Asimismo, el número de alumnos que se gradúan de la universidad es menor al de las personas que no padecen TDAH, lo que resulta menos años de estudio. Con respecto a la vida laboral, es habitual observar el cambio frecuente de centros laborales en personas con TDAH, ya que presentan 
dificultades para relacionarse con sus pares, problemas conductuales y suelen presentar un estilo de comunicación negativo que los perjudica en la solución de conflictos. Todo esto los hace propensos a renunciar o ser despedidos (Barkley, 2015).

Finalmente, Barkley (2015) hace una revisión de diversas investigaciones y nombra las consecuencias que se encuentran en los adultos con TDAH con mayor frecuencia: alto número de accidentes físicos y vehiculares, inicio de la actividad sexual a más temprana edad, mayor número de parejas sexuales y el uso de sustancias. Estos resultados se deben en gran medida a la disminuida inhibición, la desregulación emocional y la necesidad de búsqueda de sensaciones.

\subsubsection{Trastorno Comórbidos}

Según Doyle (2006), indica que la presencia del TDAH aumenta la probabilidad de la existencia de una comorbilidad, siendo esta condición una regla más que una excepción. Barkley (2015) indica que el TDAH aumenta la probabilidad de la existencia de un trastorno comórbido, así más del 80\% de personas con TDAH tiene algún otro trastorno psiquiátrico, más del 50\% tienen al menos dos desórdenes psiquiátricos y más del 33\% tiene al menos 3 desórdenes. Los trastornos de ansiedad, la depresión mayor, la distimia, los desórdenes de conducta y el abuso de sustancias, suelen tener mayor ocurrencia. Por su parte, Stahl y Mignon (2011) clasifican las comorbilidades según el subtipo de TDAH. Así, cuando predomina la inatención es más frecuente observar problemas de ansiedad, depresión y ánimo expansivo e irritable. En cambio, al tratarse de los subtipos de hiperactividad-impulsividad suelen ser más comunes los desórdenes de conducta, comportamiento oposicionista, insomnio, hipersomnia y abuso de sustancias.

En cuanto a la relación de comorbilidad con el trastorno bipolar, esta es más compleja de definir debido a que ambas patologías muestran síntomas similares que se superponen y dificultan el diagnóstico diferencial (Barkley, 2015; Klassen et al., 2010). Aun así, existe una alta 
ocurrencia de TDAH en personas diagnosticadas con trastorno bipolar, aproximadamente entre el $9 \%$ y $35 \%$ en adultos. En dichos casos, la presencia de ambos trastornos sugiere un cuadro más severo, con síntomas del estado de ánimo más acentuados y un funcionamiento psicosocial con mayor deterioro (Barkley, 2015).

\subsubsection{Modelos Terapéuticos}

A pesar de que la medicación se considera como un aspecto muy importante para el tratamiento del TDAH, por ser un desorden neurobiológico, con el paso del tiempo se ha visto la necesidad de añadir una intervención no farmacológica para abordar los síntomas que implica esta patología (Barkley, 2015).

Un estudio realizó una revisión de los tratamientos aplicados en el TDAH en adultos, realizada a través la base de datos de MEDLINE y PsychInfo, se encontró que la terapia cognitivo conductual, la terapia metacognitiva, la terapia dialéctica-conductual, el coaching y la rehabilitación cognitiva son las intervenciones que frecuentemente se utilizan para abordar esta patología. Además, numerosos estudios indican que el tratamiento farmacológico no es suficiente para un plan de intervención pues presenta diversas limitaciones, tales como la baja adherencia al tratamiento farmacológico, los efectos secundarios de la medicación y los trastornos comórbidos asociados al TDAH. El estudio concluye que la terapia cognitivo conductual ha demostrado ser el tratamiento con mayor efectividad para el abordaje del TDAH, los síntomas de ansiedad y la depresión. Añadido a esto, se encontró que la psicoeducación, las técnicas enfocadas a la solución de problemas, la producción de estrategias cognitivas para manejar la atención, el manejo de la impulsividad y la reestructuración cognitiva, son las técnicas más utilizadas en esta terapia (Vidal, Bosch, Nogueira, Casas y Ramos, 2012). 
En otra revisión teórica, Barkley (2015) muestra que la terapia cognitivo conductual brinda recursos para el desarrollo de habilidades que los adultos con TDAH carecen y que estos resultados se evidencian estadísticamente y clínicamente. Este tipo de terapia se basa en la interacción de los pensamientos, emociones y conductas como factores de mantenimiento de los trastornos, incluyendo estrategias de intervención como la psicoeducación y el entrenamiento de estrategias, (tales como la organización, planificación y sobretodo la práctica y el mantenimiento de las habilidades y estrategias en la vida diaria). Asimismo, utiliza técnica de la reestructuración cognitiva para cambiar las creencias que se han creado a lo largo de los fracasos de la persona, el reconocimiento de los pensamientos automáticos y la creación de nuevas maneras de pensar que se basen en la motivación.

En el manual de técnicas de intervención cognitivo conductuales (Ruiz, Días y Villalobos, 2012) se encuentra una descripción de las técnicas más utilizadas para abordar tanto el TDAH, como síntomas depresivos comórbidos a esta patología:

1. Psicoeducación: Se busca que el paciente acepte y este informado acerca de las patologías que lo aquejan para que aprenda a identificar sus síntomas, causas y efectos.

2. Autorregistros: El terapeuta provee al paciente un registro en el cual tendrá que identificar ante qué situaciones, personas o conductas, el estado emocional se ve alterado, así como las cogniciones que surgen de las mismas. El estado emocional se valora en una escala del 0 al 100, siendo 0 un estado en el que el paciente siente un malestar significativo, mientras que puntuar 100 muestra un estado de bienestar. Además estos registros sirven como base para comparar los progresos futuros.

3. Descubrimiento guiado (Diálogo Socrático): El objetivo de la técnica se encuentra en el alcance de nuevas perspectivas que afronten las creencias no adaptativas, por medio del cuestionamiento socrático. Dicho cuestionamiento consiste en 
guiar al paciente por medio de preguntas abiertas para llegar libremente a sus argumentos y asociaciones.

4. Evaluar las ventajas $y$ desventajas de las cogniciones, conductas y emociones: Por cada cognición, conducta y emoción vertida ante los hechos ocurridos en la vida del paciente, se analizan las dificultades que estas puedan conllevar así como las ventajas que también traen consigo, para que de esta manera el paciente aprenda anticipar sus conductas.

5. Técnica de entrenamiento en la regulación emocional: El terapeuta debe enseñarle al paciente a reconocer la presencia de un estado emocional, así como la discriminación del mismo y seguidamente aceptarlo. Luego el paciente debe evaluar sus recursos y estrategias para hacer frente a dicha situación y así poner en marcha un plan que lo ayude a inhibir la conducta impulsiva.

6. Entrenamiento en autoinstrucciones: El paciente deberá identificar, a través del uso de autorregistros, qué autoverbalizaciones mantiene ante las situaciones que le generan dificultad. De esta manera se seleccionan las autoverbalizaciones adecuadas y se eliminan las desadaptativas o irrelevantes. Luego, el mismo paciente debe ser el que genere el mayor número de autoinstrucciones adaptativas para guiar con éxito su conducta.

7. Inoculación del estrés: Consiste en la reducción de autoverbalizaciones, imágenes y emociones que afecten al individuo, así como en el aumento o implementación de aquellas que brinden un funcionamiento adecuado a las circunstancias. Se evalúan y modifican estructuras cognitivas que estén fomentando valoraciones negativas de uno mismo y del entorno.

8. Técnica de conceptualización alternativa: En un primer momento el terapeuta se encarga de buscar interpretaciones diferentes a las que normalmente el paciente estila elaborar, con el propósito de que este evite las interpretaciones únicas y aprenda a buscar solución a los problemas.

9. Técnicas de solución de problemas: El objetivo de la técnica es aumentar la capacidad del individuo para identificar soluciones 
eficaces para afrontar situaciones demandantes. Se requiere que la persona comprenda la situación, la valore de manera adecuada y se adapte a dichos eventos. Para ello también se aplican principios de psicoeducación y ejercicios de resolución de problemas interactivos para descubrir y poner en práctica las estrategias adquiridas.

10. Técnicas de relajación: El terapeuta enseña al paciente los diferentes métodos de relajación, los cuales deben ser realizados en casa para ponerlo en práctica cuando sea necesario. El objetivo de la técnica es reducir el estado de activación fisiológica que influye en los procesos emocionales, cognitivos y conductuales.

11. Entrenamiento en habilidades sociales: Este entrenamiento busca que el paciente aprenda a diferenciar conductas asertivas, agresivas y pasivas, y que a su vez implemente las conductas asertivas a través de técnicas de ensayos y modelamiento bajo sus nuevas creencias adaptativas.

12. Juego de roles: Consiste en los ensayos conductuales o modelado con el terapeuta acerca de situaciones que sean demandantes para el paciente. Con ello se logrará que el paciente sepa cómo actuar al comprobar que no siempre sus pensamientos ocurren en la realidad y percatándose de que existen alternativas diferentes de actuación.

13. Programa de actividades: La técnica consiste en que el terapeuta acuerde con el paciente una serie de actividades diarias para realizar en casa y que deben de mantener un grado de dificultad ajustado a sus habilidades. De esta manera, el paciente se percibirá capaz de ejecutar y manejar su tiempo y se así se rebate la creencia errónea de inutilidad.

14. Técnicas de retribución: La técnica busca modificar los sesgos cognitivos de control (interno/externo), estabilidad (estable/ inestable) y especificidad (global/especifico). Generalmente las atribuciones de personas en fases depresivas tienden a ser internas, estables y globales para los fracasos y externas, inestables y específicas para sus éxitos. 
15. Técnica de la distracción externa: Se selecciona con el terapeuta actividades que el paciente encuentre agradables para que se utilicen como distracción con el objetivo de aliviar los sentimientos de tristeza.

16. Análisis de la responsabilidad: Técnica que se encarga de indagar acerca de las razones que el paciente mantiene para sentirse responsable. Se busca una visión objetiva de las razones que lo conducen a experimentar culpabilidad.

\subsection{Trastorno Bipolar Tipo II}

\subsubsection{Criterios Diagnósticos}

Según el DSM-5 (APA, 2014), para diagnosticar el trastorno bipolar tipo II, es necesario que se cumplan los criterios siguientes para un episodio hipomaniaco y para un episodio de depresión mayor.

Respecto al episodio hipomaniaco, el DSM-5 (APA, 2014) indica que se deben cumplir los siguientes criterios:

A. Un período bien definido de estado de ánimo anormalmente y persistentemente elevado, expansivo o irritable, y un aumento anormal y persistente de la actividad o la energía, que dura como mínimo cuatro días consecutivos y está presente la mayor parte del día, casi todos los días.

B. Durante el período de alteración del estado de ánimo y aumento de la energía y la actividad, han persistido tres (o más) de los síntomas siguientes (cuatro si el estado de ánimo es sólo irritable), representan un cambio notorio del comportamiento habitual y han estado presentes en un grado significativo:

1. Aumento de la autoestima o sentimiento de grandeza.

2. Disminución de la necesidad de dormir (p. ej., se siente descansado después de sólo tres horas de sueño). 
3. Más hablador de lo habitual o presión para mantener la conversación.

4. Fuga de ideas o experiencia subjetiva de que los pensamientos van a gran velocidad.

5. Facilidad de distracción (es decir, la atención cambia demasiado fácilmente a estímulos externos poco importantes o irrelevantes), según se informa o se observa.

6. Aumento de la actividad dirigida a un objetivo (social, en el trabajo o la escuela, o sexual) o agitación psicomotora.

7. Participación excesiva en actividades que tienen muchas posibilidades de consecuencias dolorosas (p. ej., dedicarse de forma desenfrenada a compras, juergas, indiscreciones sexuales o inversiones de dinero imprudentes).

C. El episodio se asocia a un cambio inequívoco del funcionamiento que no es característico del individuo cuando no presenta síntomas.

D. La alteración del estado de ánimo y el cambio en el funcionamiento son observables por parte de otras personas.

E. El episodio no es suficientemente grave para causar una alteración importante del funcionamiento social o laboral o necesitar hospitalización. Si existen características psicóticas, el episodio es, por definición, maníaco.

F. El episodio no se puede atribuir a los efectos fisiológicos de una sustancia (p. ej., una droga, un medicamento u otro tratamiento).

Mientras que para el trastorno depresivo mayor indica los siguientes criterios:

A. Cinco (o más) de los síntomas siguientes han estado presentes durante el mismo período de dos semanas y representan un cambio del funcionamiento anterior; al menos uno de los síntomas es (1) estado de ánimo deprimido o (2) pérdida de interés o de placer:

1. Estado de ánimo deprimido la mayor parte del día, casi todos los días, según se desprende de la información subjetiva (p. ej., se siente triste, 
vacío o sin esperanza) o de la observación por parte de otras personas (p. ej., se le ve lloroso).

2. Disminución importante del interés o el placer por todas o casi todas las actividades la mayor parte del día, casi todos los días (como se desprende de la información subjetiva o de la observación).

3. Pérdida importante de peso sin hacer dieta o aumento de peso (p. ej., modificación de más del 5\% del peso corporal en un mes) o disminución o aumento del apetito casi todos los días.

4. Insomnio o hipersomnia casi todos los días.

5. Agitación o retraso psicomotor casi todos los días (observable por parte de otros; no simplemente la sensación subjetiva de inquietud o enlentecimiento).

6. Fatiga o pérdida de la energía casi todos los días.

7. Sentimiento de inutilidad o culpabilidad excesiva o inapropiada (que puede ser delirante) casi todos los días (no simplemente el autorreproche o culpa por estar enfermo).

8. Disminución de la capacidad para pensar o concentrarse, o de tomar decisiones, casi todos los días (a partir del relato subjetivo o de la observación por parte de otras personas).

9. Pensamientos de muerte recurrentes (no sólo miedo a morir), ideas suicidas recurrentes sin un plan determinado, intento de suicidio o un plan específico para llevarlo a cabo.

B. Los síntomas causan malestar clínicamente significativo o deterioro en lo social, laboral u otras áreas importantes del funcionamiento.

C. El episodio no se puede atribuir a los efectos fisiológicos de una sustancia o de otra afección médica.

\section{Trastorno bipolar tipo II}

A. Se han cumplido los criterios al menos para un episodio hipomaniaco (Criterios A-F en "Episodio hipomaniaco" antes citado) y al menos para un episodio de depresión mayor (Criterios A-C en "Episodio de depresión mayor" antes citado).

B. Nunca ha habido un episodio maniaco. 
C. La aparición del episodio(s) hipomaniaco(s) y de depresión mayor no se explica mejor por un trastorno esquizoafectivo, esquizofrenia, un trastorno esquizofreniforme, un trastorno de ideas delirantes, $u$ otro trastorno del espectro de la esquizofrenia y otros trastornos psicóticos especificados o no especificados.

D. Los síntomas de depresión o la incertidumbre causada por la alternancia frecuente de periodos de depresión e hipomanía provocan malestar clínicamente significativo o deterioro en lo social, laboral u otras áreas importantes del funcionamiento.

Cabe resaltar que, las respuestas a una pérdida significativa pueden incluir síntomas descritos en el Criterio A que pueden simular un episodio depresivo. Ante ello, se señala que, si bien dichos síntomas pueden considerarse apropiados a la pérdida, también debería considerarse la posibilidad de la presencia de un episodio de depresión mayor. Además, esta decisión requiere del criterio clínico basado en la historia del individuo y en las normas culturales (APA, 2014).

Finalmente, el comienzo del trastorno bipolar puede tener su inicio en la adolescencia tardía o a lo largo de la edad adulta, siendo la media de la edad de inicio la mitad de la veintena. Con frecuencia se inicia con un episodio depresivo, que se diagnostica en la mayoría de casos como un trastorno depresivo mayor. No obstante, luego aparece el episodio hipomaniaco y el intervalo entre episodios disminuye con la edad (APA, 2014).

\subsubsection{Prevalencia}

García-Blanco, Sierra y Livianos (2014) realizaron una revisión de las últimas aproximaciones sobre la epidemiologia del trastorno bipolar e identificaron tasas de prevalencia a lo largo de la vida del espectro bipolar de un $2.4 \%$, del cual el $0.4 \%$ corresponde al subtipo II. Mientras que el DSM- 5 (APA, 2014) señala que la prevalencia del trastorno bipolar tipo II a nivel internacional es de aproximadamente el $0.3 \%$ y en Estados Unidos del 0.8\%. En el Perú, la prevalencia de 
personas que presentan algún trastorno del humor, es aproximadamente el $8.2 \%$ (Instituto Nacional de salud, 2012).

\subsubsection{Etiología}

Barlow y Durand (2008) consideran el aspecto biológico, específicamente la influencia genética, como causa de los trastornos afectivos. Indican que este tipo de trastornos se deben a una alteración en los sistemas de neurotransmisores y endocrinos, en el cual los bajos niveles de serotonina influyen en las fluctuaciones de los estados anímicos. Otros autores indican que los trastornos del ánimo no solo se deben a factores biológicos (genéticos y bioquímicos), sino también a factores psicológicos y cognitivos que tienen igual importancia en la etiología y mantenimiento de los desórdenes del ánimo (Davey, 2008; Halguin y Krauss, 2008).

En una última revisión, García-Blanco et al. (2014) plantean diversas causas que pueden provocar dicha patología, entre las que incluyen: alteraciones genéticas, anomalías neurohormonales, anomalías anatómicas del cerebro e influencias psicosociales. En cuanto a las alteraciones genéticas, se ha encontrado altas tasas de heredabilidad; sin embargo, no se han hallado marcadores genéticos fiables que pueden ser considerados como causas directas. Las anomalías neurohormonales involucran una alteración en el sistema endocrino, específicamente al eje hipotalámico-pituitario- adrenal, sistema involucrado en la respuesta al estrés. Se ha observado una disfunción de este eje en todas las etapas de trastorno bipolar. Esta desregulación parece estar implicada tanto en el mantenimiento del trastorno, así como en la vulnerabilidad a episodios futuros. En cuanto a las anomalías neuroanatómicas, los autores señalan que los estudios sobre las diferencias estructurales del cerebro de personas con un trastorno bipolar aún son pocos y los hallazgos son contradictorios. Más aún, no se identifica si las anomalías encontradas serían las causas o consecuencias del trastorno. Por último, los factores psicosociales se relacionan con un aumento de los acontecimientos vitales, previos al inicio de la enfermedad o la presencia de los episodios 
afectivos. De esta manera, los sucesos negativos como fracasos y pérdidas pueden desencadenar episodios depresivos, mientras que los episodios de manía pueden estar precedidos tanto de acontecimientos negativos como positivos, tales como hostilidad familiar o las consecuencias de algún logro.

En relación con lo anterior, Bender, Alloy, Sylvia, Urosevic y Abramson (2010) consideran que esta enfermedad es desestabilizadora y estresante, lo cual aumenta las posibilidades de sufrir eventos vitales. De esta manera se genera un círculo vicioso como factor de mantenimiento. Asimismo, mencionan que algunos de los factores predisponentes del trastorno bipolar se relacionan con el pobre apoyo social, maltrato en la infancia, baja autoestima y distorsiones cognitivas. Por ejemplo, el abuso prolongado en la infancia se relaciona con la desregulación en el eje hipotalámico-pituitaria-adrenal, el cual puede predisponer a esta patología.

\subsubsection{Características Clínicas}

Sevillá y Pastor (2009) describen las características clínicas de la bipolaridad tipo II según los dominios conductual, cognitivo y emocional-fisiológico:

Tabla 2.2

Características clínicas de a bipolaridad tipo II

\begin{tabular}{|c|c|c|}
\hline Aspecto & Episodio depresivo & Episodio hipomaniaco \\
\hline Conductual & $\begin{array}{l}\text { - Abandono de actividades } \\
\text { agradables y obligatorias. } \\
\text { - En crisis depresivas: llorar, } \\
\text { estados semicatatónicos, etc. }\end{array}$ & $\begin{array}{ll}\text { - } & \text { La conducta } \\
\text { aumenta pero no de } \\
\text { manera dramática } \\
\text { - } & \text { Emplear más tiempo } \\
\text { a actividades de } \\
\text { ocio. } \\
\text { - } & \text { Aumento de } \\
\text { sociabilidad y } \\
\text { productividad } \\
\text { profesional }\end{array}$ \\
\hline
\end{tabular}




\begin{tabular}{|c|c|c|c|}
\hline Cognitivo & & $\begin{array}{l}\text { Pensamientos negativos } \\
\text { automáticos, sobre uno } \\
\text { mismo, los demás, uno } \\
\text { mismo y el futuro. } \\
\text { Pensamiento suicidas. } \\
\text { Procesos cognitivos } \\
\text { intelectuales: atención, } \\
\text { memoria, afectados. }\end{array}$ & 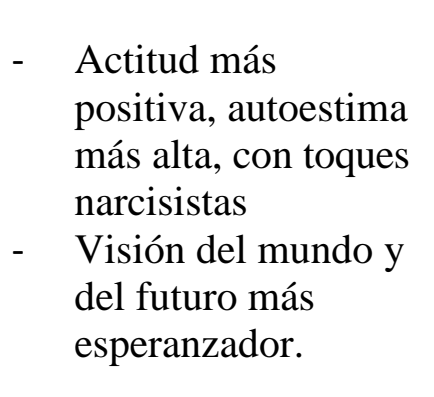 \\
\hline $\begin{array}{l}\text { Emocional- } \\
\text { Fisiológico }\end{array}$ & 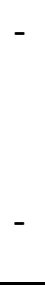 & $\begin{array}{l}\text { Tristeza, llanto, cansancio, } \\
\text { falta de apetito, problemas } \\
\text { con el sueño, disminución } \\
\text { del deseo sexual. } \\
\text { Irritabilidad, desconfianza, } \\
\text { ansiedad. }\end{array}$ & $\begin{array}{ll}\text { - } & \text { Aumento de la } \\
\text { energía, vitalidad. } \\
\text { - } & \text { Sensación de alegría, } \\
& \text { autoconfianza. } \\
\text { - } & \text { Autoimagen inflada. }\end{array}$ \\
\hline
\end{tabular}

Mientras que Jarne, Talarn, Armayones y Horta (2006) ahondan en los aspectos clínicos presentes en la fase de la depresión mayor y proponen la siguiente caracterización:

Tabla 2.3

Características clínicas en la fase de depresión mayor

\begin{tabular}{|c|c|}
\hline Áreas & Características \\
\hline $\begin{array}{l}\text { Afectividad } \\
\text { Contenido del } \\
\text { pensamiento }\end{array}$ & $\begin{array}{l}\text { Tristeza profunda y persistente sin causa aparente. } \\
\text { Sentimientos inadecuados de inutilidad, culpa. } \\
\text { Marcado por la baja autoestima, cogniciones } \\
\text { pesimistas sobre uno mismo y el futuro, suele } \\
\text { pensar en la muerte. }\end{array}$ \\
\hline Curso del pensamiento & $\begin{array}{l}\text { Se observa lentitud en los procesos mentales, } \\
\text { manifiesta dificultades para pensar, concentrarse y } \\
\text { tomar decisiones. La memoria y la atención } \\
\text { también se alteran. }\end{array}$ \\
\hline Lenguaje & $\begin{array}{l}\text { Habla lenta, reflejo de las dificultades del } \\
\text { pensamiento y de concentración, dificultades } \\
\text { para mantener una conversación. }\end{array}$ \\
\hline Conducta & $\begin{array}{l}\text { Anhedonismo, pérdida de interés y placeres por } \\
\text { actividades y relaciones interpersonales con }\end{array}$ \\
\hline
\end{tabular}


repercusiones en el área laboral. Aspecto físico e higiene puede descuidarse.

Motricidad Ralentización psicomotriz, casos extremos estupor depresivo caracterizado por un mutismo y parálisis motriz.

Síntomas Físicos

Insomnio, pérdida de peso por la disminución del apetito, disminución de la libido, experiencia subjetiva de fatiga y pérdida de energía.

Presencia de

Suelen ser auditivas y congruentes con los temas Alucinaciones depresivos como voces acusatorias o visiones de familiares muertos.

Por su parte, los episodios hipomaniacos se caracterizan por la presencia de euforia, hiperactividad y desinhibición, aunque de forma más atenuada que en el episodio maniaco. En este estado la persona desborda energía, optimismo y presenta ideas sobrevaloradas de sí mismo. A pesar de ello, la falta de contacto con la realidad no es tan grave como para provocar una desadaptación social o laboral. Estos episodios suelen presentarse inmediatamente antes o después de un episodio depresivo mayor; no obstante, el patrón de presentación es característico de cada persona (Jarne et al., 2006).

Adicionalmente, el DSM-5 (APA, 2014) identifica la impulsividad en el episodio hipomaniaco como rasgo que puede contribuir a los intentos de suicido y a los trastornos por consumo de sustancias. Aunque dicha impulsividad también puede ser producto de un trastorno de personalidad, por consumo de sustancias, de ansiedad u otros. Finalmente, cabe resaltar, que algunas personas pueden tener niveles de creatividad elevados durante un episodio hipomaniaco, por esta razón la necesidad de búsqueda de tratamiento no es frecuente.

\subsubsection{Trastorno Comórbidos}

Según el DSM-5 (APA, 2014), el trastorno bipolar tipo II presenta con frecuencia uno o más desordenes coexistentes. Alrededor del $60 \%$ de los pacientes con bipolaridad II tiene al mismo tiempo 3 o 
más trastornos mentales, el 75\% tiene un trastorno de ansiedad y el 37\% trastorno por abuso de sustancias.

Ortuño (2010) indica que la comorbilidad psiquiátrica en el trastorno bipolar es muy frecuente y que su presencia adelanta el inicio de la enfermedad, empeora el curso clínico, aumenta la refractariedad al tratamiento y eleva el riesgo suicida. Además, específica que la mayor parte de pacientes con trastorno bipolar suele presentar sintomatología ansiosa, aunque solo el $40 \%$ cumple con los criterios clínicos para establecer un trastorno de ansiedad, entre los cuales pueden estar el ataque de pánico, la fobia social y el síndrome de estrés post traumático. También identifica el abuso de sustancias, sobretodo de alcohol y drogas estimulantes, en más de la mitad de los casos diagnosticados con trastorno bipolar tipo II.

En la misma línea, Caballo, Salazar y Carrobles (2011) sugieren una alta comorbilidad del trastorno bipolar con otros problemas psicológicos. Por ejemplo, las personas con trastorno bipolar tienen 35 veces más probabilidad de sufrir un trastorno por ansiedad que la población normal. Esto indicaría que aproximadamente entre $65 \%$ y el 90\% de los bipolares van a sufrir trastornos de ansiedad. Finalmente, en cuanto a la relación de causalidad, la experiencia clínica sugiere que el trastorno bipolar suele ser el problema primario y las dificultades de adaptación que provoca en el día a día facilitan la aparición de otros trastornos.

\subsubsection{Modelos Terapéuticos}

Para el abordaje del trastorno bipolar, además de la medicación, son imprescindibles las intervenciones psicosociales, debido a que los psicofármacos no aseguran la ausencia de recaídas ni de la sintomatología subsindrómica. Al ser una patología con una predisposición biológica importante, pero cuya incidencia en episodios depende también de factores ambientales, existen diversos tipos de intervención. Entre las más utilizadas y que presentan mayor eficacia están la terapia cognitivo conductual, intervenciones familiares, terapias 
psicoeducativas y la terapia interpersonal y de ritmos sociales (Grupo de Trabajo de la Guía Práctica Clínica sobre Trastorno Bipolar, 2012). A continuación se detallarán las características principales de los abordajes terapéuticos señalados:

- Psicoeducación: Su principal objetivo es informar al paciente sobre las particularidades de su enfermedad (Lolich, Vásquez, Álvares y Tamayo, 2012). De esta manera busca generar conciencia de enfermedad, facilitar la detección de síntomas, aumentar la adherencia al tratamiento, controlar el estrés, implementar nuevos estilos de vida, incrementar el conocimiento y afrontamiento sobre las consecuencias negativas que conllevaron episodios pasados $\mathrm{y}$ mejorar actividad social (Belloso, 2012). Además, considera que las creencias y las conductas que el paciente asume sobre su enfermedad tienen un valor pronóstico, ya que al crear nuevos hábitos para su nuevo estilo de vida reduciría en gran medida próximos episodios. A través de diversas investigaciones se ha encontrado que la psicoeducación personal, familiar y grupal tienen resultados positivos (Lolich et al., 2012).

- Terapia cognitivo conductual: Busca modificar las distorsiones cognitivas sobre la enfermedad, prevenir recaídas y monitorear el desenvolvimiento de los síntomas (Lolich et al., 2012).

- Terapia familiar: Busca la mejora en la dinámica familiar a través de la psicoeducación para que las personas próximas al paciente posean conocimientos y cuenten con habilidades para el manejo del trastorno. Además, se busca que los familiares mejoren sus habilidades comunicativas y de solución de conflictos con el fin de prevenir o aminorar futuras dificultades (Belloso, 2012; Lolich, et al., 2012).

- Terapia interpersonal y de ritmos sociales: Busca instruir al paciente en la identificación de sus estados emocionales y la relación que tienen con su contexto y actividades interpersonales. También tiene como objetivo disminuir el número de conflictos 
interpersonales a través de una comunicación más asertiva con el entorno. Además, se considera importante el orden del sueño y los ritmos biológicos (Lolich et al., 2012). Otros objetivos que se plantea es la regularización de las rutinas diarias y la adherencia al tratamiento farmacológico (Belloso, 2012).

Hunsley, Elliot y Therrien (2014) resaltan que entre aquellas terapias no existe una mejor que otra, lo importante es que el tratamiento se adapte a las necesidades encontradas en el paciente. En la misma línea, Lolich et al. (2012) afirman que la que la elección de un tipo de terapia es pertinente dependiendo de las características clínicas de cada paciente. Así, por ejemplo, se ha encontrado que la terapia cognitivo conductual, la interpersonal y la psicoeducación grupal, suelen ser eficaces en pacientes eutímicos, mientras que la terapia familiar aporta mayor beneficio en pacientes con síntomas graves.

\subsection{Neuropsicología de los trastornos psiquiátricos}

\subsubsection{Evaluación Neuropsicológica}

La neuropsicología clínica es definida como la ciencia que se encarga de explorar la relación entre el comportamiento y el funcionamiento cerebral (Tirapu, García, Ríos y Ardila, 2012). Mientras que la evaluación neuropsicológica es un método utilizado para explorar el cerebro mediante el estudio del producto conductual (Lezak et al., 2004). Específicamente, existen dos tipos de aproximaciones, la primera se enfoca en el análisis de patrones, que tiene como objetivo utilizar baterías para detectar funciones afectadas. La presencia de un daño se determina comparando el desempeño del paciente con su grupo normativo igualado en las variables de edad y grado de instrucción. Los resultados se valoran según el punto de corte que corresponden con los criterios estadísticos de la población normal. Por otro lado, la segunda aproximación se centra en la comprobación de hipótesis. Este enfoque tiene como objetivo la búsqueda de síndromes neuropsicológicos, busca 
conocer la naturaleza del deterioro. No tiene como prioridad la valoración de los resultados cuantitativos, sino el proceso que sigue el evaluado durante la ejecución de las tareas asignadas. (Pérez, 2009).

Diversos autores han propuesto cuáles son las funciones que deben explorarse en una evaluación neuropsicológica. En el siguiente cuadro se resumen tres propuestas de distintos autores:

Tabla 2.4

Áreas de evaluación neuropsicológica sugeridas por cada autor

\begin{tabular}{|c|c|}
\hline Áreas & Áreas de Evaluación \\
\hline Lezak, Howieson y Loring, 2004 & $\begin{array}{l}\text { - Orientación y atención } \\
\text { - Memoria } \\
\text { - Habilidades Verbales y Lenguaje } \\
\text { - Construcción } \\
\text { - Formación de Conceptos y } \\
\text { Razonamiento } \\
\text { - Funciones Ejecutivas y Funciones } \\
\text { Motoras } \\
\text { - Funcionamiento Emocional }\end{array}$ \\
\hline Adler, Spencer y Wilens, 2015 & $\begin{array}{l}\text { - Coeficiente Intelectual } \\
\text { - Funciones Ejecutivas } \\
\text { - Atención } \\
\text { - Lenguaje } \\
\text { - Funciones Espaciales, Visuales y } \\
\text { Perceptuales } \\
\text { - Memoria y Aprendizaje } \\
\text { - Habilidades Motoras } \\
\text { - Percepción } \\
\text { - Funcionamiento Emocional } \\
\text { - Habilidades Académicas }\end{array}$ \\
\hline
\end{tabular}




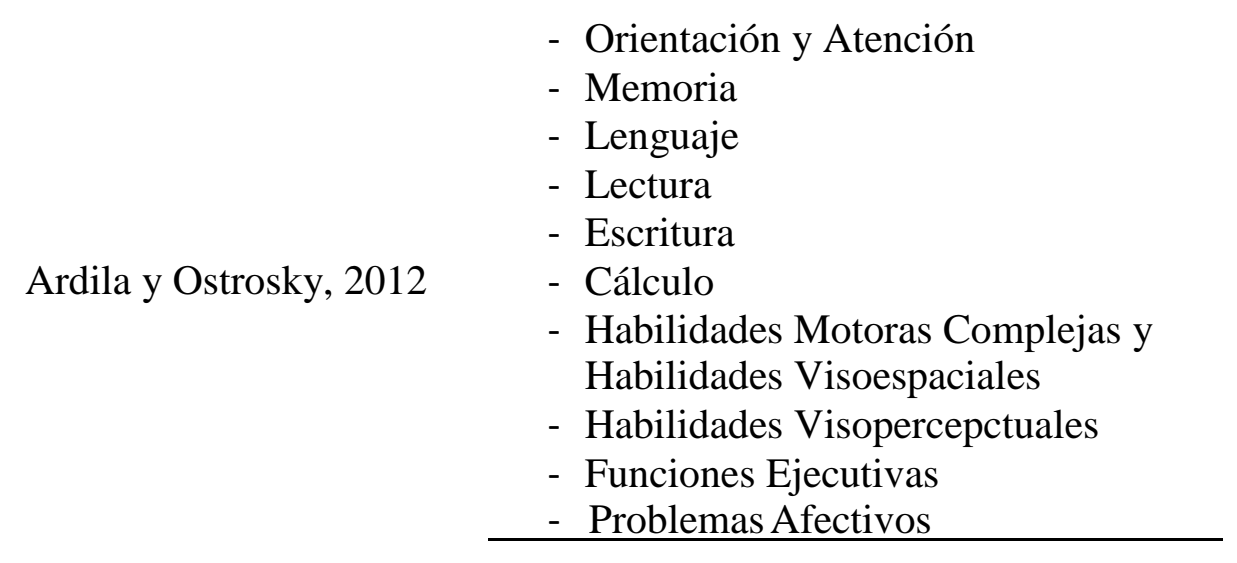


En cuanto a los instrumentos pertinentes para evaluar cada área, los autores señalados previamente coinciden en que la Escala de Inteligencia Wechsler para adultos es el mejor instrumento de medida. Respecto a evaluación de los canales atencionales, la mayoría de autores recomienda los test de rendimiento continuo como el Test of Variables of Attention (TOVA) (Adler et al., 2015; Ardila y Ostrosky, 2012; Lezak et al., 2004). Mientras que Lezak et al. (2004) resaltan que la atención se refleja en las pruebas que miden el tiempo de reacción, la vigilancia, la retención inmediata y la memoria de trabajo. Y para evaluar dichas funciones recomienda, además de los test de rendimiento continuo, el Test de Stroop, el Trail Making forma A y B y algunas subpruebas de la Escala de Inteligencia Wechsler (retención de dígitos, letras y números y clave de números).

Respecto a las funciones ejecutivas, Ardilla y Ostrosky (2012) consideran la autorregulación, la meta cognición, la memoria de trabajo y la flexibilidad cognitiva pueden ser evaluadas mediante la Prueba de Stroop, la Prueba de Laberintos de Porteus, el Test de Clasificación de Tarjetas de Wisconsin, las Torres de Hanoi, la Prueba de Generación de Categorías Semánticas y un Cuestionario de Funciones Ejecutivas. Mientras que Adler et al. (2015) recomiendan evaluar las funciones ejecutivas, con pruebas de fluidez verbal, con la Prueba de Stroop (control inhibitorio), el Test de Clasificación de Tarjetas de Wisconsin y las Torres de Hanoi (razonamiento abstracto / solución de problemas).

En cuanto a la memoria, para el componente verbal, Ardilla y Ostrosky (2012) sugieren su evaluación a través de pruebas como el Test de Aprendizaje Verbal Auditivo de California, la Escala de Memoria del Weschler y el Test de Aprendizaje Auditivo de Rey. Mientras que para la memoria visual resaltan la Figura Compleja de Rey-Osterrieth y algunos subtest de la Escala de Memoria del Weschler. Lezak et al. (2004) recomiendan la Escala de Memoria del Weschler para ambos componentes.

Como se puede observar, la evaluación neuropsicológica involucra la exploración de diversas funciones a través de diferentes instrumentos individuales. Sin embargo, existen baterías que contienen 
un conjunto de pruebas que buscan medir las funciones necesarias en una evaluación neuropsicológica, estas indican el nivel de deterioro con puntajes globales y con baremos de acuerdo a la edad y/o grado de escolaridad de la persona. Una de ellas es la Batería Neuropsicológica Breve en Español (NEUROPSI) creada por Ostrosky, Ardilla y Rosselli (1999). Esta realiza una evaluación general de las siguientes funciones: Orientación, Atención y Concentración, Codificación y Evocación Verbal y Visual, Lenguaje, Lectura, Escritura, Funciones Conceptuales, Funciones Motoras. También está la Batería Neuropsicológica de Funciones Ejecutivas y Lóbulos Frontales (BANFE-2), creada por Flores, Ostrosky y Lozano (2014), la cual profundiza la exploración del área frontal y los resultados se asocian con el área anatómica dañada. Esta tiene como propósito la evaluación de las funciones ejecutivas expresadas en la organización, control inhibitorio, flexibilidad mental, generación de hipótesis, planeación, actitud abstracta y memoria de trabajo. Finalmente, una batería dirigida específicamente a la evaluación de los procesos mnésicos es la Escala de Memoria Wechsler-IV (2008), que evalua los tipos de memoria auditiva, visual, de trabajo visual, inmediata y demorada.

Luego de haber realizado una revisión de algunas de las pruebas utilizadas para evaluar las funciones cognitivas, cabe resaltar que se sugiere interpretar los resultados obtenidos de ellas dependiendo del paciente. Esto se debe a que las pruebas previamente señaladas brindan información sobre diversas funciones, no exclusivamente una única función. Por ejemplo, el subtest de aritmética de la Escala de Inteligencia del Wechsler (WAIS-IV) mide la habilidad para resolver problemas aritméticos, sin embargo, en un paciente con dificultades atencionales los resultados proveerán mayor información sobre sus procesos atencionales (Lezak et al. 2004). 


\subsubsection{Características Neuropsicológicas Alteradas en el TDAH}

$\mathrm{Si}$ bien las investigaciones que buscan explorar las asociaciones entre el TDAH y ciertas disfunciones neuropsicológicas son diversas, los resultados encontrados son aún confusos. Mientras que algunos estudios han logrado discriminar ciertas características presentes en adultos con TDAH mediante el uso de pruebas neuropsicológicas, otros concluyen que este tipo de pruebas no son las adecuadas para la exploración de dichas características.

Dentro del primero grupo se encuentra a Rohlf et al. (2012), quienes llevaron a cabo una investigación que buscaba evaluar las funciones de cambio de categoría y memoria de trabajo en adultos con TDAH. Los instrumentos para medir la capacidad de cambio de categoría fueron el Trail Making Test y el Test Computarizado de Clasificación de Cartas (CVK) (versión modificada del Test de Clasificación de Cartas de Wisconsin). Mientras que para medir la memoria de trabajo se utilizó la subprueba de retención de dígitos de la Escala de Inteligencia del Wechsler. Los resultados indicaron que el grupo total de personas con TDAH presentaban dificultades para el cambio cognitivo y en la memoria de trabajo. Adicionalmente, no se hallaron diferencias significativas en el desempeño asociadas a la presencia de comorbilidad. Estos resultados sugieren que los déficits encontrados son atribuibles al TDAH más que a la comorbilidad.

Otros autores señalan que la evaluación de la atención mediante los test de rendimiento continuo permiten identificar las siguientes características neuropsicológicas presentes en personas con TDAH: dificultad para mantener la atención en el tiempo, dificultad en la inhibición de respuestas y una alta variabilidad del tiempo de respuesta. Esta última, se considera una de las características principales de las personas con esta patología (Adler et al., 2015; González-Gadea et al., 2013). En la misma línea, Barkley (2015) identifica las funciones ejecutivas alteradas que afectan al menos a un subgrupo de personas con TDAH: la inhibición de la repuesta, la memoria de trabajo y el cambio del set cognitivo. 
Por otro lado, la investigación de Barkley y Murphy (2011), partiendo de la premisa de que los déficits hallados son solo observables en una minoría de las personas que tienen esta patología debido a la baja validez ecológica de las pruebas, llega a otras conclusiones. Buscaron analizar la relación entre los déficits en actividades cotidianas y el rendimiento en pruebas que evalúan las funciones ejecutivas en adultos con TDAH. Para esto, aplicaron pruebas neuropsicológicas y escalas que evaluaban distintas funciones ejecutivas a tres grupos de personas: adultos con TDAH $(\mathrm{N}=146)$, un grupo de control clínico $(\mathrm{N}=97)$ y un grupo control de la comunidad $(\mathrm{N}=109)$. Se encontró que el grupo de personas con TDAH tenían calificaciones más severas en las escalas auto aplicadas y aplicadas por otros, en comparación con el grupo clínico y el grupo control de la comunidad. Pero si bien la mayoría de adultos con TDAH presentaron deficiencias según los puntajes de las escalas, solo una pequeña minoría lo hizo según los puntajes de las pruebas neuropsicológicas. Los autores concluyeron que esta disparidad entre ambos métodos de evaluación sugiere que el TDAH en el adulto implica problemas sustanciales en las funciones ejecutivas involucradas en la vida cotidiana y el funcionamiento diario.

Respecto al concepto de validez ecológica mencionado con anterioridad, García, Tirapu y Roig (2007) indican que un test posee dicha validez cuando permite inferir o predecir la capacidad funcional de la persona en sus actividades diarias. Igualmente, Bombin et al. (2014) la definen como la correspondencia de los resultados de las pruebas con la realidad clínica e indica que las pruebas clásicas que evalúan las funciones ejecutivas pueden predecir solo parcialmente las dificultades funcionales, siendo de nivel moderado la predicción de estas pruebas. Esto se debe a la interacción de múltiples factores que interfieren en el desempeño del individuo. Por su parte, Chaytor, Schmitter-Edgecombe y Burr (2006) indican que los factores que pueden intervenir en la validez ecológica de las pruebas que miden las funciones ejecutivas son: la situación artificial, el estrés de ser evaluado, que las pruebas no se asemejan con la realidad que el paciente vive a diario, la corta duración de las pruebas, la falta de acuerdo para definir el constructo que se 
pretende evaluar y que las demandas cognitivas ambientales presentes en la vida diaria del sujeto no se asemejan con la situación de la evaluación.

Otra posible explicación de la reducida evidencia del TDAH en las pruebas neuropsicológicas puede ser la que brinda la investigación realizada por Bramham et al. (2012). En ella se encontró que los síntomas medidos con pruebas neuropsicológicas y con escalas de auto reportes reflejan una mejoría con la edad. Es así que en las pruebas neuropsicológicas la atención selectiva y la inhibición de las respuestas evidencian un progreso. De la misma manera, en las escalas de auto reportes se observan menos dificultades en el área de hiperactividad, pues aseguran que en la adultez los síntomas de hiperactividad disminuyen significativamente debido al desarrollo de estrategias para afrontar los síntomas hiperactivos. Por otro lado, la experiencia subjetiva de las personas con TDAH es que sus síntomas de inatención empeoran con la edad, aunque esto se podría explicar por la presencia de síntomas comórbidos afectivos.

Finalmente, Mick, Faraone y Biederman (citados en Barkley, 2015) indican que la eficiencia del diagnóstico del TDAH mediante pruebas neuropsicológicas es limitado, tanto para niños como para adultos. Es así que las pruebas neuropsicológicas solo llegan a identifican aproximadamente el 14\% de casos de adultos con TDAH.

Luego de la revisión de los diferentes autores, se puede concluir que las pruebas neuropsicológicas pueden mostrar una eficacia disminuida para detectar el TDAH en el adulto. A pesar de ello, también se muestra que existe una mejora en las funciones neurocognitivas a través de los años, tales como la atención selectiva y control inhibitorio y en los síntomas de hiperactividad. No obstante, es posible que un subgrupo de personas con TDAH presenten alteraciones en las funciones ejecutivas tales como: el control inhibitorio, memoria de trabajo, cambio de set cognitivo y la variabilidad de tiempo de respuesta ante estímulos.

\subsubsection{Características Neuropsicológicas en el Trastorno Bipolar Tipo II}


Al igual que en el TDAH, en el trastorno bipolar también se pueden observar alteraciones a nivel cognitivo que dependen de las fluctuaciones anímicas que experimenta la persona. Así, por ejemplo, en la fase depresiva pueden presentarse dificultades en la atención, memoria $\mathrm{y}$ en la toma de decisiones, mientras que en la fase maniaca o hipomaniaca puede haber una mayor impulsividad en la toma de decisiones (Tirapu et al., 2012). En la misma línea, el DSM-5 (APA, 2014) refiere que los pacientes con trastorno bipolar tipo II obtienen puntuaciones más bajas en ciertas funciones cognitivas que los individuos sanos, siendo su rendimiento semejante al trastorno bipolar tipo I. Se ha sugerido que los cambios anímicos en el trastorno bipolar, tienen como consecuencia un impacto negativo sobre los procesos cognitivos, en la concentración, apatía, dificultades en la memoria, en la toma de decisiones, impulsividad; las cuales se relacionan con alteraciones frontales.

Latalova, Prasko, Diveky y Velartova (2011), hicieron una revisión de la base de datos de Medline y PsycInfo sobre las alteraciones cognitivas en el trastorno bipolar. Los datos hallados apoyan la existencia de alteraciones cognitivas estables en todas las fases del trastorno bipolar, específicamente en la atención sostenida, la memoria y las funciones ejecutivas. Sin embargo, resaltan que las investigaciones actuales muestran inconsistencia en los resultados, esto se debe a que el impacto de la bipolaridad sobre la cognición puede ser influenciada por los años de inicio, tratamientos farmacológicos, respuestas individuales y características clínicas.

Otros estudios han indagado si las afectaciones presentes en las etapas de depresión y manía/hipomanía se mantienen también en las fases eutímicas de la persona que presenta un trastorno bipolar. Una de ellas exploró la alteración neuropsicológica en pacientes bipolares que se encuentran en estado eutímico. Los participantes fueron 35 personas diagnosticadas con trastorno bipolar y sujetos del grupo control que fueron evaluados con el Addenbrooke's cognitive examination (ACE). Los resultados indicaron que los pacientes bipolares eutímicos demostraron un rendimiento menor en las funciones ejecutivas y en la 
memoria verbal en comparación a los sujetos sin patología, lo que sugiere estabilidad o cronicidad de los déficits cognitivos (López, 2011).

En la misma línea, Tirapu et al. (2012) realizaron un recuento de diversas investigaciones acerca del estado neurocognitivo en pacientes eutímicos. Mientras que algunas investigaciones sugieren que en dicha fase el paciente puede recuperar totalmente su funcionalidad, otras indican que los déficits cognitivos se mantienen en la eutimia. Dentro de este segundo grupo se propone que las alteraciones cognitivas podrían no deberse al estado emocional, de manera que estarían presentes antes de la enfermedad. Además, el autor indica que el funcionamiento cognitivo de los pacientes bipolares puede verse influenciado por variables como por la duración de los episodios, la edad de inicio y número de hospitalizaciones.

Más adelante, Mora, Portella, Forcada, Vieta y Mur (2013) llevaron a cabo una investigación que trataba de analizar las alteraciones neurocognitivas y su impacto negativo en el funcionamiento psicosocial en pacientes eutímicos tratados con litio. La muestra estuvo conformada por 28 pacientes eutímicos medicados con litio y 26 sujetos controles. Las pruebas aplicadas fueron la Escala de Inteligencia Weschler (vocabulario, diseño de cubos, retención de dígitos), el Test de Clasificación de Cartas de Wisconsin, el Test de Stroop, el Test Fluidez Verbal, el Trail Making Test, el Test de Aprendizaje Verbal de California y la Figura Compleja de Rey. Los resultados indicaron que las funciones ejecutivas, la inhibición, la velocidad de procesamiento y la memoria verbal se encuentran afectadas en estos pacientes. Además, se observaron repercusiones sobre la adaptación psicosocial, la cual incluye: autonomía, ocupación, funciones cognitivas, problemas financieros, relaciones interpersonales y actividades de ocio.

Otra investigación buscó evaluar y comparar el funcionamiento neurocognitivo de pacientes bipolares con el de sus hermanos no afectados. La investigación contó con 20 pacientes con bipolaridad que se encontraban en remisión, 20 hermanos no afectados y 20 sujetos control sanos. Los pacientes bipolares, en comparación con los hermanos no afectados, obtuvieron un menor rendimiento en las pruebas de 
funciones ejecutivas, memoria visual-verbal, velocidad psicomotora, concentración y habilidades grafomotoras (Nehra, Grover, Sharma, Sharma y Sarkar, 2014).

Como se puede apreciar, según las investigaciones revisadas, se ha encontrado que los mayores déficits cognitivos se relacionan con las funciones ejecutivas, la memoria verbal, la atención y la velocidad psicomotora. No obstante, la influencia de las características individuales de los pacientes, como el proceso de la enfermedad y las características clínicas, desencadenaría alteraciones cognitivas en diferentes dominios $\mathrm{y}$ en distintos niveles.

\subsection{Diagnóstico Diferencial del Trastorno por Déficit de Atención y el Trastorno Bipolar}

\subsubsection{Diferencias Clínicas}

Recordando lo que señalan Klassen et al. (2010), el diagnóstico diferencial es un desafío, puesto que ambos trastornos superponen síntomas similares. Por tal motivo, es importante saber distinguir los síntomas que pertenecen al TDAH y los que corresponden al trastorno bipolar.

En primer lugar, es importante hacer una diferenciación de las alteraciones emocionales presentes en cada trastorno. En los trastornos del ánimo se presentan oscilaciones anímicas en forma de estados de larga duración y no son necesariamente provocadas por una situación específica. De esta manera, no son racionales en el sentido de que su tiempo de duración e intensidad son justificables por las circunstancias (Barkley, 2015). Por otro lado, el TDAH se expresa a través de emociones, no estados, ni disposiciones del ánimo. Las emociones tienen una corta duración y son provocadas por situaciones específicas que las ameritan, siendo racionales y comprensibles, pero difícilmente controlables. Es así como su estado de ánimo presenta labilidad emocional, pudiendo cambiar en hora o en minutos, pero no suele ser constante por largos periodos de tiempo. Finalmente, cabe resaltar, que 
la ideación suicida y un estado de ánimo depresivo mayor a dos semanas no son características del TDAH (Barkley, 2015; Fitzgerald, Bellgrove y Gill, 2007).

En un análisis más profundo, Lavigne y Romero (2010) presentan los siguientes síntomas comunes y síntomas diferenciales entre ambos trastornos: 
Tabla 2.5

Síntomas comunes y diferenciales entre el TDAH y el trastorno bipolar

\begin{tabular}{|c|c|c|}
\hline Área & TDAH & $\begin{array}{c}\text { Trastorno } \\
\text { Bipolar }\end{array}$ \\
\hline \multicolumn{3}{|c|}{ Síntomas comunes a ambos trastornos } \\
\hline Sueño & $\begin{array}{l}\text { Dificultades en la } \\
\text { conciliación del sueño }\end{array}$ & $\begin{array}{l}\text { Disminución } \\
\text { en la necesidad } \\
\text { de sueño (se } \\
\text { acuesta muy } \\
\text { tarde y/o se } \\
\text { levanta muy } \\
\text { temprano) }\end{array}$ \\
\hline Impulsividad & Frecuente & Muy frecuente \\
\hline Baja capacidad de juicio & Menos frecuente & Muy frecuente \\
\hline Irritabilidad & Rabietas Breves & $\begin{array}{l}\text { Intensa y } \\
\text { persistente con } \\
\text { agresividad }\end{array}$ \\
\hline Hiperactividad & Continua y sin objetivo & $\begin{array}{l}\text { Episódica, muy } \\
\text { ocupados, } \\
\text { dirigido a } \\
\text { actividades } \\
\text { placenteras }\end{array}$ \\
\hline Inatención & Muy frecuente & Frecuente \\
\hline Exploración del lenguaje & Habla mucho, interrumpe & Fuga de ideas \\
\hline Abuso de Sustancias & $\begin{array}{l}\text { Mas asociado con el } \\
\text { Trastorno Negativista } \\
\text { Desafiante }\end{array}$ & Muy frecuente \\
\hline \multicolumn{3}{|c|}{ Síntomas diferenciales entre ambos trastornos } \\
\hline Autoconcepto & $\begin{array}{l}\text { Autoestima baja por } \\
\text { fracasos escolar y social }\end{array}$ & $\begin{array}{l}\text { Grandiosidad, } \\
\text { a veces } \\
\text { delirante }\end{array}$ \\
\hline Humor & $\begin{array}{l}\text { Normal o depresivo, } \\
\text { irritable si quiere evitar el } \\
\text { esfuerzo mental }\end{array}$ & $\begin{array}{l}\text { Euforia o } \\
\text { humor elevado. } \\
\text { Labilidad } \\
\text { intensa, } \\
\text { irritable }\end{array}$ \\
\hline Psicosis & No en TDAH & Frecuente \\
\hline Hipersexualidad & No en TDAH & $\begin{array}{l}\text { Inicialmente } \\
\text { verbal o } \\
\text { gestual }\end{array}$ \\
\hline
\end{tabular}


Respecto a los síntomas comunes, el DSM-5 (APA, 2014) indica que se podría evitar la "doble contabilidad" de los síntomas del TDAH y del trastorno bipolar tipo II identificando si los síntomas suponen o no un episodio diferente y si existe o no el aumento apreciable del estado basal que se requiere para el diagnóstico del trastorno bipolar tipo II.

Halmoy et al. (2010) realizaron una investigación que buscaba explorar los síntomas del trastorno bipolar en adultos con TDAH. Se evaluó 510 personas diagnosticadas con TDAH y 417 sujetos controles mediante dos cuestionarios de autoreporte: Adult ADHD self-report Scale (ASRS), el cual mide la presencia y frecuencia de síntomas actuales del TDAH, y Mood Disorder Questionnaire (MDQ), que explora de manera general el espectro bipolar. Los resultados indicaron que el 50.6\% de pacientes con TDAH presentan síntomas de bipolaridad, en comparación a un $8.3 \%$ del grupo control. Adicionalmente, se encontró que los pacientes con síntomas de bipolaridad presentan mayores dificultades con el uso de drogas, mientras que un mayor número de síntomas del TDAH indican menores niveles educativos y ocupacionales. El estudio concluye resaltando una estrecha relación entre los síntomas de la bipolaridad y del TDAH en los adultos, sugiriendo que ante los resultados positivos en el espectro bipolar se debe descartar la coexistencia del TDAH y viceversa.

\subsubsection{Diferencias Cognitivas}

Torralva et al. (2011) llevaron a cabo un estudio comparativo de algunas funciones cognitivas (atención, memoria y funciones ejecutivas) en personas con TDAH y personas con trastorno bipolar. Según los resultados, ambos grupos reflejaron un desempeño más bajo que los controles en el reconocimiento verbal, memoria no verbal y funciones ejecutivas. Sin embargo, el grupo de TDAH obtuvo mejores puntuaciones en memoria verbal y visual respecto al grupo bipolar.

Más adelante, Levent et al. (2014) realizaron una comparación entre la neuropsicología del trastorno bipolar y el TDAH. Para ello 
incluyeron 66 pacientes bipolares y 63 con TDAH a quienes se les realizó una evaluación neurocognitiva con distintos instrumentos. Este estudio encontró un menor desempeño en las pruebas que evaluaban la memoria verbal y las funciones ejecutivas por parte de los pacientes con bipolaridad, mientras que aquellos con TDAH presentaron un rendimiento menor en el Test de Stroop.

Michelini y colaboradores (2016) llevaron a cabo una investigación titulada: "trastorno neurofisiológico de alteraciones en la atención y la inhibición en mujeres con TDAH y trastorno bipolar". Seleccionaron a 20 mujeres con TDAH, 20 mujeres con trastorno bipolar y 20 mujeres controles. Se evaluó, mediante un electroencefalograma el rendimiento cognitivo, así como también se aplicaron pruebas de coeficiente intelectual y una entrevista clínica. Los resultados muestran dificultades en la inhibición conductual tanto en el grupo de personas con TDAH como con el trastorno bipolar. Afirman que estos déficits podrían explicar el comportamiento impulsivo en ambos trastornos. Adicionalmente, en el trastorno bipolar se observaron dificultades para monitorear el propio desempeño así como la selección de respuestas adecuadas. Finalmente concluyen que las diferencias encontradas podrían contribuir a la precisión del diagnóstico clínico.

Como se puede observar, sí existen alteraciones cognitivas en ambos trastornos, incluyendo memoria verbal, funciones ejecutivas y atención. Además, se observa un rendimiento más afectado en los pacientes con bipolaridad en comparación a los pacientes con TDAH. 


\section{CAPÍTULO III: OBJETIVOS}

\subsection{Objetivos Generales}

- Describir los síntomas predominantes del TDAH y del Trastorno Bipolar tipo II a lo largo de la vida del evaluado.

- Describir el perfil neuropsicológico del examinado con TDAH y del Trastorno Bipolar tipo II.

\subsection{Objetivos Específicos}

- Identificar la sintomatología del TDAH en el evaluado mediante anamnesis.

- Identificar la sintomatología del Trastorno Bipolar tipo II en el evaluado mediante anamnesis.

- Describir la sintomatología neurocognitiva del TDAH en el evaluado mediante pruebas neuropsicológicas.

- Describir la sintomatología neurocognitiva del Trastorno Bipolar tipo II en el evaluado mediante pruebas neuropsicológicas

- Establecer un plan de intervención de acuerdo a la sintomatología del TDAH y del Trastorno Bipolar tipo II a lo largo de la vida del evaluado. 


\section{CAPÍTULO IV: MÉTODO}

\subsection{Tipo y Diseño de Investigación}

La presente investigación es desarrollada bajo la modalidad del estudio de caso único, la cual se encarga de describir la variedad de conductas de un individuo y la correlación que tienen con su ambiente actual e historia. Además, esta forma de investigación busca entender el comportamiento de un individuo según su ambiente y la tarea del evaluador es recoger los datos acerca del presente, experiencias pasadas y la relación entre ellos (Ary, Jacobs, Razavieh y Sorensen 2009).

También, Morley (citado en Roussos, 2007), identifica diferentes utilidades que brindan los casos únicos en la psicología clínica:

1. Pedagógicos generales, se hace uso de la ejemplificación de conceptos lo cual lo hace didáctico.

2. Se generan modelos de acción clínica, para el entrenamiento de profesionales.

3. Se crean nuevas ideas, tendencias de pensamientos y peculiaridades clínicas.

La revisión hecha por Roussos en el 2007, sobre los estudios de caso único en la psicología clínica, identifica dos tipos de diseño, el primero hace referencia a los casos únicos experimentales y el segundo al diseño observacional. Este último tiene dos usos principales, los estudios de caso de evaluación diagnóstica y los estudios que se enfocan en la intervención terapéutica. En la evaluación diagnóstica, el objetivo es dar ejemplo del uso de los instrumentos psicométricos para realizar un diagnóstico o medir un resultado, mientras que en la intervención terapéutica, el reto es describir un 
trastorno o la evaluación de los efectos de un tratamiento. En el presente estudio de caso se buscó la aplicación de instrumentos psicométricos para hallar sintomatología cognitiva en un paciente con comorbilidad y también se exploró mediante el uso de la anamnesis la sintomatología del TDAH y del trastorno bipolar a lo largo de la vida del sujeto. Luego, con aquellos resultados se pretende proponer un plan de trabajo que ayude a reducir los síntomas que más aquejen al paciente, ya sean cognitivos y/o emocionales.

Se consideró de suma relevancia el análisis del caso de Adrián puesto que es un paciente que ya cuenta con un diagnóstico y tratamiento farmacológico. De esta manera se busca ahondar en las características y consecuencias negativas de ambas patologías a lo largo de su vida. Además, también se pretende explorar la dificultad existente para diferenciar síntomas entre el TDAH y trastorno bipolar tipo II, pues ambas suponen un reto (Klassen, 2010). Asimismo, se plantea una evaluación neuropsicológica para analizar las alteraciones a nivel neurocognitivo debido a que, como ya se mencionó con anterioridad, el TDAH es un trastorno del neurodesarrollo y el trastorno bipolar contiene causas biológicas. Finalmente, luego de determinar la sintomatología del paciente a lo largo de su vida y los síntomas neurocognitivos, se considera fundamental proponer un plan de intervención que se ajuste a sus necesidades.

\subsection{Participante}

Adrián es un adulto de 49 años de edad y su grado de instrucción es superior incompleta (segundo ciclo de la carrera de administración). Él es un varón diestro que mide aproximadamente 1.95 metros y su contextura es normal promedio, además su apariencia guarda relación con su edad. Es de tez blanca, ojos color marrón oscuro al igual que su cabello. En la actualidad, vive con su familia nuclear, la cual está compuesta por su esposa de 47 años, su hija mayor de 18, un hijo de 17 y el último de 11 años de edad. Adrián y su esposa son los encargados de la crianza y cuidados de sus hijos. El 
participante, en el 2013, fue diagnosticado por un médico psiquiatra con Trastorno Bipolar II y Trastorno por Déficit de Atención.

A continuación se detalla la medicación prescrita por el médico psiquiatra desde abril del 2013 hasta la última fecha que el paciente asistió a consulta, junio 2014: 
Tabla 4.1

Tratamiento farmacológico por fechas y su evolución

Fecha Fecha

\footnotetext{
- Wellbutrin (Bupropion):150mg, 1 por la mañana.

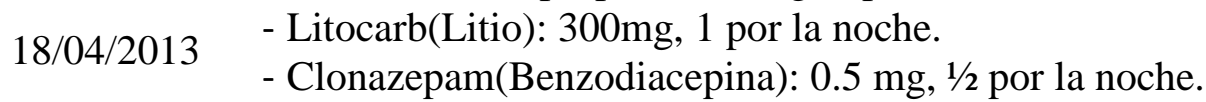

- Siente mejoría en el ánimo pero presenta ansiedad.

- Wellbutrin (Bupropion): $300 \mathrm{mg} 1$ por la mañana.

03/05/2013 - Litocarb (Litio): 300mg, 2 por la noche.

- Clonazepam (Benzodiacepina): $0.5 \mathrm{mg}, 1 / 2$ por la mañana y 1 por la noche.

- Buena evolución.

- Wellbutrin (Bupropion): 300 mg, 1 por la mañana.

17/05/2013 - Litocarb (Litio): 300mg, 3 por la noche.

- Clonazepam (Benzodiacepina): $0.5 \mathrm{mg} \mathrm{1/2}$ por la mañana y 1 por la noche.

03/06/2013 - Misma medicación: buena evolución.

08/07/2013 - Misma medicación: buena evolución.

- Buena evolución.

- Dificultades para dormir y mareos.

- Wellbutrin (Bupropion): $300 \mathrm{mg}, 1$ por la mañana.

5/08/2013 - Litocarb (Litio): $300 \mathrm{mg}, 3$ por la noche.

- Clonazepam (Benzodiacepina): $0.5 \mathrm{mg} 1$ por la noche.

- Quetidin (Quetiapina): 25 mg 1 por la noche.

$\begin{array}{ll}4 / 10 / 2013 & \begin{array}{l}\text { - Buena evolución } \\ \text { - Temblores }\end{array} \\ 8 / 11 / 2013 & \text { - Buena evolución }\end{array}$

$10 / 12 / 2013$

$15 / 01 / 2014$

$29 / 02 / 2014$

- Buena Evolución

$27 / 03 / 2014$

2/06/2014
} 
El paciente refiere no haber tenido tratamiento farmacológico ni psicológico previo, a lo largo de su vida antes del diagnóstico. Luego del mismo, recién acude a tratamientos psicológicos, los cuales tienen corta duración. La primera vez que acude a un psicólogo, fue con un terapeuta, al cual describe como una persona con la que no se pudo generar vínculo, además añade que el precio de las sesiones era elevado y como consecuencia abandonó la terapia. Luego de unos meses por recomendación de su médico psiquiatra acudió a una aseguradora que brindaba servicio de psicología. Adrián describe a su nueva psicoterapeuta como una persona "buena gente, pero nunca me decía nada, solo me escuchaba”. El evaluado, refiere haber esperado retroalimentación por su parte, y ello lo considera como causa de su abandono. Aquella terapia era de orientación psicodinámica. Desde ese momento no ha vuelto a asistir a consulta psicológica.

\subsection{Técnicas de Recolección de Datos}

La investigación tiene como fuentes de recopilación de información: la entrevista semiestructurada y pruebas psicométricas. Para el desarrollo del primer objetivo (identificar la sintomatología del trastorno por déficit de atención e hiperactividad así como para el trastorno bipolar tipo II en el evaluado mediante anamnesis), se hizo uso de la entrevista semiestructurada. Mientras que para el segundo objetivo (describir el perfil neuropsicológico del examinado con trastorno por déficit de atención e hiperactividad y trastorno bipolar tipo II), se utilizaron las siguientes pruebas psicométricas:

- Escala de Inteligencia de Wechsler para adultos - WAIS IV

- Evaluación Neuropsicológica Breve en Español (NEUROPSI)

- Batería Neuropsicológica de Funciones Ejecutivas y Lóbulos Frontales (BANFE-2)

- $\quad$ Test De Rendimiento Continuo Visual (T.O.V.A)

- $\quad$ Escala de Memoria de Wechsler- IV (WMS-IV) 
La duración del proceso de evaluación, fue de ocho sesiones, siendo las tres primeras de ellas para desarrollar la entrevista semiestructurada, la cual tenía el propósito de hallar el motivo de consulta y la historia de vida del evaluado. Luego las cinco sesiones restantes estuvieron destinadas a la exploración de los procesos cognitivos.

El objetivo de las sesiones y su actividad evaluativa, se encuentran descritas en la siguiente tabla: 
Tabla 4.2

Proceso de evaluación por sesión, objetivo y actividad evaluativa

\begin{tabular}{|c|c|c|}
\hline Número de sesión & Objetivo & $\begin{array}{c}\begin{array}{c}\text { Instrumento y/o técnica de } \\
\text { evaluación }\end{array} \\
\end{array}$ \\
\hline 1 & $\begin{array}{l}\text { Recopilación de los } \\
\text { datos de la historia }\end{array}$ & Entrevista semiestructurada \\
\hline 2 & $\begin{array}{l}\text { Recopilación de los } \\
\text { datos de la historia }\end{array}$ & Entrevista semiestructurada \\
\hline 3 & $\begin{array}{l}\text { Recopilación de los } \\
\text { datos de la historia }\end{array}$ & Entrevista semiestructurada \\
\hline 4 & $\begin{array}{l}\text { Evaluación } \\
\text { neuropsicológica } \\
\text { general y evaluación } \\
\text { especifica de la } \\
\text { atención sostenida }\end{array}$ & $\begin{array}{l}\text { Evaluación Neuropsicológica Breve } \\
\text { en Español (NEUROPSI) } \\
\text { Test De Rendimiento Continuo } \\
\text { Visual (T.O.V.A) }\end{array}$ \\
\hline 5 & $\begin{array}{l}\text { Evaluación } \\
\text { neuropsicológica de } \\
\text { las funciones } \\
\text { ejecutivas }\end{array}$ & $\begin{array}{l}\text { Batería Neuropsicológica de } \\
\text { Funciones Ejecutivas y Lóbulos } \\
\text { Frontales (BANFE-2) }\end{array}$ \\
\hline 6 & $\begin{array}{l}\text { Evaluación del } \\
\text { coeficiente } \\
\text { intelectual }\end{array}$ & $\begin{array}{l}\text { Escala de Inteligencia de Wechsler } \\
\text { para adultos - (WAIS IV) }\end{array}$ \\
\hline 7 & $\begin{array}{l}\text { Evaluación del } \\
\text { coeficiente } \\
\text { intelectual }\end{array}$ & $\begin{array}{l}\text { Escala de Inteligencia de Wechsler } \\
\text { para adultos - (WAIS IV) }\end{array}$ \\
\hline 8 & $\begin{array}{l}\text { Evaluación de los } \\
\text { procesos mnésicos }\end{array}$ & Escala de Memoria de (WMS- IV) \\
\hline
\end{tabular}


Fichas técnicas de los Instrumentos

\section{Escala de Inteligencia para adultos de Wechsler (WAIS-IV)}

Nombre: Escala de Inteligencia para adultos de Wechsler (WAIS-IV)

Autor y año: David Wechsler, 2008.

Administración: Individual

Duración: 60 a 90 minutos

Aplicación: Adolescentes y Adultos (16 a 89 años)

Editor de la Edición Española: Pearson Educación, 2012

Significación: Compuesto por 11 subtests obligatorios y 4 opcionales, los cuales están agrupados en cuatro áreas (Comprensión Verbal, Memoria de Trabajo, Razonamiento Perceptivo y Velocidad de Procesamiento)

Material: Manual, cuadernillo, hoja de respuesta y plantillas de corrección.

\section{Descripción:}

El instrumento está comprendido por 15 subtests y estos a su vez pertenecen a cuatro factores. El factor de Comprensión Verbal cuenta con los subtests de Vocabulario, Información, Semejanzas y Comprensión; este último es optativo. El factor de Memoria de Trabajo está compuesto por los subtests de Retención de dígitos, Aritmética y el opcional, Letras y números. El factor Razonamiento perceptivo, está comprendido por los subtests de Construcción de cubos, Matrices, Puzles Visuales y los opcionales son Completamiento de Figuras y Balanzas. Finalmente el Factor de Velocidad de Procesamiento consta de los subpruebas de Búsqueda de Símbolos, Clave de Números y el opcional, Cancelación. La estimación del coeficiente intelectual global se desprende de los cuatro factores mencionados.

La confiabilidad de las puntuaciones del WAIS-IV se estimó en una muestra española de 1002 participantes por medio de dos métodos: dos mitades y consistencia interna a partir del coeficiente Alfa de Cronbach. El coeficiente de confiabilidad de cada prueba basado en el método de las dos 
mitades es la correlación entre las puntuaciones de las dos mitades de una prueba corregida mediante la fórmula de Spearman-Brown para la prueba completa. Por otro lado, los subtests de Claves de Números, Búsqueda de Símbolos y Cancelación, son pruebas que comprometen a la velocidad de procesamiento, por ende la confiabilidad fue medida con el coeficiente de estabilidad test-retest. El resultado promedio de los coeficientes de confiabilidad se sitúan en un nivel adecuado y excelente [.77, .91]. En un nivel adecuado se encuentran los subtests de Semejanzas, Búsqueda de Símbolos y Figuras incompletas, mientras que en el rango excelente se hallan: Cubos, Dígitos, Matrices, Vocabulario, Aritmética, Puzles Visuales, Información y Balanzas. El resto de coeficientes de confiablidad se ubican en la categoría buenos. Por otro lado, los coeficientes de confiabilidad de las puntuaciones compuestas, índices y CI Total, calzan en la categoría excelente.

La validación de las interpretaciones derivadas de los puntajes obtenidos tras aplicar el instrumento fue por medio de evidencias basadas en el contenido de la escala, en los procesos de respuesta, en la estructura interna, en las relaciones con otras variables y estudios con grupos especiales. Las evidencias de validez vinculadas al contenido presentan resultados adecuados, el funcionamiento intelectual cubre un amplio rango de procesos cognitivos comprometidos tales como: el razonamiento verbal, analógico, secuencial, y cuantitativo; la formación de conceptos; el procesamiento secuencial y simultáneo; la comprensión auditiva; la flexibilidad cognitiva; la memoria de trabajo; la organización perceptiva y la velocidad de procesamiento, agrupados en cuatro factores Comprensión verbal (CV), Razonamiento perceptivo (RP), la Memoria de trabajo (MT) y la Velocidad de procesamiento (VP). En cuanto a la validez vinculada a la estructura interna, el análisis factorial confirmatorio preserva la estructura del modelo de inteligencia de Weschler y la división entre un factor $\mathrm{g}$ y cuatro factores de primer orden, CV, RP, MT, VP. Del mismo modo la prueba evidencia correlaciones adecuadas con otras pruebas buscan medir también la inteligencia, reportando adecuadas evidencias de validez vinculadas a la relación con otras variables. 


\section{Escala de Memoria de Wechsler- IV}

Nombre: Escala de Memoria de Wechsler- IV

Autores: David Wechsler, publicación 2008, adaptación Española 2013

Administración: Individual

Duración: 45-60 minutos aproximadamente

Aplicación: Personas de habla hispana desde los 6 años hasta los 89 años

Significación: Evaluación de la memoria del adulto

Material: Manual técnico, Manuales de aplicación y puntuación, Cuadernos de elementos, Cuaderno de anotación, Tablero con cubos, Cuadernillo de dibujo.

\section{Descripción:}

La Escala de Memoria de Wechsler está conformada por siete subtests: Memoria lógica I y II, Pares de palabras I y II, estas subpruebas forman el índice de memoria auditiva. Las siguientes pruebas son: Diseños I y II y Reproducción visual I y II, estas conforman el índice de memoria visual. El subtest de Suma espacial y Span de símbolos forman parte del índice Memoria de Trabajo Visual. Finalmente la última subprueba es el Test breve para la evaluación del estado cognitivo (Brief cognitive status exam, BCSE). Las seis primeras pruebas son las principales y hay que aplicarlas para obtener las puntuaciones de los diferentes índices. El BCSE es una prueba optativa y no se cuantifica en las puntuaciones anteriores, brinda una estimación rápida del estado cognitivo de la persona evaluada. Para la aplicación en las personas que tienen entre 65 y 89 años, no se incluyen los subtests de Diseño I y II y Suma Espacial.

La confiabilidad de las puntuaciones obtenidas tras la aplicación de la batería fue estimada mediante el análisis de consistencia interna y el método de dos mitades en una muestra española $(\mathrm{N}=810)$. No obstante, para las puntuaciones escalares de las subtests de Recuerdo de pares de palabras II y dentro de ella, las tareas de reconocimiento, se utilizaron los coeficientes de estabilidad test-retest. La media de los coeficientes de confiabilidad para las pruebas, fluctúan entre .70 (Diseños I) y .96 (Recuerdo visual II) para la Batería para adultos. La confiabilidad promedio de los índices oscila entre 
.92 (Índices de memoria inmediata, demorada y memoria de trabajo visual) y .95 (Índice de memoria visual) de la Batería para adultos.

Asimismo, se reportan favorables evidencias de validez vinculadas al contenido, la estructura interna y la relación con otras variables. Las evidencias de validez vinculadas al contenido fueron obtenidas de la consulta a expertos, análisis del contenido de los ítems y de los procesos de respuesta. Los resultados indican que el contenido de los subtests y los subtests representan adecuadamente los procesos que pretende medir la batería. Asimismo, la validez también fue explorada y confirmada por el estudio de las intercorrelaciones entre las puntuaciones de la pruebas, análisis factorial confirmatorio (AFC) y evidencias de validez vinculadas a la relación con otras variables.

\section{Evaluación Neuropsicológica Breve en Español}

Nombre: Evaluación Neuropsicológica Breve en Español (NEUROPSI)

Autores: Feggy Ostrosky Shejet, Alfredo Ardila, Mónica Roselli 1999

Administración: Individual

Duración : 20-40 minutos aproximadamente

Aplicación: Personas de habla hispana desde los 6 hasta los 85 años

Significación: Evalúa la orientación, atención y concentración, lenguaje, memoria, funciones ejecutivas, lectura, escritura y cálculo.

Material: Manual, protocolo y láminas de aplicación

\section{Descripción:}

Este instrumento tiene como propósito la evaluación del funcionamiento cognoscitivo general, el cual proporciona baremos estandarizados en población normal latinoamericana hispanohablantes monolingües. Comprende diversos subtest que miden el funcionamiento neuropsicológico general, compuesto por 8 áreas. El resultado de la suma de los puntajes obtenidos en estas áreas, se interpretan bajo los rangos de normal, alteración leve, alteración moderada o alteración severa. 
La muestra se estandarizó en 800 sujetos normales entre los 16 y 85 años de edad y se dividió por rangos de edades: 16-30, 31-50, 51-65, 66-85, cada uno de los grupos estuvo conformada por 200 sujetos. Además, también se dividió la muestra según el grado de instrucción: 0 años de estudio, 1-4 años de estudio (bajo), 5-9 años de estudio (medio) y 10-24 años de escolaridad (alto).

En lo que respecta a las propiedades psicométricas del NEUROPSI, la confiablidad, en primer lugar, de las puntuaciones derivadas de la aplicación de la prueba fue analizada por medio del test-retest en un grupo de 40 participantes. Estos presentaron un funcionamiento cognitivo intacto y se llevó a cabo la segunda medición 3 meses después. La confiabilidad global test-retest fue de .87 .

En segundo lugar, se reportaron evidencias de validez vinculadas a la relación con otras variables de tipo discriminante, en la cual se verifico la sensibilidad del NEUROPSI en poblaciones con depresión, demencia, lupus, esquizofrenia, alcoholismo, daño focalizado derecho e izquierdo. La batería calificó correctamente a pacientes con demencia leve y moderada de un grupo control con una exactitud mayor de $91.5 \%$ y en sujetos con daño comprobado por Tomografía Axial Computarizada (TAC), la prueba clasifico con un 95\% de acierto. Además, se realizó una comparación entre el NEUROPSI y MiniMental sobre su sensibilidad en los falsos negativos y en los falsos positivos de los dos instrumentos en una población de 40 pacientes con lesiones neurológicas documentadas con TAC. El NEUROPSI identifico 38 pacientes con trastornos cognoscitivos, mientras que el Mini-Mental, 16.

\section{Batería Neuropsicológica de Funciones Ejecutivas y Lóbulos Frontales}

Nombre: Batería Neuropsicológica de Funciones Ejecutivas y Lóbulos Frontales, Segunda Edición (BANFE - 2)

Autores y año : Julio Cesar Flores Lázaro, Feggy Ostrosky Shejet y Asuzena Lozano Gutiérrez, 2014.

Administración : Individual

Duración : 50 minutos aproximadamente 
Aplicación: Personas de habla hispana desde los 6 hasta los 80 años

Significación: Medida del funcionamiento de las funciones ejecutivas y lóbulos frontales.

Baremos: Percentiles para las 4 áreas y la escala global.

Material: Manual, protocolo, láminas de aplicación, juego de cartas, tarjetas para clasificación de cartas y torres de Hanoi.

\section{Descripción:}

Este instrumento contiene 14 subtests que fueron divididos según el criterio anatómico-funcional que evalúan las funciones que dependen de la corteza orbitofrontal (COF), corteza prefrontal medial (CPFM), corteza prefrontal dorsolateral (CPFDL) y la corteza prefrontal anterior (CPFA). Los subtest que evalúan las funciones que dependen principalmente de la COF y de la CPFM son: Efecto Stroop, Juego de cartas, Laberintos. Para las funciones que dependen de la CPFDL son: Señalamiento Autodirigido, Memoria de trabajo visoespacial, Ordenamiento alfabético de palabras, Clasificación de cartas, Laberintos, Torre de Hanoi, Suma y resta consecutiva y Fluidez verbal. Por último, las que obedecen a la CPFA son: Clasificación semánticas, Selección de refranes y Metamemoria.

Los resultados cuantitativos de la suma de los puntajes obtenidos en estas áreas, se interpretan bajo los rangos de: normal alto, normal, alteración leve, alteración moderada o alteración severa. Es importante añadir que la batería brinda normas estandarizadas en población hispanohablante en personas de 6 a 80 años de edad. Para la obtención de las normas, se aplicó a 450 sujetos normales, compuesta por 142 niños y 308 adultos.

Los subtest que conforman la batería se seleccionaron con base a su validez neuropsicológica: son pruebas altamente utilizadas por la comunidad internacional, con soporte en la literatura científica y con especificidad de área, determinada tanto por estudios con sujetos con daño cerebral como por estudios de neuroimagen funcional. Los reactivos que incluye la prueba tienen adecuadas evidencias de validez vinculadas a la estructura interna, pues se basan en estudios de neuroimagen y neuropsicología, los cuales muestran alta correlación entre los procesos evaluados y la actividad cerebral. 
La sensibilidad se evaluó mediante la aplicación en grupos de personas con depresión, Alzheimer, demencia vascular, abuso de alcohol, marihuana y cocaína, traumatismo craneoencefálico, TDAH, y en psicopatía. La batería clásico pacientes con demencia y con alteraciones leves y moderadas en relación al grupo control, y se encontró un $90 \%$ de aciertos. La concordancia entre aplicadores es de 0.80. Este coeficiente de confiabilidad entre examinadores indica que el uso de instrucciones estandarizadas garantiza que la calificación de la prueba es consistente.

\section{Test of Variables of Attention (TOVA)}

Nombre: Test of Variables of Attention

Autores: Robert Leark, Lawrence Greenberg, Carol Kindschi, Tammy

Dupuy y Steven Hughes, 2007.

Administración: Individual

Duración : 30 minutos

Aplicación: 6 a 80 años de edad

Significación: Prueba de rendimiento continuo visual y auditivo

Material : Computadora y un Microswitch estandarizado

Descripción:

El TOVA es una prueba de rendimiento continuo y contiene una forma visual y auditiva. Su objetivo es evaluar la atención y el control de los impulsos en cuatro áreas: variabilidad de tiempo de respuesta, tiempo de respuesta, control de impulsos (errores por comisión) e inatención (errores por omisión) en pacientes normales y clínicos. Esta prueba es computarizada y se requiere un software especializado y un microswitch estandarizado para llevarla a cabo. Para la evaluación visual se presenta dos figuras geométricas y una de ellas es la figura objetivo. Estas imágenes aparecen de manera aleatoria sin ninguna secuencia establecida y se busca que la persona presione el microswitch cada vez que observe la figura objetivo. Estas figuras aparecen durante 21.6 minutos y cada dos segundos se presenta una figura distinta, por lo tanto el evaluado debe estar mirando fijamente la pantalla para presionar el microswitch cada vez que aparezca el estímulo meta. Además la pruebase 
divide en dos mitades, la primera el estímulo meta no aparece con frecuencia y en la segunda mitad, el estímulo meta incrementa su aparición. Durante la ejecución se evalúan la variabilidad de tiempo de respuesta, los errores por comisión, omisión y tiempo de respuesta. Con estos resultados se obtiene la puntuación " $\mathrm{D}$ "” D prima, ésta se considera como una medida del decremento del rendimiento a lo largo del tiempo, reflejando la precisión ante el estímulo meta y la discriminación del estímulo no meta. Luego de obtener estos resultados, se arroja un puntaje TDAH, en el cual el resultado obtenido por el paciente se compara como una muestra identificada con TDAH. Este puntaje indica la similitud entre el desempeño del evaluado con el grupo de personas diagnosticadas con TDAH. Esta puntuación se obtiene de la sumatoria de la puntuación $\mathrm{Z}$ de la mitad I del tiempo de respuesta, la puntuación $\mathrm{Z}$ de la D’ de la mitad II y el puntaje $\mathrm{Z}$ del total de la variabilidad de tiempo de respuesta. Estos resultados previamente explicados son mostrados en el reporte automático que la prueba genera inmediatamente después de la aplicación.

La prueba fue normada en adultos y niños desde los 6 a los 80 años de edad, a su vez, las normas están diferenciadas según la edad y género. Para las normas en adultos, la muestra estuvo conformada por 250 personas de 20 años a más, los cuales eran estudiantes de tres universidades de Estados Unidos, así también como adultos pertenecientes a comunidades de dicho país. Para la verificación de la confiabilidad de las puntuaciones derivadas de la aplicación de la prueba, se utilizó el coeficiente de correlación de Pearson para todas las variables a través de las dos condiciones, estímulos infrecuentes (mitad I) y estímulos frecuentes (mitad II). Después de dicha exploración se concluye que las dos etapas de evaluación representan una medida consistente con cada condición. Se estimaron las evidencias de validez vinculadas a la relación con otras variables, específicamente discriminantes, mediante la sensibilidad pretende averiguar la capacidad del test para identificar los casos del TDAH, mientras que la especificidad, sería la habilidad para identificar correctamente personas sin la patología. Para ello, en 1992, se examinaron 73 sujetos diagnosticados con TDAH y se buscó la selección de pacientes sin comorbilidad y para ello se utilizó la historia clínica, entrevista, pruebas psicológicas y escalas aplicadas a los profesores 
de los sujetos. El diagnostico se realizó independientemente de los resultados de la prueba pues estas personas fueron referidas de la clínica de especializada en TDAH de la universidad de Minnesota. Los resultados obtenidos en el TOVA, fueron convertidos a puntuación Z, basados en una data normativa para la edad y género. Se utilizó el one-way MANOVA para comparar los puntajes $\mathrm{Z}$ de la muestra de TDAH con la muestra normativa. Para este enfoque la muestra aleatoria de la mitad de la muestra de personas con TDAH, fueron seleccionados y el análisis realizado dio dos puntos de corte diferentes para lograr tasas de "falsos positivos" de 10\% $(0.90$ especificidad) y $20 \%$ (especificidad). Los puntos de corte idénticos se aplicaron luego a la muestra y al cálculo de los índices de sensibilidad.

\subsection{Procedimiento de Recolección de Datos}

Adrián fue seleccionado por ser un paciente que fue evaluado con anterioridad en el centro laboral de la autora y cuyo diagnóstico era de interés para la realización de un estudio de caso único. A continuación se detallan los pasos que se siguieron para la recolección de datos:

1. Se explicó el estudio al psiquiatra de Adrián y dueño del centro solicitándole el permiso de contactar al paciente con el fin de plantearle la posibilidad colaborar con la investigación

2. El psiquiatra aceptó y realizó la solicitud mediante un contacto por vía telefónica con Adrián para preguntarle si aceptaría ser parte de una investigación. El paciente aceptó cordialmente y de manera voluntaria.

3. La evaluadora llamó al paciente para presentarse y explicarle en qué consistía la investigación, él nuevamente aceptó. Seguidamente se coordinó el número de sesiones necesarias, las fechas y los horarios.

4. Las primeras tres sesiones fueron destinadas a la recopilación de información con respecto a su historia. Tales citas se realizaron en el centro del psiquiatra a cargo de Adrián .

5. Las siguientes 5 sesiones, realizadas nuevamente en el centro psiquiátrico, estuvieron enfocadas en la ejecución de las pruebas psicométricas. La primera fecha fue el 10 de junio, en la cual se le aplicó la Evaluación 
Neuropsicológica Breve en Español (NEUROPSI) y el Test De Rendimiento Continuo Visual (T.O.V.A).

6. El 17 de junio se le aplicó la Batería Neuropsicológica de Funciones Ejecutivas y Lóbulos Frontales (BANFE-2) en las instalaciones de la Universidad de Lima.

7. Las siguientes dos sesiones, realizadas 23 y 25 de junio en el centro psiquiátrico, se aplicó la Escala de Inteligencia de Wechsler para adultos - (WAIS- IV), también en el Instituto de Neurociencias Aplicadas.

8. Finalmente la Escala de Memoria del Wechsler (WMS- IV) se ejecutó también en el centro el 8 de Julio del 2015. 


\section{CAPÍTULO V: RESULTADOS}

\subsection{Anamnesis}

\section{Datos de filiación}

1. Nombres y Apellido

: A.A.I

2. Sexo

: Masculino

3. Edad

: 49 años

4. Lugar y fecha de nacimiento

: Buenos Aires, 2 de noviembre de 1965

5. Tiempo de residencia en Lima

: Desde las dos semanas de nacido

6. Estado civil

: Casado

7. Grado de instrucción

: Superior incompleta (Administración, primer ciclo)

8. Ocupación actual

: Rentista (vive de rentas)

9. Religión

: Judía (no practicante), esposa e hijos católicos

10. Idiomas

: Inglés/ Hebreo/ Castellano

11. Con quién(es) vive

: Esposa e hijos

12. Número de hijos

: 3 hijos

13. Número de hermanos

: No conoce

14. Dirección

: Surco

15. Informantes

: Paciente mismo

16. Fechas de las entrevistas

: 29/04/2015, 13/05/2015, 22/05/2015, 10/06/2015, 17/06/2015, 23/06/2015, 25/06/2015 у 8/07/2015.

17. Evaluador

: Karen Marquez Benza 


\section{Problema actual}

\section{Motivo de consulta}

El paciente asiste a consulta porque refiere experimentar cansancio y abatimiento para iniciar proyectos laborales, ya que no mantiene un trabajo hace 7 años. Al recordar que no labora o al tener tiempo libre en casa, se le presentan las ideas tales como: "soy un bueno para nada", "no tengo fuerzas para volver a comenzar y para creer en mí", "soy un fracaso", "no acabo con lo que empiezo", "no sé qué hacer con mi tiempo libre", "mis hijos no tienen el mejor ejemplo", "ya trabajé de todo hace algunos años, ya no estoy para eso", "no sé qué pasará de acá a unos años", "necesitaría de alguien para comenzar, pero no se quien querrá invertir", "la situación del país cada vez está peor, no sé si será bueno invertir", "no tengo idea por donde comenzar". En esos momentos siente tristeza, frustración y falta de motivación y recurre a fumar un cigarrillo o ver televisión. Esto ocurre aproximadamente dos veces por semana con una intensidad de 7/10, alrededor de hace 6 años. Ante esta situación, incrementa su tristeza y su sentimiento de inutilidad. Cabe resaltar que desde que toma la medicación para el tratamiento de la bipolaridad (Litio, bupropion, benzodiacepinas), estas situaciones aún se siguen repitiendo; sin embargo, presenta mayor energía para realizar actividades del hogar, pero al realizarlas y no obtener los resultados que quisiera, experimenta dificultades para manejar su molestia.

Además el paciente comenta dificultad para expresar ira y rabia, cada vez que sus hijos no lo obedecen, cuando juega con su hijo menor y él pierde, al manejar su vehículo y se interponen en su camino o le tocan la bocina, cuando realiza actividades en su casa como cocinar, pintar, arreglar gasfitería y no obtiene los resultados que él quisiera. En esos momentos experimenta cólera intensa, afirmando: "es como si la sangre me hirviera", "como si viniera un maretazo, pero viene con todo", estas emociones se acompañan de tensión muscular, sudoración e ideas como "mis hijos no hacen las cosas como deberían, no se dejan ayudar" "en Lima manejan puros idiotas", cuando arregla elementos de la casa piensa "soy un idiota, un estúpido”. En esas situaciones, grita a sus hijos, los critica, si está jugando 
con alguno de ellos deja de jugar, al conducir, baja del carro a enfrentarse con el otro conductor y en algunas ocasiones ha llegado a los golpes. En la casa al realizar las actividades las tira al suelo o las arroja a la basura. Luego de ello, fuma un cigarro y como consecuencia indica: "me malogra todo el día", y reconoce que su impulsividad e irritabilidad genera conflicto y distanciamiento en la relación con sus tres hijos y esposa, ya que al dirigirse a los demás lo hace de una forma muy directa llegando a herirlos verbalmente, lo cual le genera conflictos en casa . Estas situaciones están presentes desde que el paciente recuerda, pero hace aproximadamente 5 años indica que tales conductas se han vuelto más recurrentes con una intensidad de 7/10. Por otro lado, indica que su esposa e hijos dicen verlo "mejor", después del tratamiento, pues antes pasaba la mayor parte del tiempo en cama y evitaba conversar con las personas mientras que en la actualidad se muestra dispuesto "a todo", afirmando: "tengo más ganas de conversar, hacer cosas, pero no sé qué, algunas veces hago los quehaceres de la casa". En el área social, Adrián refiere que tiene mayores deseos de salir, por ejemplo, todos los miércoles se junta con un grupo de personas aficionados a las motos y con ellos organizan viajes dentro del país.

Además, indica que desde hace aproximadamente 2 años, tiene dificultades en la relación de pareja afirmando "somos buenos padres, pero no esposos". Adrián comenta que no comparten actividades que involucren a ambos, la comunicación que existe entre ellos solo se reduce a temas con respecto a sus hijos, por tales razones, el paciente ya le comunicó a su esposa su insatisfacción. Si bien manifiesta esta dificultad, añade, que la relación es muy lineal, no pelean, "yo si quisiera esos altos y bajos, peleas para reconciliarme, es bonito pelear", "Nunca nos peleamos, sí hay discusiones por desacuerdos pero muy rápido lo arreglamos”. No obstante, no mantienen relaciones sexuales con frecuencia, el periodo más largo sin mantener una relación sexual fue de cuatro meses, "no hay momento para nosotros y en la casa no podemos tener sexo porque están los chicos”. Él considera que sólo son pretextos por parte de su esposa, lo cual le genera una cólera de 7/10. En esas situaciones, en las que la esposa no desea tener relaciones sexuales, el paciente se ofusca y tiene pensamientos como: "me voy a ir de la casa", "ya 
no aguanto esta situación", "me quiero divorciar", y lo que hace seguidamente es salir a la calle a tomar una cerveza.

\section{Desarrollo cronológico}

Con respecto al trastorno bipolar, el paciente indica que a los 19 años en kibutz (En Israel, colonias agrícolas de producción y consumo comunitarias) por 2 semanas aproximadamente durmió 3 horas y trabajaba haciendo "de todo". El paciente afirma que decidió irse de Perú para vivir solo y "hacerse hombre", comenta que durante esa etapa sintió un ánimo elevado el cual se caracterizó por sentir más energía de la usual sin necesidad de dormir, su horario de trabajo era el siguiente: trabajaba como guardián de 7 pm a 7 am, luego tenia clases de 8 a 1pm, dormía 3 horas y luego se reincorporaba a su trabajo de guardián nuevamente. Además, recuerda que sus pensamientos parecían ser "más rápidos" que lo convencional, pero aun así era productivo en su trabajo. El paciente recalca que aún no había comenzado el consumo de marihuana.

Ya a los 23 años, en Lima tuvo un "decaimiento" de ánimo que tuvo aproximadamente 2 semanas de duración. Resulta que fue a un evento social en el cual se encontró con una chica con la que habían salido previamente, Adrián al verla en dicho evento se sorprendió y le pidió conversar. Ella se rehusó, tras lo cual él la tomó del brazo y ella empezó a gritar diciendo que le dolía y que le estaba haciendo daño. El paciente le dijo que sólo quería conversar con ella a lo que respondió gritando, diciendo que no quería conversar. Adrián decidió entonces irse, "salí friqueado" pues nunca había estado involucrado en un "show" semejante; caminó hasta su casa y recuerda con poca claridad pedirle a su madre entre llantos que por favor trajera la chica a la casa pues quería conversar con ella. Las dos semanas siguientes después del incidente Adrián comenta haber sentido gran tristeza y abatimiento, en el cual su apetito disminuyó y sus ganas de realizar sus actividades disminuyeron notablemente, comenta que las ganas de conducir 
(su afición) se vio reducida. Afirma que dicho evento tuvo gran repercusión sobre su estado anímico.

Posteriormente, durante sus primeros años de casado, a los 35 años, el paciente reconoce una energía inusual la cual le permitió ser más productivo, pues podía permanecer despierto hasta las 2 am para escribir todo lo que tenía que realizar al día siguiente y luego se levantaba a las 5 de la mañana para ir al gimnasio y al trabajo. También reconoce que sus ideas “iban más rápido" sintiéndose más activo. Mantuvo este ritmo por dos semanas aproximadamente. Durante ese periodo, también reporta haber tenido un apetito voraz y haber estado involucrado en varios proyectos simultáneos, como su empresa constructora y una óptica. El paciente comenta que su esposa también se percató de la diferencia en el estado anímico; mas no denotó preocupación puesto que el paciente era altamente productivo en el área laboral.

En el 2003 quebró la empresa consultora que había iniciado con dos socios, hace aproximadamente 5 años atrás. Uno de los socios decidió desvincularse tras lo cual instauraron la política de que cada persona que consiga un proyecto, se quedaría con el $10 \%$ de las ganancias que el mismo trajera. En uno de los proyectos, "el único que iba a la obra era yo desde las 6:00 de la mañana hasta las 10:00 de la noche. La obra acabó con una ganancia deficitaria por lo que decidió abandonar la empresa. Manifiesta que esta decisión tuvo un impacto significativo sobre él "fue como un hijo que desaparece o que tiene una enfermedad incurable". Luego de abandonar la empresa, comenzó una búsqueda de empleo fuera del país. Tras tener varios trabajos de corta duración en el extranjero, la relación con sus hijos fue haciéndose progresivamente más distante, especialmente con el menor de ellos, que nació en el 2002. "Prácticamente mi hijo menor no me conocía". Por un periodo de 3 meses trabajó en Panamá y Argentina. En este último país, consiguió un trabajo, colegio y casa para su familia. Sin embargo, pasados tres meses le informaron que ya no podían seguir empleándolo y pasó a sustentarse mediante el ingreso económico de las rentas. A partir de ese momento empezó a pasar más tiempo en casa arreglándola "si se quemaba el foco, lo cambiaba, arreglaba el jardín, era un multiusos". Pasado un tiempo su esposa quiso volver a Lima en donde tenía trabajo. Él por su parte, no logró 
conseguir trabajo "En Perú cuando eres mayor no encuentras trabajo, yo no busco un sueldo alto ni tremendo puesto, solo me interesa estar ocupado".

Cuando finalmente se quedó sin trabajo, el paciente empezó a pasar cada vez más tiempo dentro de casa, se sentía más cómodo dentro de ella. Refiere que debido a que sus hijos tenían amigos con padres que trabajaban, él pensaba: "seguro a mis hijos sí les ha afectado verme echado en la cama sin hacer nada", lo cual le causa un malestar significativo. Recuerda que en esa época prefería quedarse en casa viendo televisión y como su esposa prefiere actividades en solitario, dejó de frecuentar a sus amistades. No sentía ganas de ver a sus amigos y se volvió más selectivo con los que frecuentaba; no obstante, atribuye esto a su familia: "a raíz de la familia cambié, yo era parrandero. Ahora todo lo que decida la familia”.

Así, su ánimo decayó al punto que quería "no estar presente". Tenía pensamientos como "más valgo muerto que vivo", pensaba que sería mejor que sus hijos tengan un recuerdo de un padre trabajador, que el de él echado como "una momia" en la cama. Además indicó dificultades para conciliar el sueño de manera significativa. Este fue el motivo de consulta que lo llevó a visitar al médico psiquiatra por primera vez a los 48 años. En conversaciones con su esposa, le manifestaba el deseo de irse de la casa "no quiero estar más acá, arréglate tú, ya veo que hago"; ella, en respuesta, lloraba, hasta que en una oportunidad le sugirió acudir al médico. En esta época, el paciente afirma que en ocasiones era "contradictorio" pues además de los pensamientos anteriormente expuestos, refiere que a pesar de no querer existir, "me daba cuenta que "todavía hay, todavía existo" "sería un cobarde si no soporto la carga". Igualmente, el paciente comenta el abandono de las drogas para esa época.

En la actualidad manifiesta sentir más ganas que antes para realizar las actividades hogareñas, asimismo, su esposa le comenta que ve en él un cambio notable puesto que hace algunos años en una etapa, el paciente tendía a permanecer en silencio echado en la cama, sin tener ganas de realizar ninguna actividad. Ahora su familia le dicen que esta "más hablador", que “critica todo como antes"; de igual manera el reconoce sentirse con más ganas de hacer cosas; no obstante, cuando algo no se da en la manera que él quisiera, no controla su molestia y reconoce que puede ocasionar daños con su trato. 
En lo referido a su atención, el paciente relata que sus dificultades atencionales afectaron marcadamente en su niñez; desde el colegio tendía a distraerse con mucha facilidad en las clases, extendiéndose hasta secundaria provocando dos veces la repetición de tercer año y el cambio de colegio en el cual abandonó del quinto año de secundaria antes de finalizar el periodo escolar. Durante toda la etapa escolar, el paciente reporta haber sido "muy movido" en colegio como en casa; así refiere que al llegar a su casa después del colegio saltaba de techo en techo de las casas jugando con amigos: "nunca estaba en mi casa, mientras mi mamá trabajaba yo jugaba en la calle”.

Al ingresar a la universidad también reporta dificultades para prestar atención así como dificultades en la relación con los profesores; estos factores provocaron el abandono del primer ciclo universitario. En la actualidad también presenta dificultades para mantener su atención en actividades que no son de su agrado, por ejemplo las reuniones escolares de sus hijos el paciente se rehúsa a asistir por el aburrimiento que experimenta en ese contexto; de igual manera indica que al conversar con gente se distrae rápidamente y puede perder la ilación de la conversación al no ser de su interés "cuando me pierdo y no sé de qué estaban hablando me voy al baño o cambio de tema". Estas características, refiere, han estado presentes durante toda su vida y con el paso de los años se han ido acentuando.

$\mathrm{Su}$ conducta impulsiva tuvo repercusiones graves, a los 18 años, mientras realizaba piques ilegales, sufrió un accidente automovilístico. Estando con sus amigos en su auto, un carro se posicionó atrás de ellos estando con las luces delanteras altas. El paciente cuenta que "como siempre alguien que friega y a mí se me fue la mano y le saqué el dedo”. Por tal razón, se inició un correteo entre ambos autos; al llegar a una esquina, el paciente aceleró y chocó contra otro auto y las consecuencias que sufrió él de este accidente fueron 8 puntos en una oreja, mientras que su acompañante estuvo un mes internado en la clínica.

Estas conductas impulsivas se han visto reflejadas a lo largo de su historia, así el paciente refiere haber estado involucrado en más de 30 accidentes automovilísticos, causados en ocasiones por él y en otras por alguien más. Afirma: "me gusta correr y la velocidad, me gusta estar al filo. Siempre, desde chico". Cuando era niño experimentaba la velocidad en su 
bicicleta y al crecer, pasó a buscarla en su auto. Además, ha sufrido varios accidentes en diferentes partes del cuerpo, como tobillos, rodillas, muñecas y dedos. La mayoría de estos accidentes han sido consecuencia de la práctica deportiva.

El paciente afirma que desde pequeño ha sido impulsivo y poco tolerante, características que reconoce que aún se encuentran presentes y le generan dificultades en su hogar. Por ejemplo, cuando juega videojuegos con su hijo menor, y ve que este está ganando, el paciente reporta sentir enojo y cólera, exclamando: “¡hasta acá nomás llego, este juego es una porquería! Y tira los controles. El niño en respuesta, erra adrede en el juego para que su padre gane. Sin embargo, éste luego se siente aburrido y decide retirarse. Pasadas unas horas, trata de volver a iniciar una actividad con su hijo, pues reconoce no haberse portado con él adecuadamente.

\section{Historia personal}

\section{Desarrollo inicial}

No se tiene información acerca del parto pues el paciente fue adoptado. No obstante, se sabe que su lugar de nacimiento fue Argentina. En aquella época, las personas que no podían concebir hijos, pertenecientes a la colonia Judía en Perú, viajaban a Argentina debido a que había varias personas jóvenes que no tenían los medios económicos para mantener a sus hijos. Cabe resaltar que Adrián se enteró de su adopción a los 37 años de edad; anteriormente, tenía sospechas respecto al tema y preguntó a su madre si éstas eran ciertas. La respuesta que obtuvo fue que "estaba loco y que yo era hijo de su vientre". No tiene información acerca de sus familiares en Argentina, sólo el nombre de la partera que asistió su nacimiento.

Cuando el paciente cumplió 5 años de edad, su padre adoptivo fue expulsado de su casa. Esta decisión se desencadenó como resultado de que en una oportunidad, Adrián estaba jugando bajo la lluvia a las 8 de la noche. Cuando su madre llegó del trabajo y lo vio con toda la ropa empapada a tal hora de la noche, tomó las maletas de la empleada doméstica y la despidió. 
En medio de su enojo, llamó a su esposo, el cual respondió que se encontraba en camino; sin embargo, llegó a la 1 de la madrugada. Ante esto, su madre exclamó "esto no funciona así”, empacó las cosas del padre adoptivo del paciente y nunca más fue visto. Su abuela falleció ese mismo año en el que sus padres se separaron, por lo que Adrián creció con su abuelo y su madre.

En su niñez, el paciente comenta haber sido hiperactivo. No hacía tareas escolares y cuando estaba en su casa, solía salir por su ventana para ir a jugar fútbol. Subía al techo de su casa a los 9 años, a los 12 empezó a fumar tabaco y a los 15 empezó a trabajar y a manejar automóviles: a los 13 años ya daba una vuelta a la manzana e espaldas de su madre. Además, hacía “todos" los deportes. Recuerda haberse sentido feliz en esos años.

Con respecto a sus orígenes biológicos, en su adultez viajó a Buenos Aires y fue a la Plaza de Mayo donde están las madres religiosas para averiguar más sobre su pasado. Éstas le informaron que desde el año 1970 no atienden partos y dado que su fecha de nacimiento es 1965, el récord no se encuentra disponible. Posteriormente, decidió publicar su historia en el internet tras lo cual una mujer, también judía y adoptada, se comunicó con él pues ella había tenido la misma partera. Acordaron encontrarse en un centro comercial; al conversar, ella le aconsejó que "no haga mucho lío" pues la partera seguramente tenía una edad avanzada o fallecida. El paciente afirma que no tiene gran interés en ella pero que le gustaría saber de su historia "de dónde vengo".

Fue a los 15 años que inicialmente sintió la necesidad de aclarar su identidad, la cual se fue mitigando hasta la segunda década de su vida, en la que volvió a urgirle el tener dicho conocimiento. Sin embargo, su madre se negaba a darle información. En una ocasión, relata, su padre le dijo: “Tú no eres adoptado, eres recogido y costaste 15 mil dólares". Después de esto, fue a los 37 años, cuando ya tenía a sus hijos, que enfrentó a su madre aunque él afirma que "dentro de mí sí sabía". Cuando finalmente su madre admitió haberlo adoptado, él sintió mucho resentimiento pues el que se le haya ocultado información de dicha índole le causó mucho dolor. Su madre había mantenido esta información secreta siguiendo las instrucciones de un psicólogo. El paciente está inscrito en una página de internet dirigida a personas en busca de otras y comenta que si algún día sus padres o algún 
familiar lo contactan "el día que tenga que ser llegará y si no se da, no importa, porque yo tengo mi propia familia". A la vez, siente que sería "un capítulo en blanco" en su vida. Sus hijos están enterados de la historia y opinan que por lo menos "tuviste a tu madre".

\section{Educación}

\section{a. Historia escolar}

Asistió al colegio particular judío hasta tercer grado de secundaria y afirma que su recorrido escolar fue "normal", pues no tenía notas altas, pero siempre aprobaba los cursos. En cuanto a la conducta, empieza afirmando que no era revoltoso, situándose en medio de "dos bandos: los intelectuales y los vándalos". Recuerda haber tenido muchos dolores de cabeza para los que le hicieron electroencefalogramas. En cuanto a la atención, reporta haber experimentado desinterés para algunos cursos; asimismo, refiere haber sido un niño muy activo, siempre se encontraba realizando alguna actividad y gustaba mucho de los deportes.

En secundaria fue cuando empezaron sus dificultades. Tenía peleas con sus amigos, pero eran "absurdas", originadas por "celos, envidia o chicas". Fue en esa época en la que desaprobó el curso de Biología. Afirma haber "sentido" que su profesora lo desaprobó adrede debido a que ésta pensaba que él era "muy vago" y que "podía dar mucho más". Así, tuvo que ir al vacacional para dar un examen. El día anterior al mismo, estudió 4 horas con su madre y obtuvo un 18; su profesora, en respuesta, le preguntó por qué no podía obtener esos resultados así en clase. Adrián respondió diciendo “¿Cómo mi mamá me pudo meter todo un curso en 4 horas?, eso significa que también depende de quién enseñe”. Fue ahí cuando comenzó su “calvario". En tercero de secundaria desaprobó 4 cursos, de los que aprobó 3 en el vacacional. Dentro de esos 3, se encontraba el curso de hebreo, en el que obtuvo un 14 en el examen. A pesar de ello, el director del colegio se negaba a colocar dicha nota en la libreta de estudios alegando que no reflejaba su desempeño en el curso. El paciente refiere haber pensado que eso era 
injusto y que además el hebreo era un idioma secundario, fuera de la malla curricular de estudios del Perú. Aun así, su madre accedió a que repitiera el año. Ante esto, Adrián se molestó, tenía pensamiento como "si ella no me apoya, ¿quién lo hará?”. En protesta, el paciente refiere no haber estudiado pues "no me parecía justo lo que estaban haciendo conmigo". Como resultado, desaprobó tercero de secundaria por segunda vez. Por otro lado, sus amigos dejaron de jugar con él en el recreo pues ya no pertenecían a la misma promoción; además, varios compañeros fueron expulsados del colegio y no pudieron asistir ni a la fiesta ni al viaje de promoción. Al terminar el año, pidió a su madre un cambio de colegio para poder cursar el cuarto de secundaria; así, la administración del colegio accedió a asignarle una nota aprobatoria con la condición que cambiara de colegio. Relata que en términos generales, no hacía sus tareas; al llegar a casa, almorzaba con su mamá y abuelo después de lo cual se quedaba solo en las tardes. En este tiempo del día, se dedicaba a saltar de techo en techo, agarraba su carabina y le disparaba a la gente, montaba bicicleta, iba a la casa de sus amigos, a la costa verde, etc. Nunca se quedaba dentro de casa.

En cuarto de secundaria, entró a otro colegio particular el cual se refiere como "un dolor de cabeza" debido al contraste con su colegio anterior. "Es como irse de Lima a un colegio metido en el cerro, nada que ver". Refiere que había diferentes clases sociales, como "un arca de Noé” y que el nivel de exigencia era muy bajo; así, lo aprendido en su colegio previo le sirvió para cuarto y quinto de secundaria. A mediados del último año escolar, el paciente relata que sus amigos tenían planes de viajar al extranjero para estudiar y trabajar, lo que le dio la idea de entrar a una academia pre universitaria. Logró recibir su libreta de calificaciones en el mes de julio a cambio de dinero. Así, al salir del colegio a mediados de año, entró a una academia preuniversitaria. Su madre no protestó pues ya tenía todos los documentos con sus notas.

\section{b. Otros estudios realizados}

Tras haber asistido a la academia pre-universitaria, el paciente se presentó al examen de ingreso a la Universidad de Lima. Relata que "De lechero ingreso" pues debía pasar con un puntaje de 195 y él obtuvo 190; sin 
embargo, varios ingresantes optaron por no inscribirse a dicha universidad, por lo que logró llegar al punto de corte. Había acordado con su madre que si lograba ingresar a la universidad, ella le daría un carro. Después de una semana de haberlo recibido, Adrián tuvo un accidente automovilístico. Para este entonces, él tenía ya 18 años. Este accidente ocasionó que no pudiera asistir para los exámenes parciales del primer ciclo de universidad.

De todas maneras, Adrián se presentó para sus exámenes finales. Afirma que esa etapa la recuerda con dificultad "me queda un poco borrosa" pues “no sé cómo pasé a segundo ciclo, pero sí jalé algunos cursos”. No llegó a terminar el segundo ciclo de la carrera pues tuvo un conflicto con el profesor de psicología debido a que éste anunció que un tema en particular no iba a ser incluido para el examen, pero si lo fue. Adrián se enfureció “¡Pucha, no hay peor cosa que me mientan!”. Habló con su profesor y le dijo: “¡Tú estás loco! Yo voy a hacer que te boten". Así, reunió una carta con 20 firmas para dicho propósito, a lo que cuenta que el profesor respondió “A los 19 los voy a aprobar, pero a ti no. ¡Qué mierda!”. Decidió conversar con el decano, le explicó todo y la respuesta del mismo fue "preferimos botar a un alumno que botar a un profesor". Adrián respondió diciendo que él no es una persona a la que le gustara estudiar ni estar en un salón de clase, que él es "manual". Luego de esta conversación, estuvo pensando que su madre pagaba una carrera que a él no le gustaba; además, había cursos como cosmología y cultura política que le causaban gran desagrado.

Después de este incidente, empezó a averiguar en la embajada de Israel cómo podía ir a dicho país. A los 19 años logró reunir sus papeles y partió. En Kibutz, Jerusalén, postuló a la universidad, obteniendo un puntaje de 90 en el examen de ingreso. No obstante, no logró ingresar pues el puntaje mínimo necesario era 92. Estuvo ahí por 3 meses.

Antes de volver a Lima, viajó a Los Ángeles para seguir unos cursos de óptica en un instituto de oftalmología. Sin embargo, no quiso quedarse pues no le gustó la ciudad además de parecerle muy costosa. Una vez en Lima asistió de invitado a unos cursos de marketing que duraron dos días. Para tal época, ya tenía 21 años.

\section{Ocupación}


A los 15 años trabajó para un DJ armando el equipo y consiguiendo contactos. A los 19 años trabajó en Kibutz de gasfitero, vigilante, pelando naranjas, trabajó también alimentando gallinas, cocodrilos, en limpieza y de lavaplatos. Por dos semanas dormía 3 horas al día, hasta que su madre y su primo lo fueron a visitar y le ofrecieron un viaje a Europa. Adrián se rehusó, pero su madre le propuso viajar por dicho continente, luego volver a Lima y si para ese entonces él quería volver a Israel, prometió pagarle el pasaje. No obstante, permaneció en Lima.

Al volver a Lima, trabajó de administrador en una Óptica en el Centro de Lima, negocio de la madre. Luego pasó al local de Chacarilla en donde agregó la venta de relojes, cámaras fotográficas, maletines, billeteras y bicicletas, así como el servicio de revelado. Posteriormente instauró su propio negocio.

Entre los años 1998 y 2003 fundó una empresa constructora con dos socios más. Paralelamente, entre los años 2001 y 2003 abrió una cafetería con 4 de sus amigos junto con sus esposas, la cual fracasó por conflictos internos.

En el 2003 quebró la empresa consultora que había iniciado con dos socios, hace aproximadamente 5 años. Uno de los socios decidió desvincularse tras lo cual instauraron la política de que cada persona que consiga un proyecto, se quedaría con el $10 \%$ de las ganancias que el mismo trajera. En uno de los proyectos, "el único que iba a la obra era yo desde las 6:00 de la mañana hasta las 10:00 de la noche. La obra acabó con una ganancia deficitaria por lo que decidió abandonar la empresa. Manifiesta que esta decisión tuvo un impacto significativo sobre él "como un hijo que desaparece o que tiene una enfermedad incurable".

Luego de abandonar la empresa, comenzó una búsqueda de empleo fuera del país. En el año 2005 viajó a Estados Unidos, fue ayudante de mozo, recepcionista y mozo por 3 meses. Asimismo, por un periodo de también 3 meses trabajó en Panamá como encargado de un almacén y posteriormente, en el 2007, trabajó como archivador en una empresa de etiquetados en el depósito de documentos en Argentina. Viajó a dicho país tras el fallecimiento de su madre y de su suegra. Ambas fallecieron de cáncer con 3 meses de diferencia; afirma que fueron "dos años densos" (2005-2006). Decidieron así 
viajar a Argentina pues se sentían hastiados de pasar tiempo en clínicas. Ahí vieron "todo lindo, los árboles y el sol, todo brillaba" por lo que decidieron mudarse.

Consiguió un trabajo, colegio y casa para su familia. Sin embargo, pasados cuatro meses le informaron que ya no podían seguir empleándolo y pasó a sustentarse mediante el ingreso económico de rentas de propiedades. A partir de ese momento empezó a pasar más tiempo en casa arreglándola "si se quemaba el foco, lo cambiaba, arreglaba el jardín, era un multiusos". Pasado un tiempo su esposa quiso volver a Lima en donde tenía trabajo. Él por su parte, no logró conseguir trabajo: "En Perú cuando eres mayor no encuentras trabajo, yo no busco un sueldo alto ni tremendo puesto, solo me interesa estar ocupado".

Actualmente se dedica al diseño de muebles de manera ocasional. Lo considera como un hobbie pues ha realizado esto en una sola ocasión para una amiga. Manifiesta que "me gusta ver una idea hecha realidad". Comenta que siempre ha sido muy bueno en dibujo.

Su principal ingreso actual proviene de sus rentas.

\section{Relaciones interpersonales}

\section{a. Amistades}

El paciente refiere que durante su adolescencia y juventud tenía "varios amigos por todos lados", tenía bastantes grupos y uno de ellos era el de "los bacanes" con los que causaba "revuelo".

Recuerda dentro de sus anécdotas relacionadas a las relaciones interpersonales en Israel, vivía con un argentino que "no aguantaba mucho" pues un día lo hizo enojar. En ese incidente, le dijo "concha de tu madre" ocasionando que su compañero se asuste y se vaya del cuarto que compartían.

Actualmente no se reúne con sus amistades con la frecuencia de antes, pero si mantiene relación con un grupo de "moteros", una vez a la semana, se juntan en un restaurante para conversar y organizar viajes dentro del país. Refiere también que varios de sus amigos también se encuentran medicados como él: "varios de mis amigos los moteros también toman litio". 


\section{b. Relaciones con el sexo opuesto}

El paciente refiere haber tenido un gran número de relaciones sentimentales. A los 19 años manifiesta haber pasado por "una crisis emocional" por mantener una relación con una chica que no era Judía, sino Católica, de nombre Ingrid, ante lo cual su madre se mostraba en desacuerdo. Paralelamente, Adrián había desaprobado cursos en la universidad y su madre le había retirado el carro y la propina. Así, él pasaba la mayor parte del día en la casa de su enamorada, consumía sus alimentos ahí y no se retiraba antes de las doce y media de la noche. Refiere haberla pasado "bien" en aquella época. Cuenta que no necesitaba dinero para tener un buen rato con su novia pues iban al parque o eventualmente tomaban un helado. Fue su primera relación. Poco después partió a Israel.

El paciente refiere que durante su juventud, entre los 21 y 27 años, no mantuvo una relación de pareja estable y duradera, el máximo tiempo de relación con una mujer fue de 2 meses. Afirma también, que en estos años conoció "chicas de todo tipo, buenas, locas, malísimas, etc."

Antes de conocer a su esposa, Adrián se encontraba en el estado de Miami; cuando su abuelo falleció, Ingrid fue a visitarlo. "La pasamos genial, muy bacán”. La relación, sin embargo, volvió a terminar pues él se regresaba a Lima y ella a España; ni uno de los dos quería mudarse al otro país. Posteriormente se encontraron dos veces más cuando ella visitaba a su madre; además, hace dos o tres años atrás lo llamó y se encontraron. Esto sucedió mientras el paciente estaba casado con otra mujer. Su esposa no sabe de esto ya que "no entendería, pensaría que no la quiero, que no está bien”. Comenta: "pudo haber sido una relación muy bacán, la comunicación era mental, ambos sabíamos lo que pensábamos".

Posteriormente, estando en la playa, avistó a una mujer con la que luego se casaría. Relata que iba con frecuencia a la playa "señoritas", en donde vio a Maritza (su esposa). Al verla, le preguntó a una señora que trabajaba ahí si conocía a "la pelirroja", a lo que respondió afirmativamente. Adrián le dijo que tenía interés en conocerla y la señora le indicó que regresaría el miércoles, pero Maritza no fue aquel día, ni al día siguiente. 
Entonces, él dejó una nota dirigida a Maritza con la señora que lo había ayudado. Aquella es la época en la que el paciente tenía una tienda en Chacarilla, a la que un día coincidentemente Maritza entró. En ese momento, Adrián le indicó a la trabajadora que le diera una factura o una boleta en el que apareciera su nombre, teléfono y dirección, pero "la cojuda se olvidó". Entonces, relata, salió de la tienda para ver a donde se iba; la siguió hasta su auto y pensó: "si voltea y sonríe es porque le gusto". Así, pasó caminando a su costado, ella se volteó, rio y se fue. Un tiempo después, él estaba en su carro con una de sus trabajadoras hablando de Maritza a lo que ella decía "si tiene que ser, será". En ese momento, Adrián volteó y vio a Maritza pasar. Manifiesta que no recuerda con claridad, pero que logró conseguir su número de teléfono en la playa y al llegar a su casa después de verla caminando por la calle, empezó a buscarla en las páginas amarillas. Así, la llamó por teléfono y salieron en un par de oportunidades. Sin embargo, a la semana siguiente él debía asistir a una reunión de judíos solteros fuera del país. Posteriormente la llamó por año nuevo, pero ella no estaba en Lima. Había viajado a Trujillo y "no me había contado nada, me tenía sacando chispas". El paciente llegó el 10 de enero a Lima, se encontró con Maritza y ese mismo día iniciaron su relación de enamorados. A los dos días de conocerla le dije para estar y comenzamos a salir. En julio de ese año viajaron a Chile por temas de trabajo, pero al llegar a Lima, tomó la decisión de terminar la relación en respuesta a la presión de su madre. Al poco tiempo, inició una relación con una mujer judía con la que "no pasó ni michi y con las justas le toqué la mano".

Pasado un tiempo, con sus amigos "juergueros", volvió a encontrarse con Maritza y "no podía creerlo" y decidió retomar la relación. Le pidió disculpas y regresaron con la "condición" de que si en 6 meses todo marchaba correctamente, se casarían. Efectivamente, se casaron, pasado dicho tiempo.

\section{Historia psicosexual}

\section{a. Información sobre el sexo}


Recibió información acerca del sexo por parte de sus amistades, su madre no se lo mencionaba. Relata que los padres de sus amigos "nos querían estrenar", además, era un orgullo en el colegio decir "me quemé el fin de semana", lo cual indicaba que se había tenido relaciones sexuales con una prostituta. En esa época compraba revistas de pornografía, así como posters de mujeres desnudas detrás del ropero.

\section{a. Historia sexual}

A los 9 años tuvo interés por una niña, veían chistes en toboganes y se visitaban en sus respectivas casas, pero "no hubo ni un beso".

Comenzó a masturbarse a los 12 años. A los 13 años, con cuatro amigos más, fueron a la casa de uno de ellos donde su empleada doméstica, una "vieja, gorda, fea, horrible" les daba sexo oral. No obstante, el paciente refiere haberse negado a recibirlo pues "yo era un poco exquisito" salvo por una oportunidad en la que, junto con sus amigos, contrataron a una prostituta. Relata que recuerda a esa experiencia como "bacán” pero no la llegó a repetir; en esa época tenía la idea de tener relaciones sexuales "con una persona igual a mí, de mi misma edad, que me guste".

Después de esa experiencia, no tuvo otra hasta los 18 años. A esa edad, después de mucho tiempo de salir con una muchacha, tuvo sexo con ella y "fue espectacular". Ella fue su primera enamorada y su relación duró dos años; sin embargo, reporta haber sido infiel. Su enamorada de ese entonces se fue de viaje por un mes a Estados Unidos, mientras que la mejor amiga de su novia lo llamó y le pidió que lo acompañara a comprar; él accedió. Al encontrarse, se dieron un beso. Después de esto, Adrián refiere haberse sentido "mal" pero después pensó: "tengo 18 años, no pasa nada". Después de aquello, empezaron a ir al cine o a comer de manera frecuente, mientras su novia estaba de viaje. Un día, el paciente fue a recoger a esta muchacha (amiga de su novia) del colegio, que era el mismo al que su enamorada asistía. En ese momento, se encontró con Ingrid (su novia) que le preguntó qué hacía ahí, a lo que él respondió con “la cagué”. Terminaron la relación pues afirma haberse sentido más atraído por la amiga de Ingrid en ese momento. 
No obstante, en una oportunidad se encontró con ella (Ingrid) en un parque y le dijo que necesitaba 10 minutos de su tiempo y que no pedía ser perdonado. Así, se amistaron y empezaron a salir nuevamente. Esta relación terminó con el viaje que el paciente hizo a Israel a los 19 años. Al regreso, Ingrid se mudó a España.

Entre los 21 y 27 años, el paciente comenta haber frecuentado a varias mujeres por periodos de tiempo de aproximadamente 2 meses y que a su vez mantenía relaciones sexuales con ellas afirmando: "por mi carro han pasado pelos de todos los colores". No hubo una relación formal en ese periodo, relata que "habían experiencias de todo tipo, buenas, locas, malísimas". A los 27 años conoció a Maritza (su esposa) y el paciente comenta que su vida sexual en ese entonces era "muy divertida" tenía relaciones sexuales en la calle, playa, en el carro y en hostales.

Actualmente, en contraste, su esposa no quiere tener relaciones sexuales. Manifiesta fastidio por la falta de motivación por parte de su esposa respecto al área sexual, "no sé por qué". Cuenta que al casarse, tuvo a sus hijos y “misión cumplida”. Su esposa se niega tener sexo por que en la casa están presentes sus hijos; él reitera que "hay mil maneras de hacerlo, lo tuyo son pretextos". Ha llegado a irse de la casa debido a que no tenían relaciones sexuales durante tres meses y ella se molestó. Le dijo "si tanto lo quieres hacer, búscalo en la calle".

En marzo del 2014, él sugirió a su esposa darse una oportunidad e ir a Nueva York los dos solos. En tal viaje relata que tuvieron "una noche de sexo en el hotel" pero el resto de días estuvieron en la casa de la tía de su esposa.

\section{Educación hogareña y religión}

El paciente refiere habérsele inculcado en su familia la honestidad y respeto a su apellido. Además, un aspecto importante es no tener deudas "no puedo deber un sol a nadie, no duermo. Mis servicios los pago antes de tiempo. Nunca pido ayuda, si es que necesito pagar un servicio o comer, primero me muero de hambre antes de pedir plata o un favor". Cuenta que cuando sus hijos eran más pequeños en ocasiones le interrumpían el servicio 
de luz por dejar de pagar por varios meses. Sin embargo, él se las agenciaba para conseguir dinero. Nunca faltó comida ni leche para ellos. Sólo una vez, relata, pidió ayuda para trabajar en Argentina. Usualmente no le importa qué trabajo sea "con tal de hacer algo".

En cuanto a su religión comenta que "a veces creo, a veces no". E1 tema religioso "fue muy liviano" en casa. Su familia pertenece a la comunidad Judía pero a él se le tenía permitido consumir jamón en el colegio, comer chifa con chancho, etc. Su abuelo era el miembro de la familia que le daba más importancia a la religión, hacía rezos de tres horas diarias. En las reuniones religiosas, él nunca fue llamado a leer el "libro sagrado", mientras que todos sus primos sí. Este hecho fue uno de los factores que lo hicieron dudar acerca de su procedencia; la razón por la que no era llamado es que no se le consideraba como hijo "legítimo", no se sabía el vientre de dónde provenía.

Opina que existen varias contradicciones en las enseñanzas religiosas, y basta con que se siga la voluntad de Dios, el cual desea que se haga el bien "procura que tu familia viva bien y feliz, no te metas en los problemas de otro y punto". No obstante, en presencia de su abuelo, el seguimiento de las reglas religiosas era más riguroso. Actualmente afirma que cree en Dios en "ciertos momentos, en otros no. No hay religión, mi comunicación es directa con él."

\section{Historia de la recreación y de la vida social}

El paciente recuerda que en la niñez jugaba con sus amigos del barrio, recuerda esas épocas como "bonitas", puesto que después del colegio se juntaba con ellos para jugar futbol, saltar de techo en techo, disparar con carabina, etc. Recuerda también haberse peleado con algunos amigos pero califica esas peleas como parte de la infancia. En la adolescencia y juventud, también mantenía sus amistades de la infancia, pero ahora mas frecuentaba a los amigos del colegio, con los que iban a fiestas, reuniones y también realizaban piques ilegales. En la etapa de la adultez el paciente indica que se dedica a los temas hogareños más que a la vida social; sin embargo, pertenece 
a un grupo de personas aficionadas a las motos, con los cuales se reúnen una vez por semana en un restaurante conocido. A partir de ello, se programó un viaje en moto hacia Pacasmayo.

\section{Hábitos}

El paciente refiere fumar cigarros de tabaco con regularidad, aunque en ocasiones suspende su consumo por dos o tres meses, para luego retomarlo. "Fumo cuando me provoca". Ha consumido cocaína, pasta básica, hachís y sobre todo marihuana. Hubo una época en la que tenía una planta de la misma en su domicilio. Actualmente manifiesta tener mayores deseos de fumarla para tener un momento consigo mismo, por ejemplo viendo una película.

La primera droga que consumió fue la marihuana a los 19 años. Lo hacía con regularidad, los fines de semana con sus amistades, comenta que lo hacía viendo una película y que después iban a comer y luego dormir, lo describe como "la mejor sensación". Su consumo se extendió hasta los 32 años y la abandonó cuando tuvo a su primer hijo "tenía que seguir el ritmo de mis hijos". Afirma que si bien su esposa no gusta del consumo de marihuana, no tenía problema con que él la consumiera. Desde los 20 años hasta los 21 inició consumo de cocaína mantuvo una frecuencia de una vez por semana y también lo realizaba con amigos, afirma no haber tenido dificultades para dejarla. En este periodo también probó pasta básica "no me gusto" y el hachís. Con el hachís, explica, está contenido en un pomo dentro del cual se olfatea y "te vas para atrás". "Esta última droga es marihuana repotenciada por 10 veces"; la diferencia es que la marihuana tiene un pico alto de ahí muere; el hachís en cambio, tiene varios picos y su duración es mayor”.

Actualmente, considera que sus hábitos son buenos; en su hogar se promueve el orden y limpieza, se preocupa por el estado de sus vehículos (carro y moto) y disfruta de la cocina, así como de ver películas y manejar automóviles. Durante la semana él es el encargado de arreglar los artefactos defectuosos, realizar los pagos, recoger a sus hijos del colegio o academia cuando Maritza no puede y además como rutina, una vez por semana se junta 
con amigos: "los moteros". El paciente afirma: "Me gusta correr y la velocidad, me gusta estar al filo. Siempre, desde chico". Cuando era niño experimentaba la velocidad en su bicicleta y al crecer, pasó a buscarla en su auto. Cuenta que tiene un "mundo paralelo" en su automóvil, "manejaría cualquier cosa". Al preguntársele por la práctica de deportes extremos, reporta haber corrido tabla por un tiempo.

\section{Enfermedades y accidentes}

Relata que a los 5 años de edad, la empleada doméstica le cerró la puerta en el dedo adrede "Me dejaron solo con la empleada y ella vivía en el segundo piso. Yo subí porque tenía miedo, era chico y ella pensó que subía para verla calata y me cerró la puerta". No abrió la puerta por más que su dedo estaba colgando "por eso tengo doble uña”. Después de eso, hirvió agua, puso sal a la herida y la vendó “desde chiquito sabía cómo currarme raspones y heridas". Cuando su madre llegó y vio su herida, a pesar de que él le dijo que todo estaba bien, despidieron a la empleada.

Aproximadamente a los 7 años de edad, recuerda que frente a su casa había un pampón en el que "nos enfrentábamos a piedrazos con otros vecinos". En una oportunidad, una piedra cayó en su cabeza y le hizo una herida para la que "sólo usé algodón y un parche".

A los 15 años se le diagnosticó Mononucleosis Hepática, cuya ocurrencia le impide donar sangre hasta el día de hoy. Ha sufrido de varios accidentes en diferentes partes del cuerpo, como tobillos, rodillas, muñecas y dedos. La mayoría de estos accidentes han sido consecuencia de la práctica deportiva; por ejemplo, jugando fútbol se rompió un ligamento de la rodilla y practicando el voleibol tuvo un accidente que ameritó una operación pues se vio impedido de caminar.

Además, hace poco más de 20 años se dañó la mano derecha tras dar un golpe al parabrisas de un carro con el puño. En esta oportunidad, estaba manejando y un microbús no lo dejó pasar "te exaltas y te pones rabioso porque no comprendes como gente así maneja en este país y tú quieres hacer las cosas bien o como en otro lado". En esta oportunidad, cuenta que "mi 
cólera estalló" y bajó de su vehículo a increpar al chofer. Éste utilizó gas pimienta y en respuesta, Adrián golpeó y rompió el parabrisas del microbús. Tuvo que llamar a la compañía de seguros pues el chofer también había roto el parabrisas de su auto. Finalmente, cada uno arregló sus daños respectivos.

\section{Movilidad e instalación}

A los 19 años Adrián viajó a Israel para trabajar en Kibutz (colonia agrícola de producción y consumo comunitarios), por un periodo de 3 meses. Luego a los 41 años se dirigió a Estados Unidos, también por 3 meses para buscar trabajo, se desempeñó como mozo, recepcionista y en ese mismo año se traslada a Panamá para trabajar en un almacén. Luego, a los 43 años viaja a Argentina para buscar trabajo y labora como archivador de una empresa, ahí trabajo 4 meses aproximadamente y decide trasladar a su familia también a Argentina y viven ahí alrededor de 1 año.

\section{Delincuencia, récord policial y judicial}

No tiene un record policial, pero refiere haber estado involucrado en más de 30 accidentes automovilísticos. Han sido causados en ocasiones por él y en otras por alguien más. Afirma que "me gusta correr y la velocidad, me gusta estar al filo. Siempre, desde chico". Por tal razón manifiesta haber sido partícipe de varios accidentes.

\section{Personalidad}

El paciente refiere que en la infancia era un niño alegre con mucha energía, siempre estaba realizando algún deporte o actividad. Se califica como un niño distraído en el colegio, le costaba mantener su atención a las clases. Se molestaba rápidamente cuando alguien lo atacaba o le hacían burlas, pero si eso no ocurría tendía mantener buena relación con sus amistades.

En la adolescencia también se consideraba alegre y extrovertido, sobre todo impulsivo, siempre estaba realizando alguna actividad, como un 
deporte o manejando su auto a grandes velocidades; el paciente afirma que disfrutaba de la velocidad y la sensación de "estar al filo". También reporta oportunidades en la que ha reaccionado de manera agresiva por discusiones con amigos y confrontaciones con otros conductores. Además, en esta etapa en la juventud, comenzó a experimentar estados anímicos elevados y depresivos, los cuales estuvieron aproximadamente dos semanas presentes.

En la adultez, la impulsividad, la baja tolerancia a la frustración y la irritabilidad, fueron características que han perdurado y que a su vez han tenido diversas repercusiones sobre su funcionamiento diario, al igual que sus oscilaciones en el estado anímico. Por ejemplo, al estar en la cocina preparando panqueques y uno se le pega a la sartén comenta: "lo tiro con sartén y todo por cólera”. Dice ser renegón cuando los demás no siguen lo que él dice o no realizan las cosas a su manera. Si es que las cosas le salen mal "me enerva, no se dejan enseñar". Esto le sucede con sus hijos, manifiesta haberle gustado tener un padre que le explicara cómo son las cosas "ellos no quieren nada conmigo, no me hacen caso". Se describe como una persona alegre en ocasiones pero cuando las cosas no resultan como él quiere, siente mucha rabia.

\section{Historia Familiar}

El paciente se enteró de su adopción a los 37 años de edad tras haber tenido sospechas por varios años.

\section{Padre}

\section{a. Datos de filiación:}

1. Nombre y apellidos: N.A.Y

2. Sexo: Masculino

3. Edad: 85 años

4. Lugar y fecha de nacimiento: Rumania, 20 de Marzo de 1928

5. Tiempo de residencia en lima: Vivió en Huacho hasta los 3 años

6. Estado civil: Divorciado

7. Grado de instrucción: Superior (Odontólogo - nunca ejerció)

8. Ocupación actual: Retirado 
9. Religión: judía

\section{b. Características personales}

El paciente describe a su padre adoptivo como una persona egocéntrica y egoísta, lo considera como una persona poco tolerante "no aguanta a la gente" e indica que era económicamente dependiente de su madre hasta que se divorciaron. No lo conoce bien pues vivió con él hasta los 5 años y sus encuentros han sido muy puntuales. Por ejemplo, en los cumpleaños de sus hijos "comía y se iba". Nunca mostró interés en acercarse a él.

Su padre formó otra familia y tuvo una hija. Un día lo llamó por teléfono para pedirle ayuda para acercarse a su hija; el paciente relata que "yo no tuve ningún inconveniente y lo apoyé”. Así, fueron al colegio de la niña a buscarla, pero la madre de ésta indicó que su padre no podía acercarse. Él entonces fue como su hermano, pero tampoco le permitieron verla. Finalmente ella lo llamó y lograron un acercamiento entre ellos y su padre. No obstante, él la abandonó. Su hermana vive ahora en Estados Unidos y no usa el apellido de su padre. "El distanciamiento que tuvo con su hija fue porque él es una persona que no le gusta compartir, es alguien que le gusta estar solo". Actualmente vive solo con una empleada doméstica.

\section{c. Relación del paciente con su padre}

Adrián no mantiene relación con su padre, dejaron de convivir cuando el paciente tenía 5 años de edad y en la actualidad no se ven hace un par de años. Las únicas ocasiones en las que se han frecuentado, fueron en algunos cumpleaños de los hijos de Adrián. El evaluado afirma: "solo iba comía y se iba, no mostraba interés en conversar con nosotros".

\section{Madre}

\section{a. Datos de filiación:}


1. Nombre y apellidos: R.I.S

2. Sexo: Femenino

3. Edad: Falleció a los 75 años.

4. Lugar y fecha de nacimiento: 23 de Octubre de 1930

5. Tiempo de residencia en Lima: No recuerda

6. Estado civil: Divorciada

7. Grado de instrucción: Desconocido

8. Ocupación actual (centro de trabajo y cargo): -

9. Religión: judía

\section{b. Características personales}

Fue una mujer cariñosa, inteligente, trabajadora, responsable, alegre, emprendedora y tenaz. Sin embargo, a la vez, el paciente la percibía como sobreprotectora y manipuladora "movía las piezas de ajedrez hacia su conveniencia". Refiere que de niño lo trataba de manipular con regalos y que la percibía como la jefa de la familia.

\section{c. Relación del paciente con su madre}

De adulto tenía conflictos con ella referidos a sus relaciones amorosas "con las enamoradas, ninguna le parecía, todas eran putas o brujas, menos las judías”. Además, debido a que su relación con ella era estrecha y compartían bastante tiempo juntos en viajes y de manera diaria, su opinión tenía una gran influencia. Él cedía a lo que su madre dijera pues "ella hacía mucho esfuerzo por mí, me ha mantenido, me ha criado y ha dado todo por mí". Su obediencia para él era "como un agradecimiento".

\section{Relación entre los padres}

Cuando Adrián tenía 5 años, su madre tomó la decisión de divorciarse de su padre y lo expulsó de la casa. A partir de su divorcio la relación entre ambos fue interrumpida de manera definitiva. 
5.2 Presentación de los resultados de cada técnica de recolección de información

\subsubsection{Escala de Inteligencia de Wechsler WAIS-IV}

\section{a. Observaciones generales}

Con respecto a su comportamiento durante las dos sesiones de evaluación, Adrián se mostró colaborador y amable la mayor parte del tiempo, pero ante ciertas pruebas demostró su fastidio. No presentó dificultades en la comprensión de las consignas de las pruebas aplicadas; sin embargo, el evaluado pidió que se le repitieran ítems de las subpruebas de Aritmética, Dígitos y Números y Letras; manifestando no recordar los enunciados con claridad. También reflejó su aburrimiento ante la actividad de aritmética en la que señaló: "uy matemáticas, nunca me gustaron, que aburrido pero bueno..."

\section{b. Resultados cuantitativos}

Tabla 5.1

Puntajes obtenidos tras la aplicación del WAIS IV

\begin{tabular}{|c|c|c|c|}
\hline Subtest & P.D. & P.E. & Categoría \\
\hline Cubos & 51 & 12 & Promedio \\
\hline Semejanzas & 20 & 10 & Promedio \\
\hline Dígitos & 28 & 11 & Promedio \\
\hline Matrices & 21 & 13 & $\begin{array}{l}\text { Promedio } \\
\text { Alto }\end{array}$ \\
\hline Vocabulario & 46 & 16 & $\begin{array}{l}\text { Promedio } \\
\text { Alto }\end{array}$ \\
\hline Aritmética & 16 & 12 & Promedio \\
\hline $\begin{array}{l}\text { Búsqueda de } \\
\text { Símbolos }\end{array}$ & 27 & 9 & Promedio \\
\hline $\begin{array}{l}\text { Puzles } \\
\text { Visuales }\end{array}$ & 17 & 13 & $\begin{array}{l}\text { Promedio } \\
\text { Alto }\end{array}$ \\
\hline
\end{tabular}




$\begin{array}{lccc}\begin{array}{l}\text { Información } \\ \text { Clave de }\end{array} & 14 & 10 & \text { Promedio } \\ \begin{array}{l}\text { Números } \\ \text { Letras y }\end{array} & 59 & 10 & \text { Promedio } \\ \begin{array}{l}\text { Números } \\ \text { Balanzas }\end{array} & 20 & 12 & \text { Promedio } \\ \text { Comprensión } & 28 & 14 & \begin{array}{c}\text { Promedio } \\ \text { Alto }\end{array} \\ \text { Cancelación } & 39 & 10 & \text { Promedio }\end{array}$

$\begin{array}{llll}\text { Cancelación } & 39 & 10 & \text { Promedio }\end{array}$

Figuras

Incompletas

$14 \quad 12 \quad$ Promedio

Figuras 5.1

Perfil de puntuaciones compuestas del WAIS IV

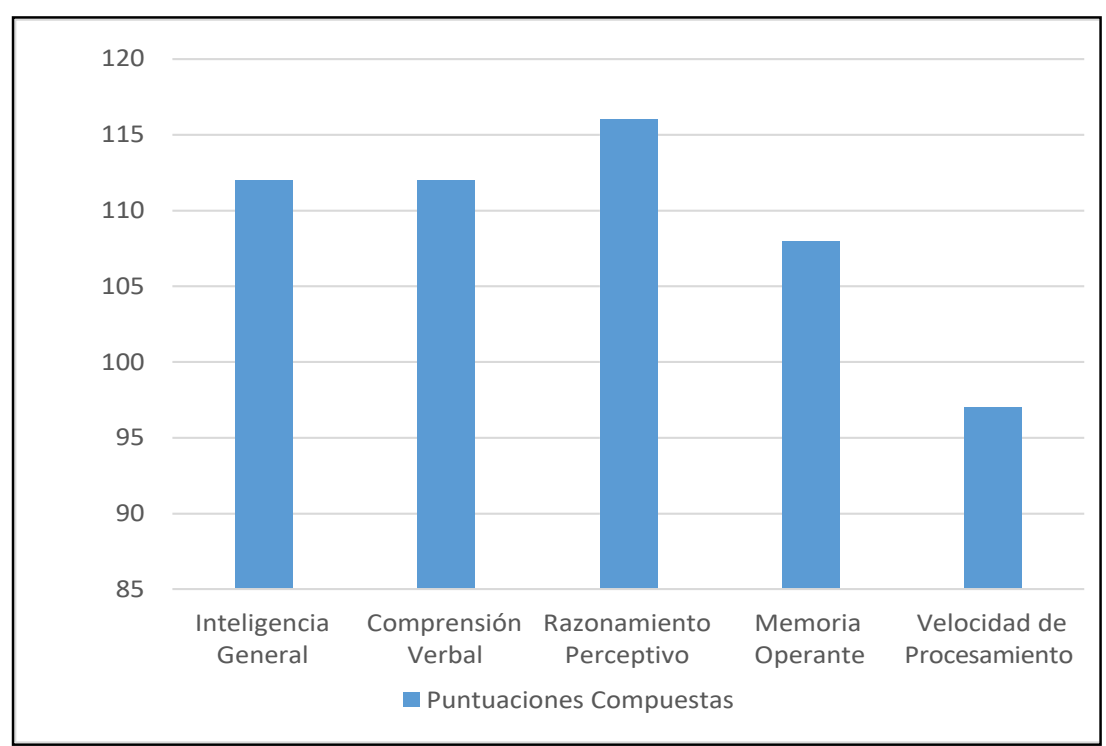


Tabla 5.2

Perfil de puntuaciones compuestas del WAIS IV

\begin{tabular}{|c|c|c|}
\hline Coeficiente Intelectual & $\mathrm{CI}$ & Categoría \\
\hline Inteligencia General & 112 & $\begin{array}{l}\text { Promedio } \\
\text { Alto }\end{array}$ \\
\hline Comprensión Verbal & 112 & $\begin{array}{l}\text { Promedio } \\
\text { Alto }\end{array}$ \\
\hline Razonamiento Perceptivo & 116 & $\begin{array}{l}\text { Promedio } \\
\text { Alto }\end{array}$ \\
\hline Memoria Operante & 108 & $\begin{array}{l}\text { Normal } \\
\text { Promedio }\end{array}$ \\
\hline Velocidad de Procesamiento & 97 & $\begin{array}{c}\text { Normal } \\
\text { Promedio }\end{array}$ \\
\hline
\end{tabular}

\section{c. Resultados cualitativos}

Adrián obtuvo un Coeficiente Intelectual General, tal como es medido por el WAIS-IV, y se clasifica como perteneciente al rango Promedio Alto, en comparación con su grupo etario.

No obstante, el análisis cuantitativo de los índices que componen este coeficiente, a saber, Comprensión Verbal, Razonamiento Perceptual, Memoria Operante y Velocidad de Procesamiento, muestran una variabilidad significativa dentro y entre ellos, por lo que el Coeficiente Intelectual General calculado no puede considerarse una estimación fiable y válida de su capacidad intelectual global.

Respecto del Índice de Comprensión Verbal (C.I 112), su rendimiento es correspondiente a una categoría Promedio Alto. Los resultados muestran que su comprensión social, la cual refleja su juicio práctico, sentido común y adecuada adquisición e interiorización de elementos culturales, se sitúa en el promedio alto. En cuanto a su riqueza léxica y semántica, su reserva de información adquirida a través de la educación formal e informal de su ambiente; junto con su capacidad de pensamiento asociativo y abstracto, se ubican dentro del rango normativo.

En el Índice de Razonamiento Perceptual (C.I 116), Adrián presenta un Coeficiente Intelectual ubicado en una categoría Promedio Alto. Evidencia un rendimiento por encima del promedio en funciones que 
se relacionan con su razonamiento abstracto no verbal - serial y orientación espacial para el procesamiento de la información visual, con su capacidad para establecer relaciones entre partes de una figura. Estas funciones se sitúan por encima del promedio, siendo fortalezas en su desempeño. Por otro lado, su coordinación mano-ojo, en cual hace uso de procesos de análisis y síntesis para la reproducción de una figura geométrica abstracta, se ubica dentro de la norma.

En el Índice de Memoria Operante (C.I 108) su desempeño es correspondiente a la categoría Promedio. Así, en lo referido a su memoria auditiva inmediata para seguir una secuenciación auditiva, se halla por encima del promedio, constituyendo un punto fuerte en su funcionamiento. En cuanto a su atención y memoria de trabajo y su habilidad para realizar operaciones numéricas básicas, los resultados se ubican dentro del promedio.

Finalmente, su ejecución en el Índice de Velocidad de Procesamiento (C.I 97) lo ubica en el nivel Promedio. Así, muestra una velocidad y precisión perceptiva para procesar información visual simple; así como una destreza visomotora para la reproducción de material nuevo adquirido mediante un de aprendizaje asociativo, ubicados dentro de los límites normales.

Por lo tanto, el desempeño intelectual general de Adrián corresponde al nivel Promedio Alto en relación a su grupo normativo. No obstante, se observan diferencias significativas entre los índices que componen al coeficiente global, restando confiabilidad y validez a su interpretación como constructo unitario.

Además, los índices de Razonamiento Perceptivo y Comprensión Verbal, se ubican dentro del Promedio Alto. Por otro lado, el factor de Memoria Operante y Velocidad de Procesamiento, pertenecen al rango Promedio. Sus principales fortalezas implican a su comprensión social, su memoria auditiva inmediata para seguir una secuenciación auditiva, el razonamiento abstracto no verbal - serial y orientación espacial para el procesamiento de la información visual. 


\subsubsection{Evaluación Neuropsicológica Breve en Español- NEUROPSI}

\section{a. Observaciones generales}

El paciente se mostró colaborador y amable durante la sesión de evaluación; asimismo, comprendió las instrucciones de las actividades sin dificultad. En la tarea de cálculo, al mencionarle las indicaciones, exclamó: ¡no, matemáticas!, y al finalizar dicha actividad: "bueno no fue tan difícil como pensé”.

\section{b. Resultados cuantitativos}

Tabla 5.3

Puntuaciones por área del NEUROPSI

\begin{tabular}{clc}
\hline Áreas Cognoscitivas & \multicolumn{1}{c}{ Actividad } & Puntaje \\
\hline \multirow{2}{*}{ Orientación } & Tiempo & $3 / 3$ \\
& Espacio & $2 / 2$ \\
& Persona & $1 / 1$ \\
& Dígitos en regresión & $6 / 6$ \\
Atención y concentración & Detección Visual & $12 / 16$ \\
& $20-3$ & $5 / 5$ \\
& Memoria Verbal & $5 / 6$ \\
Codificación & Espontanea & $11 / 12$ \\
& Proceso Visoespacial & $8 / 8$ \\
& Denominación & $4 / 4$ \\
& Repetición & $6 / 6$ \\
& & $5 / 8$ \\
\hline
\end{tabular}




\begin{tabular}{clc}
\hline Lectura & Lectura & $3 / 3$ \\
\multirow{2}{*}{ Escritura } & Dictado & $1 / 1$ \\
& Copiado & $1 / 1$ \\
\multirow{2}{*}{ Funciones Ejecutivas } & Conceptual & $9 / 10$ \\
& Funciones Motoras & $6 / 8$ \\
\multirow{2}{*}{ Funciones de Evocación } & Memoria & $9 / 12$ \\
& Visoespacial & $15 / 18$ \\
\hline
\end{tabular}

Tabla 5.4

Puntuación total y diagnóstico del NEUROPSI

\begin{tabular}{lcc}
\hline \multicolumn{1}{c}{ Puntuación Total } & Puntuación Natural & Diagnóstico \\
\hline $\begin{array}{l}\text { Total Batería } \\
\text { Neuropsicológica }\end{array}$ & 111 & Normal Promedio \\
\hline
\end{tabular}

\section{c. Resultados cualitativos}

En la Evaluación Neuropsicológica Breve en Español NEUROPSI, el evaluado obtuvo un puntaje general de 111, situándolo en un nivel normal promedio. 
En el área de orientación, el evaluado se presenta orientado en el tiempo, espacio y persona. Asimismo, la lectura y escritura no presentan alteración, obtiene el puntaje mayor en dichas áreas.

En la atención y concentración, específicamente en la tarea de dígitos en regresión y la resta consecutiva, alcanza la puntuación máxima; no obstante, en la detección visual obtiene 12/16 puntos.

Los procesos mnésicos, para la codificación de información verbal, obtiene un puntaje de 5/6 y para la visual 11/12. Por otro lado, la evocación de la misma indican 15/18 para el componente verbal y 9/12 para el visual.

El lenguaje, tanto para la denominación, repetición y comprensión se encuentran dentro del rango de la normalidad; sin embargo, en la tarea de fluidez verbal obtuvo un puntaje de 5/8.

Finalmente en las funciones ejecutivas compuestas por el área conceptual y motora, se observa un desempeño normal promedio para la primera, mientras que las funciones motoras, el evaluado registro 6/8 puntos.

\subsubsection{Batería Neuropsicológica de Funciones Ejecutivas y Lóbulos Frontales (BANFE-2)}

\section{a. Observaciones generales}

Durante la ejecución de la prueba el examinado mostró una disposición amable y colaboradora. Permaneció en su asiento en todo momento y en ocasiones se reacomodó. Cabe añadir que ante la prueba de “Juego de cartas”, Adrián indicó que esa subprueba no tenía “sentido", ya que no podía cumplir el objetivo de la prueba, el cual era generar la mayor cantidad de puntos. 
Tabla 5.5

Puntuaciones del BANFE por área y subprueba

\begin{tabular}{|c|c|c|c|}
\hline Área & Subprueba & \multicolumn{2}{|c|}{ Puntuación } \\
\hline \multirow{10}{*}{ Orbitomedial } & & Natural & Codificada \\
\hline & Laberintos. Atravesar & 0 & 4 \\
\hline & $\begin{array}{l}\text { Juego de Cartas. Porcentaje de } \\
\text { cartas en riesgo }\end{array}$ & 33,3 & 4 \\
\hline & $\begin{array}{l}\text { Juego de Cartas. Puntuación } \\
\text { Total }\end{array}$ & 40 & 5 \\
\hline & $\begin{array}{l}\text { Stroop forma "A". Errores tipo } \\
\text { Stroop }\end{array}$ & 0 & 5 \\
\hline & Stroop forma "A". Tiempo & 70 & 5 \\
\hline & Stroop forma "A". Aciertos & 82 & - \\
\hline & $\begin{array}{l}\text { Stroop forma "B". Errores tipo } \\
\text { Stroop }\end{array}$ & 2 & 3 \\
\hline & Stroop forma "B". Tiempo & 63 & 5 \\
\hline & Stroop forma "B". Aciertos & 82 & - \\
\hline
\end{tabular}




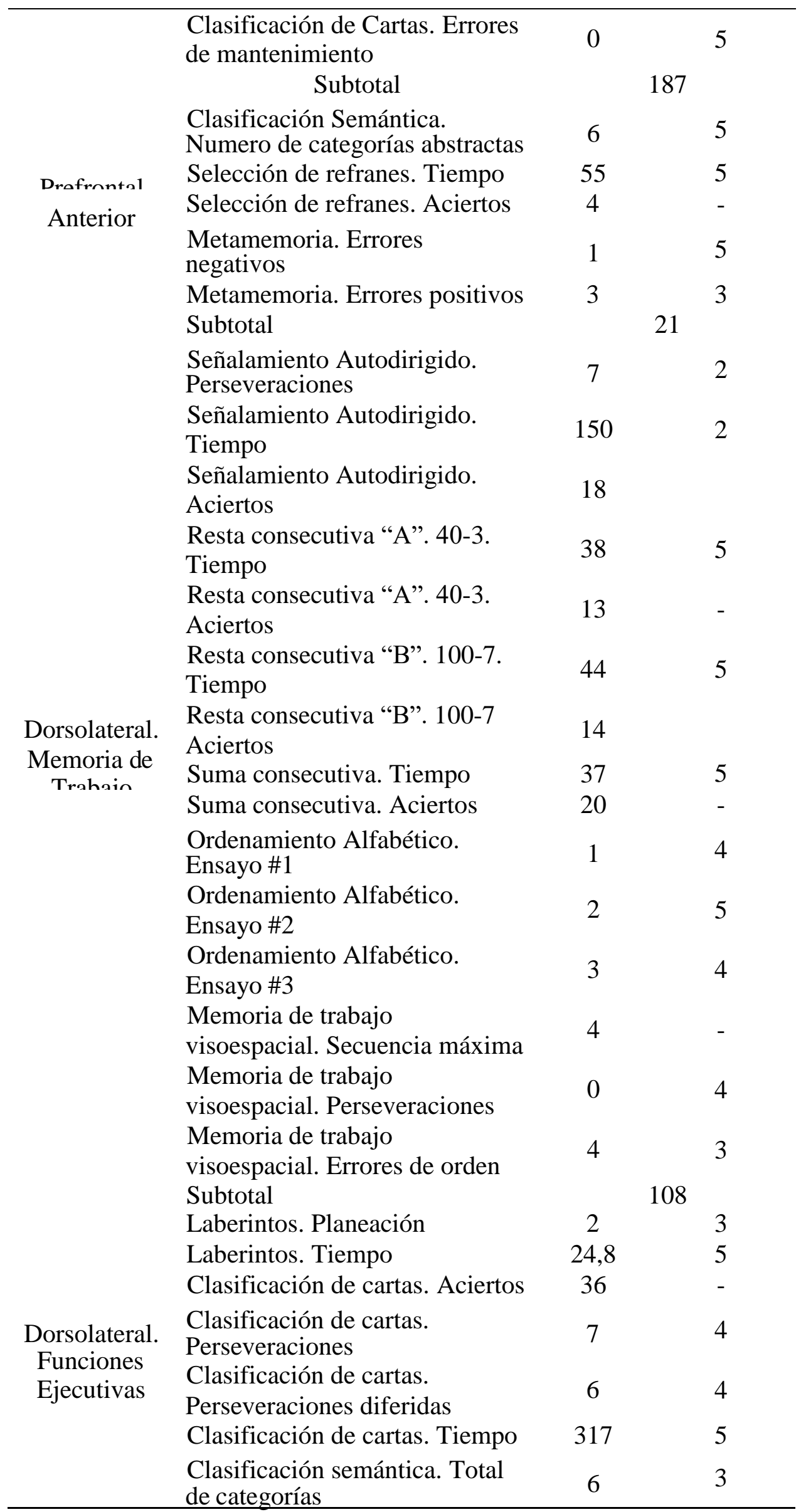




\begin{tabular}{|c|c|c|}
\hline $\begin{array}{l}\text { Clasificación semántica. } \\
\text { Promedio total de animales }\end{array}$ & 6,5 & 4 \\
\hline $\begin{array}{l}\text { Clasificación semántica. Puntaje } \\
\text { Total }\end{array}$ & 18 & 3 \\
\hline Fluidez Verbal. Aciertos & 13 & 3 \\
\hline Fluidez Verbal. Perseveraciones & 1 & 4 \\
\hline $\begin{array}{l}\text { Torre de Hanoi } 3 \text { discos. } \\
\text { Movimientos }\end{array}$ & 12 & 4 \\
\hline $\begin{array}{l}\text { Torre de Hanoi } 3 \text { discos. } \\
\text { Tiempo }\end{array}$ & 29 & 5 \\
\hline $\begin{array}{l}\text { Torre de Hanoi } 4 \text { discos. } \\
\text { Movimientos }\end{array}$ & 15 & 5 \\
\hline $\begin{array}{l}\text { Torre de Hanoi } 4 \text { discos. } \\
\text { Tiempo }\end{array}$ & 41 & 5 \\
\hline Subtotal & & \\
\hline
\end{tabular}

Tabla 5.6

Puntuaciones Totales del BANFE

\begin{tabular}{lccc}
\hline Puntuaciones Totales & $\begin{array}{c}\text { Puntuación } \\
\text { Natural }\end{array}$ & $\begin{array}{c}\text { Puntuación } \\
\text { Normalizada }\end{array}$ & Diagnóstico \\
\hline $\begin{array}{l}\text { Subtotal orbitomedial } \\
\begin{array}{l}\text { Subtotal prefrontal } \\
\text { anterior }\end{array}\end{array}$ & 200 & 106 & Promedio \\
$\begin{array}{l}\text { Total dorsolateral } \\
\text { (MT+FE) }\end{array}$ & 21 & 111 & Promedio \\
$\begin{array}{l}\text { Total Batería de } \\
\text { Funciones Ejecutivas }\end{array}$ & 422 & 97 & Promedio \\
\hline
\end{tabular}

\section{c. Resultados cualitativos}


La puntuación total obtenida por Adrián en la Batería Neuropsicológica de las Funciones Ejecutivas y los Lóbulos Frontales (BANFE), según su puntuación normalizada, es correspondiente al nivel normal promedio.

Esta estimación global está compuesta por funciones complejas que dependen de la corteza orbitofrontal (COF), corteza prefrontal medial (CPFM), corteza prefrontal dorsolateral (CPFDL) y de la corteza prefrontal anterior (CPFA).

Para el área orbitomedial, específicamente para la COF y CPFM, el rendimiento del evaluado se clasifica en un nivel normal promedio. Los subtest que se encargan de medir dicha área fueron: Efecto Stroop, Juego de Cartas y Laberintos. Sus resultados muestran que su capacidad de control inhibitorio, la capacidad para detectar y evitar decisiones de riesgo, la capacidad para mantener las selecciones de beneficio y la destreza para respetar los límites y seguir las reglas, se encuentran dentro del rango de la normalidad.

El área prefrontal anterior (CPFA) refleja un rendimiento también situado en la categoría promedio. Para ello se utilizaron las pruebas de Clasificación Semántica, Selección de Refranes y Metamemoria. Tales subtests, evalúan la capacidad para producir grupos semánticos relacionado con la actitud abstracta, la habilidad para comprender, comparar y seleccionar respuestas en sentido figurado y la capacidad para desarrollar una estrategia de memoria, predicción de rendimiento y finalmente la modificación de su predicción ante su desempeño real. Ante dichas tareas descritas, su rendimiento se encuentra sin alteración.

En relación al área dorsolateral, la evaluación de se divide en las funciones de memoria de trabajo y en funciones ejecutivas. Para la primera, se toman en cuenta los subtests de Señalamiento Autodirigido, Resta Consecutiva "a" y "b", Suma Consecutiva, Ordenamiento Alfabético y Memoria de Trabajo Visoespacial. Dichas pruebas miden la capacidad del evaluado para: utilizar la memoria de trabajo visoespacial, desarrollar secuencias en orden inverso, manipular y ordenar mentalmente la información verbal y retener - reproducir activamente un orden visual. En cuanto a la evaluación de las funciones ejecutivas, las pruebas que se 
consideran son: Laberintos (tiempo y cantidad de veces que se queda sin salida), Clasificación de Cartas, Clasificación Semántica, Fluidez Verbal y Torres de Hanoi. Estas a su vez se encargan de medir la habilidad para anticipar y planear una conducta visoespacial, generar hipótesis de clasificación, la capacidad de flexibilidad cognitiva ante situaciones cambiantes, producir categorías abstractas y verbos de manera espontáneamente y finalmente la anticipación de forma secuenciada de acciones en orden progresivo como regresivo. Igualmente, su desempeño, tanto para el área de memoria de trabajo como de las funciones ejecutivas se ubica dentro de la norma de acuerdo a su grupo etario y grado de instrucción.

\subsubsection{Escala de Memoria de Wechsler WMS- IV}

\section{a. Observaciones generales}

Durante la ejecución de la prueba el evaluado se mostró amable y colaborador, indicó preferencia por las actividades en las que debía dibujar, pues refirió que en su tiempo libre gusta de dibujar. Asimismo, comprendió las consignas sin dificultad, pero ante el recuerdo de una historia el evaluado señaló haberse olvidado los datos presentados; sin embargo, optó por cerrar los ojos y recordar la historia con la mayor cantidad de detalles posibles. Además, su postura corporal se mantuvo en una misma posición y ocasionalmente se reacomodó en su asiento.

\section{b. Resultados cuantitativos}

Tabla 5.7

Puntajes del WMS- IV por subtest

\begin{tabular}{lccc}
\hline Subtest & P.D. & P.E. & Categoría \\
\hline $\begin{array}{l}\text { Memoria } \\
\text { Lógica I }\end{array}$ & 27 & 12 & $\begin{array}{c}\text { Normal } \\
\text { Promedio }\end{array}$
\end{tabular}




\begin{tabular}{|c|c|c|c|}
\hline $\begin{array}{l}\text { Memoria } \\
\text { Lógica II }\end{array}$ & 21 & 11 & $\begin{array}{l}\text { Normal } \\
\text { Promedio }\end{array}$ \\
\hline $\begin{array}{l}\text { Pares de } \\
\text { Palabras I }\end{array}$ & 33 & 11 & $\begin{array}{l}\text { Normal } \\
\text { Promedio }\end{array}$ \\
\hline $\begin{array}{l}\text { Pares de } \\
\text { Palabras II }\end{array}$ & 14 & 10 & $\begin{array}{l}\text { Normal } \\
\text { Promedio }\end{array}$ \\
\hline Diseños I & 69 & 10 & $\begin{array}{l}\text { Normal } \\
\text { Promedio }\end{array}$ \\
\hline Diseños II & 55 & 10 & $\begin{array}{l}\text { Normal } \\
\text { Promedio }\end{array}$ \\
\hline $\begin{array}{l}\text { Reproducción } \\
\text { Visual I }\end{array}$ & 40 & 12 & $\begin{array}{l}\text { Normal } \\
\text { Promedio }\end{array}$ \\
\hline $\begin{array}{l}\text { Reproducción } \\
\text { Visual II }\end{array}$ & 36 & 13 & $\begin{array}{l}\text { Promedio } \\
\text { Alto }\end{array}$ \\
\hline $\begin{array}{l}\text { Suma } \\
\text { Espacial }\end{array}$ & 12 & 10 & $\begin{array}{c}\text { Normal } \\
\text { Promedio }\end{array}$ \\
\hline $\begin{array}{l}\text { Span de } \\
\text { Símbolos }\end{array}$ & 30 & 13 & $\begin{array}{l}\text { Promedio } \\
\text { Alto }\end{array}$ \\
\hline
\end{tabular}

Figura 5.2

Perfil de puntuaciones compuestas del WMS- IV 


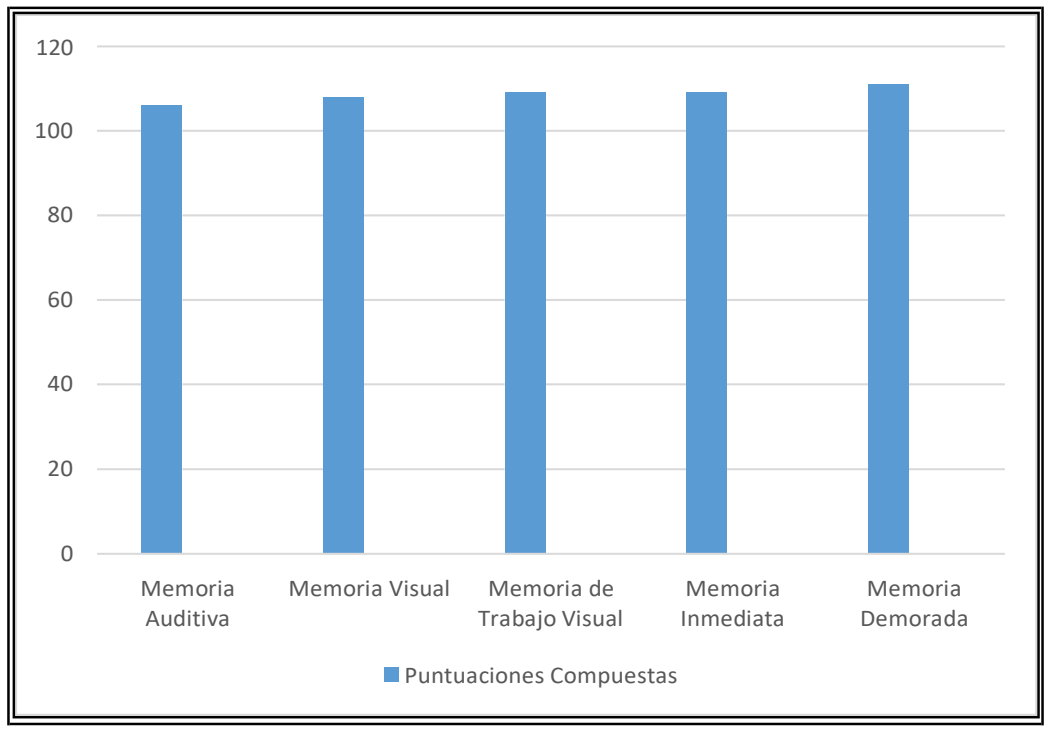

Tabla 5.8

Perfil de puntuaciones compuestas del WMS- IV

\begin{tabular}{lll}
\hline $\begin{array}{l}\text { Coeficient } \\
\text { e }\end{array}$ & CI & $\begin{array}{l}\text { Categorí } \\
\mathrm{a}\end{array}$ \\
Intelectual & & $\begin{array}{l}\text { Normal } \\
\text { Promedi } \\
\text { Memoria }\end{array}$ \\
Auditiva & 10 & Normal \\
Memoria & 6 & Promedi \\
Visual & 10 & o \\
Memoria & 8 & Normal \\
de & 10 & Promedi \\
Trabajo & 9 & Normal \\
Visual & & Promedi \\
Memoria & & o \\
Inmediata & 10 & Promedi \\
Memoria & 9 & oflto \\
\hline Demorada & 11 &
\end{tabular}




\section{c. Resultados cualitativos}

Adrián, en el Test breve para la evaluación del estado cognitivo (BCSE), obtiene un puntaje global normal promedio de acuerdo a su grupo de edad y nivel educativo. Dicha prueba evalúa de manera rápida las funciones de: orientación, estimación temporal, denominación, control mental, planificación y organización, recuerdo incidental, inhibición y producción verbal.

A continuación se desarrollaran los índices de Memoria Auditiva (IMA), Memoria Visual (IMV), Memoria De Trabajo Visual (IMTV), Memoria Inmediata (IMI), Memoria Demorada (IMD).

Respecto del Índice de Memoria Auditiva (C.I 106), su rendimiento es correspondiente al nivel normal promedio. Sus resultados reflejan que mantiene un desempeño dentro de la norma para codificar y evocar información auditiva para una historia lógica y para un conjunto de palabras.

De igual modo, el Índice Memoria Visual (C.I 108), también se sitúa dentro de la norma y sus resultados muestran que su capacidad para codificar y evocar detalles de figuras y la localización espacial de estímulos se encuentran conservadas.

En cuanto al índice Memoria De Trabajo Visual (C.I 109), su desempeño se sitúa dentro del rango de la normalidad lo que sugiere que el evaluado presenta aptitud adecuada para mantener temporalmente información visual, tanto detalles visuales como localizaciones espaciales y para manipular dichos datos.

Asimismo, la Memoria Inmediata (C.I 109), también se sitúa dentro del promedio y muestra una capacidad dentro del promedio para recordar información auditiva como visual, seguidamente después de ser presentada.

Finalmente, el índice de Memoria Demorada (C.I 111), evidencia un rendimiento ubicado en el rango promedio alto. Este índice muestra que el evaluado posee aptitud por encima del promedio para evocar detalles visuales, considerándose una fortaleza, mientras que su 
rendimiento se encuentra dentro del promedio para recordar localizaciones y detalles espaciales. Igualmente, dentro de la norma se sitúan los estímulos auditivos diferidos, compuestos por una historia lógica y pares de palabras.

\subsubsection{Test of Variables of Attention (T.O.V.A)}

\section{a. Observaciones generales}

Durante la evaluación el paciente se mostró amable y colaborador, y comprendió rápidamente las instrucciones de la prueba. Al comentarle sobre la duración de la prueba (22 minutos) el paciente exclamó: “¡Asu tanto tiempo!, me voy a aburrir apretando el botoncito, pero bueno, caballero!' En la ejecución de la actividad, mostró una postura encorvada apoyando la cabeza sobre una de sus manos, donde sus codos estaban apoyados sobre la mesa, con la otra mano tenia sujetado el microswitch. En el trascurso de la prueba realizaba ciertos comentarios como: “¡casi se me escapa una figurita!”, “¡ay no la vi!”. A pesar de ello, la evaluación se concluyó de manera adecuada. 


\section{b. Resultados cuantitativos}

Tabla 5.9

Puntuaciones del TOVA

\begin{tabular}{lccccccc}
\hline & \multicolumn{3}{c}{ Cuartos } & \multicolumn{2}{c}{ Mitades } & Total \\
\hline & 1 & 2 & 3 & 4 & 1 & 2 & \\
\hline $\begin{array}{l}\text { Variabilidad } \\
\text { de tiempo }\end{array}$ & 99 & 92 & 58 & 57 & 95 & 48 & 59 \\
$\begin{array}{l}\text { de respuesta } \\
\text { Tiempo de }\end{array}$ & 94 & 108 & 104 & 121 & 102 & 112 & 110 \\
$\begin{array}{l}\text { respuesta } \\
\text { Errores por }\end{array}$ & 110 & 106 & 102 & 110 & 117 & 108 & 111 \\
$\begin{array}{l}\text { comisión } \\
\text { Errores por }\end{array}$ & 102 & 102 & 102 & 90 & 104 & 91 & 94 \\
omisión & & & & & & & \\
\hline
\end{tabular}

* Los resultados están convertidos a puntuación estándar

\section{c. Resultados cualitativos}

La exploración de la atención sostenida mediante una prueba de rendimiento continuo visual arroja los siguientes resultados.

En el cuarto I, la variabilidad de tiempo de respuesta, el tiempo de respuesta, los errores por comisión y omisión se encuentran dentro del rango de la normalidad. Por lo tanto ante una tarea de menor nivel de estimulación su desempeño se halla sin alteración. (Pe: 99, 94, 110,102).

En el segundo cuarto, de igual manera las variables de variabilidad de tiempo de respuesta, tiempo de respuesta, errores por comisión y omisión, se sitúan dentro del nivel normal promedio. (Pe: 92, $108,106,102)$.

En el tercer cuarto, la variable de variabilidad de tiempo de respuesta se halla en un nivel significativamente por debajo del promedio (Pe: 58), mientras que el tiempo de respuesta, los errores por comisión y omisión se sitúan dentro de la norma (Pe: 104, 102, 102). 
En el último cuarto, nuevamente se halla una disminución significativa en la variable: variabilidad de tiempo de respuesta (Pe: 57). Las variables de tiempo de respuesta, errores por comisión y omisión se muestran sin alteración (Pe: 121, 110,90).

Por lo tanto, la evaluación de las mitades, señala que el evaluado en la mitad I, ante una estimulación poco frecuente, mantiene un desempeño esperado para su edad en todas las variables evaluadas; mientras que en la segunda mitad donde la tarea consta de estímulos visuales frecuentes, se encuentra una alteración significativa para la variable, variabilidad de tiempo de respuesta, con un desempeño muy por debajo de la norma. Por último, la evaluación del total indican resultados dentro de los esperado para el tiempo de respuesta, errores por comisión y omisión; no obstante, la variabilidad de tiempo de respuesta se encuentra se sitúa por debajo del promedio.

Por tanto, la inconsistencia en la variabilidad de tiempo de respuesta que fue anormal en los cuartos 3, 4 por ende en la mitad II y en el total, los resultados totales sugieren un desorden atencional, el cual es consistente con el grupo de personas diagnosticadas con Trastorno por Déficit de Atención (TDAH), pues obtuvo un puntaje de -1.98 en el índice del rendimiento de la atención. .

Los resultados totales muestran un desempeño consistente con el grupo de personas diagnosticadas con TDAH, debido a los puntajes obtenidos ante una tarea de alta estimulación, cuartos III y IV, en la variable variabilidad de tiempo de respuesta.

Las variables de tiempo de respuesta, errores por comisión y omisión, se sitúan dentro de la norma en todos los momentos de la prueba, incluyendo el total. 


\section{CAPÍTULO VI: DISCUSIÓN}

El primer objetivo del presente estudio apuntaba a la descripción de los síntomas del TDAH y del Trastorno bipolar tipo II a lo largo de la vida del sujeto mediante la exploración de la anamnesis, mientras que el segundo objetivo se orientaba a la descripción de los síntomas neurocognitivos asociados a estos trastornos a través del análisis de los resultados en los tests psicométricos. Es así como se expondrá, en primer lugar, cómo la sintomatología clínica pasada y los síntomas experimentados en la actualidad corroboran el diagnóstico de dichos trastornos. Luego de esto, se describirá el perfil neuropsicológico del paciente como expresión de sus patologías.

Respecto a la descripción de los síntomas del TDAH, en la etapa de la infancia del evaluado pueden evidenciarse signos como la inatención, la hiperactividad y las conductas disruptivas presentes tanto en el área escolar como en su hogar. Si bien, según el DSM-5, estos síntomas son característicos de dicho trastorno, la información recabada es insuficiente para establecer un diagnóstico. Es por ello que se considerarán de mayor relevancia los datos obtenidos en las etapas de la adolescencia y la adultez.

En la adolescencia, los síntomas de inatención se expresaron principalmente a través de un bajo rendimiento académico; en la etapa escolar, el paciente repitió dos años académicos consecutivos y seguidamente fue trasladado de colegio. Asimismo, en la nueva escuela no llegó a concluir con sus estudios, aunque sí pudo culminar la secundaria por otros medios. Nuevamente, en la etapa universitaria no finalizó sus estudios por presentar dificultades con la autoridad y por un rendimiento insuficiente. Estos acontecimientos atañen directamente al estudio realizado por Barkley (2015), el cual indica que entre el 16 y $40 \%$ de personas con TDAH, repiten el año escolar, la minoría concluye estudios superiores y presentan menos años de estudios. Igualmente, el DSM-5 (2014); señala que estas personas presentan mayores dificultades en el desempeño académico y conductual.

Respecto a la expresión de la inatención en la adultez, esta es la sintomatología predominante y se evidencia principalmente en la falta de persistencia, la desorganización y el reducido esfuerzo mental ante actividades demandantes (Barkley, 2015). Todos estos síntomas se encuentran presentes y repercuten en el área familiar del evaluado, por ejemplo al evitar las actividades y reuniones escolares de sus hijos. También afectan el área social mediante la dificultad para mantener una conversación en temas que no son 
de su interés. Asimismo, estos síntomas de inatención han perjudicado al paciente en el ámbito laboral, esto se evidencia en la alta rotación de centros de trabajo que ha presentado debido a conflictos con los trabajadores, despidos o por encontrar su labor como monótona. Esto último se relaciona a lo expresado por Barkley (2015), quien señala que los constantes cambios de trabajo pueden deberse a los problemas de inatención presentes en las actividades demandadas por el centro laboral.

En cuanto a la sintomatología de la hiperactividad- impulsividad, en la adolescencia se expresaban a través de inquietud motora, mientras que en la adultez hay un claro predominio por parte de la sensación de inquietud interna; la necesidad de estar ocupado constantemente se encuentra presente en ambas etapas. A pesar de ello, en donde más se pueden apreciar la hiperactividad e impulsividad es en las repercusiones que estas generan. Según Barkley (2015) debido a la dificultad para inhibir conductas, regular emociones y la necesidad de búsqueda de sensaciones, son frecuentes conductas tales como el consumo de drogas, el inicio temprano de la vida sexual y el número elevado de accidentes físicos y de accidentes vehiculares. Adrián ha sido consumidor de diversas sustancias tóxicas (marihuana, cocaína, PBC) desde los 19 hasta aproximadamente los 32 años. Así también, su vida sexual inició a los 13 años y ha mantenido diversas parejas sexuales por cortos periodos de tiempo. Finalmente, ha presentado un alto número de lesiones físicas y accidentes automovilísticos (más de 30).

Por otro lado, el DSM-5 (2014) considera factores no específicos del trastorno pero que pueden apoyar al diagnóstico como la baja tolerancia a la frustración, la irritabilidad y la labilidad emocional. Tales particularidades también se observan en el paciente y repercuten de manera negativa en el ámbito familiar, generando conflictos y distanciamiento con los miembros de su familia, y en el ámbito social, debido los altercados y discusiones que suele presentar al no ser capaz de tolerar ciertas situaciones.

En concordancia con lo previamente señalado, diversos autores indican que la desregulación emocional, la planeación, y el autocontrol forman parte de las funciones ejecutivas y se encuentran comprometidas en el funcionamiento de las personas con TDAH (Barkley, 2012; Ardilla y Ostrosky, 2012; Duda, 2011). Por su parte, Barkley (2015) plantea el término de impulsividad emocional como síntoma central en las personas con TDAH. Este se expresa en impaciencia, baja tolerancia a la frustración, sobrerreacción e irritabilidad, características que responden a la dificultad para inhibir emociones que presentan las personas con dicho trastorno. Diversas investigaciones 
confirman la presencia de estas características (Barkley, Murphy y Fischer citados en Barkley, 2015; Surman et al., 2013; Skirrow y Asherson, 2013).

Como se puede apreciar, los síntomas de inatención, hiperactividadimpulsividad y las otras características que apoyan el diagnóstico como la irritabilidad, la baja tolerancia a la frustración y la labilidad emocional, han permanecido durante todas las etapas de su vida repercutiendo en distintos contextos. Por ejemplo, en la infancia se vio afectado el ámbito escolar; en la adolescencia, el académico y social; mientras que en la adultez, el social, laboral y familiar. En conclusión, la sintomatología hallada coincide con los criterios diagnósticos A, B, C, D y E del DSM-5. Dentro del listado de síntomas del criterio A, se puede observar que presenta un estilo predominantemente inatento, cumpliendo 5 síntomas necesarios para determinar el TDAH en la edad adulta. Finalmente, también se observan síntomas de hiperactividad, pero no son suficientes para su diagnóstico.

Ahora se analizará, la presencia de un trastorno bipolar tipo II mediante la revisión de la historia del paciente. Como se sabe, dicho trastorno se caracteriza por las fluctuaciones en el estado anímico, tanto episodios hipomaníacos como depresivos. Siguiendo los criterios del DSM- 5, es posible que a los 19 años el evaluado haya presentado su primer episodio hipomaniaco al experimentar un estado de ánimo elevado, más energía de la usual, disminución de la necesidad de dormir, incremento en las horas de trabajo y una sensación de mayor velocidad en sus ideas; situación que duró aproximadamente 2 semanas. Además, a pesar de los síntomas señalados, no se evidenció deterioro en su funcionamiento ni repercusiones negativas, por lo que se asocia preferentemente a un episodio hipomaniaco. Incluso en esta fase el paciente aún no consumía drogas. Por todo lo anteriormente expuesto, este episodio cumple con los criterios A, B, C, E, F del DSM-5.

Otro episodio relevante sucedió a los 23 años, luego una decepción amorosa el paciente experimentó fuertes sentimientos de tristeza que permanecieron dos semanas y estuvieron acompañados de abatimiento, reducción del apetito y disminución del disfrute de sus actividades de ocio. Si bien dichos síntomas podrían pertenecer a una fase depresiva mayor, no son suficientes para cumplir con los 5 síntomas requeridos por el criterio A del DSM-5.

Más adelante, en la adultez, exactamente a los 35 años, el paciente experimentó nuevamente un estado anímico atípico, en el cual percibió una energía inusual, caracterizada por una alta productividad en el área laboral, así como un aumento 
significativo del apetito. Igualmente, la velocidad de sus pensamientos se incrementó y la necesidad de dormir disminuyó. Este ritmo de actividad se mantuvo aproximadamente por 2 semanas. Esta etapa también cumple con los criterios A, B, C, D, E y F que lo califican como un episodio hipomaniaco.

El último episodio encontrado en la historia del paciente se desencadenó ante la carencia de estabilidad laboral. Experimentó una disminución del interés ante las actividades que el antes encontraba agradables, falta de energía, sentimientos de inutilidad y culpabilidad, ánimo deprimido, dificultades para conciliar el sueño y pensamientos de muerte. Según el DSM- 5, este episodio sí cumple con los criterios A, B, C para la fase depresiva mayor. Además, como Sevillá y Pastor (2009) refieren, el estado depresivo mayor se expresa mediante síntomas conductuales, cognitivos y emocionales - fisiológicos, condiciones que el paciente manifestó.

García-Blanco, et al. (2014), indica que los sucesos negativos, tales como fracasos o pérdidas, podría desatar un episodio depresivo, mientras que los episodios de euforia pueden estar precedidos de acontecimientos negativos o positivos. En el caso del evaluado, tanto el primer episodio en el que presenta síntomas depresivos pero no llega a cumplir los criterios para un diagnóstico, como en el episodio que cumple con las características de una depresión mayor, presentan un componente psicosocial como desencadenante (la decepción amorosa y la pérdida del empleo respectivamente). Por otro lado, en los episodios hipomaniacos no se logran identificar causas psicosociales precedentes relevantes.

Con el análisis de las características pertenecientes a los episodios anteriormente mencionados, se puede corroborar la presencia de un episodio de depresión mayor precedido de, al menos, un episodio hipomaniaco. De esta manera el evaluado califica con los criterios A, B, C y D para un trastorno bipolar tipo II.

Luego de haber analizado la sintomatología del paciente, es probable la existencia de ambas patologías, TDAH y trastorno bipolar tipo II, por ello se considera de importancia argumentar por qué las alteraciones emocionales que manifiesta el evaluado no son reductibles únicamente a una de ellas. Como se ha mencionado con anterioridad, el TDAH tiene como característica fluctuaciones en el estado emocional; sin embargo, estas solo se mantienen por un corto periodo de tiempo y son causadas por algún evento que lo amerite. Esta labilidad emocional se observa claramente a lo largo de la vida del paciente, de manera que su estado emocional con frecuencia varía ante los eventos que le generan estrés. En cambio, en un trastorno bipolar los síntomas depresivos 
y/o hipomaniacos tienen una mayor duración en el tiempo. Estos episodios de alteraciones significativas en su ánimo por periodos de larga duración también son distinguibles en la historia del paciente, donde existe aumento apreciable del estado basal (DSM-5, 2014). Finalmente, cabe resaltar que diversos estudios han encontrado una estrecha relación entre los síntomas de la bipolaridad y los del TDAH en adultos, sugiriendo descartar su comorbilidad una vez que se encuentra la presencia de uno de ellos. (Halmoy et al., 2010)

Sería útil contar con información por parte de los padres biológicos, pues ambos trastornos presentan una alta predisposición genética. Según Fernández et al. (2012), el TDAH puede ser causado por factores ambientales en un 20-30\% y explicado en un 70 a $80 \%$ por componentes genéticos, así en los estudios de familiares, con mellizos, indican una heredabilidad del 76\%. Roselli et al., (2010), también aseguran sólidas evidencias acerca de una alteración genética como principal causa del TDAH. Igualmente, para el trastorno bipolar, Barlow y Durand (2008) Halguin y Krauss (2008); García-Blanco et al., 2014, señalan que los mayores predictores de la enfermedad son las influencias genéticas, siendo altas las tasas de heradabilidad. A pesar de no contar con los antecedentes psiquiátricos familiares que expliquen la presencia de las patologías, sí se posee información de los descendientes del paciente. Debido a que uno de sus hijos cuenta con el diagnóstico del TDAH y trastorno bipolar, existe una mayor probabilidad de la existencia de ambas patologías en el evaluado.

Es importante resaltar que a pesar de que el paciente se encuentra medicado para el trastorno bipolar, aún se observan síntomas depresivos (no tener motivación para emprender nuevos proyectos laborales, sentimientos de incapacidad, culpabilidad, tristeza, sentimientos de desesperanza hacia el futuro, insatisfacción por la relación de pareja). A pesar que estos no califican como un episodio depresivo mayor, estos rasgos depresivos pueden ser consecuencia del trastorno bipolar, pues esta enfermedad es desestabilizadora y estresante y predispone a sufrir eventos trascendentes que repercuten de manera negativa, convirtiéndose en un factor de mantenimiento (Bender et al., 2010). Además, cabe añadir que el paciente hace 7 años no mantiene estabilidad laboral, lo cual podría relacionarse con lo mencionado por el DSM-5. Esta fuente indica que la velocidad del recobro funcional en los pacientes bipolares, tarda más tiempo que la recuperación de los síntomas, por ello es común observar mayores probabilidades de desempleo prolongado. Igualmente, estos síntomas podrían ser consecuencia de la presencia del TDAH, pues como se sabe, dicha patología trae consigo diversas repercusiones negativas 
que afectan su funcionamiento diario, las cuales podrían predisponer a una vulnerabilidad.

Una vez evidenciada la existencia de la comorbilidad entre ambas patologías, convendría pasar al segundo objetivo y realizar el análisis de los resultados en las pruebas neuropsicológicas. De esta manera se buscará determinar la existencia de alguna alteración a nivel cognitivo como producto de ellas para así hallar una relación entre el funcionamiento cerebral y la conducta (Tirapú et al., 2012).

Para empezar se tomarán los resultados de la Evaluación Neuropsicológica Breve en Español- NEUROPSI, la cual mide el funcionamiento neuropsicológico de manera general. El desempeño del evaluado se caracteriza por un rendimiento normal promedio, manteniendo puntuaciones promedio en las áreas de orientación, atención y concentración, lenguaje, memoria, funciones ejecutivas, lectura, escritura y cálculo. Sumado a esto, Adler et al. (2015) incluye al coeficiente intelectual como elemento trascendente para explicar el funcionamiento cognitivo de un individuo. En esta línea, los resultados obtenidos según la Escala de Inteligencia de Wechsler WAIS- IV indican un coeficiente intelectual general perteneciente al rango promedio alto.

Debido a que los resultados generales del funcionamiento neuropsicológico y del coeficiente intelectual muestran un rendimiento sin alteración, convendría profundizar en el análisis de las pruebas que midan a mayor detalle las funciones ejecutivas, la memoria y la atención, funciones neuropsicológicas que frecuentemente se encuentran afectadas en el TDAH y en el trastorno bipolar. En las personas con TDAH, se suelen observar alteraciones en el control inhibitorio, la memoria de trabajo y la variabilidad de tiempo de respuesta en pruebas de rendimiento continuo, entre otros (Adler et al., 2015; Rohlf et al., 2012; Bramham et al., 2012; Barkley y Murphy, 2011). Mientras que para el trastorno bipolar, las funciones ejecutivas, la memoria verbal, la atención y la velocidad psicomotora, son las que normalmente evidencian un mayor déficit. (Mora et al., 2013; Nehra et al., 2014).

En cuanto a la evaluación de los procesos mnésicos, mediante la Escala de Memoria de Wechsler WMS- IV, el desempeño del evaluado se sitúa dentro de la normalidad para la memoria auditiva, la visual, la de trabajo visual y la inmediata. De igual manera, al evaluar las funciones ejecutivas mediante la Batería Neuropsicológica de Funciones Ejecutivas y Lóbulos Frontales (BANFE-2), los resultados indican rendimiento sin alteración para la corteza orbitofrontal (COF), corteza prefrontal medial (CPFM), corteza prefrontal dorsolateral (CPFDL) y la corteza prefrontal anterior 
(CPFA). Estos hallazgos muestran un adecuado funcionamiento para el control inhibitorio, memoria de trabajo visual y verbal.

Por otro lado, los resultados del evaluado según el Test of Variables of Attention (TOVA), prueba de rendimiento continuo, señalan que su desempeño es compatible con el rendimiento de personas diagnosticadas con TDAH, ya que la variabilidad de tiempo de respuesta se encuentra disminuida significativamente. Esto concuerda con los hallazgos que señalan que las personas con TDAH suelen tener dificultades para mantener la atención ante tareas de rendimiento continuo visual (Adler et al., 2015) y que la alteración en la variabilidad del tiempo de respuesta en este tipo de pruebas es una característica usual en personas con dicha patología (González-Gadea, 2013).

En conjunto se puede observar que el paciente mantiene un rendimiento neurocognitivo dentro del rango de la normalidad, según su grupo etario y grado de instrucción, para pruebas de inteligencia, memoria y funciones ejecutivas. Sin embargo, se halló una disminución en sus canales atencionales, específicamente reflejados en una variabilidad de tiempo en sus respuestas. Esto puede encontrar sentido en lo expuesto Barkley y Murphy (2011), quienes mencionaron que en realidad es la minoría de personas con TDAH reflejan alteración en las pruebas de funciones ejecutivas; no obstante, en el funcionamiento de la vida diaria es donde se evidencia dificultades en las funciones ejecutivas. Además, como se mencionó con anterioridad, la variabilidad de tiempo de respuesta suele verse afectada (Adler et al., 2015), como es en el caso de estudio. Además es importante añadir los efectos colaterales de la medicación; Solé et al. (2012) indican que la administración prolongada de benzodiacepinas, pueden producir disfunciones atencionales.

Con respecto al trastorno bipolar, si bien diversos autores (Mora et al., 2013; Nehra et al., 2014) afirman la existencia de alteraciones en las funciones ejecutivas, memoria visual-verbal, velocidad psicomotora, concentración, habilidades grafomotoras e inhibición, otros indican que existen diversas variables que pueden afectar el rendimiento neurocognitivo en un paciente con bipolaridad (Latalova, et al., 2011). Dichas variables incluyen, los años de inicio de la enfermedad, los tratamientos farmacológicos, las respuestas individuales y las características clínicas. Es probable que este sea el caso del evaluado, quien mantiene un rendimiento neurocognitivo dentro de la normalidad. Debido a la reducida cantidad de episodios hipomaniacos y depresivos experimentados es probable que estos no le hayan generado un deterioro notable. Otro 
factor explicativo sería el hecho de haberse encontrado bajo medicación durante la etapa de evaluación.

Finalmente, tanto para el TDAH como para el trastorno bipolar, según los resultados neuropsicológicos, no se muestran alteraciones significativas en el funcionamiento del lóbulo frontal; sin embargo, en el ejercicio diario del evaluado si hallan síntomas correspondientes a una alteración en las funciones ejecutivas. Esta condición podría estar fundamentada en la reducida validez ecológica que presentan las pruebas neuropsicológicas (Bombin et al., 2014), en las cuales no se evidencia correspondencia de los resultados de las pruebas psicométricas con la realidad clínica, a excepción de la atención sostenida.

Después de haber identificado los síntomas clínicos/neuropsicológicos en el evaluado y respondiendo al quinto objetivo específico, sería relevante proponer un plan de intervención en base a las dificultades emocionales encontradas. Asimismo, la ausencia de un deterioro cognitivo, permite una intervención psicoterapéutica.

Luego de la revisión teórica acerca del tratamiento en ambas patologías, se considera imprescindible que su abordaje mediante psicofármacos, pues, como se sabe, sus etiologías corresponden a un nivel biológico (Barkley, 2014; García-Blanco et al., 2014). Si bien el examinado ya se encuentra siguiendo un tratamiento farmacológico para el trastorno bipolar, no sigue uno para el trastorno por déficit de atención. De la misma manera, se considera de gran importancia un tratamiento psicoterapéutico para tratar los síntomas de los trastornos que no pueden ser tratados con la medicación (Belloso, 2012; Hunsley et al., 2014; Lolich et al., 2012; Miklowitz, 2013).

Los síntomas que aún permanecen en el paciente y se han observado a lo largo de su historia son la irritabilidad, la impulsividad, la dificultad para la organización y la inatención. Asimismo, a pesar de estar medicado para el trastorno del ánimo, aún se observan síntomas depresivos en la actualidad que podrían ser producto de las consecuencias de tener un cuadro comórbido sin tratamiento previo y/o por la constante necesidad de saber su origen (recordar que el paciente fue adoptado y en la adultez fue cuando tomó conocimiento). Por lo tanto, luego de haber revisado los métodos más utilizados y eficaces para ambas patologías, se considera, en primer lugar que la psicoeducación es de vital importancia para el abordaje tanto del TDAH como para el trastorno bipolar. Esto implicaría ofrecer tanto al paciente como a su familia información sobre la enfermedad (prevalencia mundial, etiología, características clínica, tipos de 
tratamiento y pronóstico), sobre la importancia de la adherencia al tratamiento (farmacológico y terapéutico) y entrenamiento en la detección y manejo de los síntomas.

Mientras que para el abordaje del TDAH y la sintomatología depresiva que aún persiste, se propone la terapia cognitivo como enfoque terapéutico. Las características de esta intervención están detallas por síntomas, objetivos y técnicas en anexo número 5. 
- Los síntomas predominantes del TDAH a lo largo de la vida del evaluado son la inatención, hiperactividad-impulsividad; asimismo, las características que apoyan el diagnóstico y que se encuentran presentes a lo largo de su vida y que a su vez han repercutido en diferentes contextos son: la irritabilidad, la baja tolerancia a la frustración y la labilidad emocional. En la infancia influyó en el ámbito escolar, en la adolescencia, el académico y social y finalmente en la adultez, en el social, laboral y familiar.

- En cuanto al trastorno bipolar, se ha encontrado un episodio depresivo mayor y al menos un episodio hipomaniaco; no obstante, existen otros episodios que reflejan también sintomatología depresiva e hipomaniaca; sin embargo, al contar con insuficientes datos de la historia, no pueden ser catalogados como tales. Pese a ello, los episodios antes corroborados, si indicarían la presencia de un trastorno bipolar II.

- La existencia de la comorbilidad se basa en la presencia de episodios afectivos marcados desde la adolescencia (hipomanía, depresión), en los que su estado base se ha visto alterado de manera significativa a pesar de mantener conductas hiperactivas y labilidad emocional en la adolescencia por el TDAH.

- El factor de heredabilidad genética es un aspecto presente en ambas patologías; sin embargo, el paciente no cuenta con antecedentes familiares psiquiátricos, por lo tanto predispone una limitación para confirmar su diagnóstico; pese a ello, se toman en cuenta los diagnósticos presentes en uno de sus hijos, TDAH y trastorno bipolar, como aspecto relevante para elevar la probabilidad del diagnóstico.

- Luego de analizar la sintomatología de ambas patologías, es importante añadir que en la actualidad el paciente se encuentra medicado, pero aún permanecen síntomas depresivos que no califican como un episodio depresivo mayor. Este hecho es consecuencia de la recuperación funcional tardía del trastorno bipolar, dentro la presencia del TDAH como patología que afecta el funcionamiento diario y predispone a una vulnerabilidad.

- Los resultados de las pruebas neuropsicológicas muestran que tanto el coeficiente global, las funciones ejecutivas y los procesos mnésicos, se caracterizan por un rendimiento promedio con tendencias altas. Sin embargo, la atención sostenida se encuentra afectada de manera significativa. Esta última condición podría ser parte del cuadro del TDAH, trastorno bipolar y/o ser parte de los efectos secundarios de las benzodiacepinas. 
- Los resultados de las pruebas neuropsicológicas no identifican alteraciones que afecten su desempeño; de acuerdo con las investigaciones presentadas para el TDAH y trastorno bipolar, esta condición sugeriría una reducida validez ecológica y/o la sintomatología medida con las pruebas neuropsicológicas reflejarían una mejora con la edad.

- Finalmente, al no evidenciarse alteraciones cognitivas significativas que puedan influir sobre el tratamiento psicológico, se propone un plan de intervención de orientación cognitivo conductual, específicamente para tratar los síntomas del TDAH y los síntomas depresivos. 
- Luego de explorar los síntomas neurocognitivos, sería recomendable una evaluación psicológica integral que abarque los síntomas emocionales que aquejan en la actualidad al examinado, ya que la presente investigación no tuvo como objetivo la evaluación de aquella área.

- Por otro lado, los datos encontrados en la anamnesis sí indican síntomas depresivos propios a un ánimo disfórico, así como sintomatología del TDAH, los cuales afectan su desenvolvimiento en el área social, laboral y familiar. Por lo tanto se recomienda un plan terapéutico con orientación cognitivo conductual que aborden dichos síntomas, así como psicoeducación para el paciente y la familia para el trastorno bipolar.

- Para próximas evaluaciones neuropsicológicas y en búsqueda de resultados más fiables, se recomienda la utilización de pruebas que posean una alta correspondencia con la realidad del sujeto; es decir, que posean un nivel adecuado de validez ecológica. 


\section{REFERENCIAS}

Adler, L., Spencer, T., \& Wilens, T. (2015). Attention-Deficit Hyperactivity Disorder in Adults and Children. United Kingdom: Cambridge University Press.

American Psychiatric Association. (2014). Manual Diagnóstico y Estadístico de los Trastornos Mentales ( $5^{\text {ta }}$ edición). Barcelona: Masson.

Ardila, A., y Ostrosky, F. (2012). Guía para el diagnóstico Neuropsicológico. Recuperado de http://www.ineuro.cucba.udg.mx/libros/bv_guia_para_el_diagnostico_ neuropsicologico.pdf

Ardila, A., y Roselli, M. (2007). Neuropsicología clínica. Recuperado de: https://books.google.com.pe/books?hl=es\&lr\&id=mT3HCQAAQBAJ\&oi=fnd\& $\mathrm{pg}=\mathrm{PP} 1 \& \mathrm{dq}=$ importancia+neuropsicolog $\% \mathrm{C} 3 \% \mathrm{ADa} \&$ ots $=\mathrm{xFAGA} 4 \mathrm{mrJ} 4 \& \operatorname{sig}=$ 17UVbohCPeMVHr9kScN73rMPvAQ\#v=onepage\&q=importancia\%20neurops icolog $\% \mathrm{C} 3 \% \mathrm{ADa} \& \mathrm{f}=$ false

Ary, D., Jacobs, L. C., Razavieh, A., \& Sorensen, C. (2009). Introduction to research in education. Belmont, CA: Wadsworth.

Barkley, R. A. (2012). Distinguishing sluggish cognitive tempo from attentiondeficit/hyperactivity disorder in adults. Journal of Abnormal Psychology, 121(4), 978-990. doi: 10. 1037/a0023961

Barkley, R. A. (2015). Attention-Deficit Hyperactivity Disorder a Handbook for Diagnosis and Treatment. New York: Guilford.

Barkley, R. A., \& Murphy, K. R. (2011). The Nature of Executive Function (EF) Deficits in Daily Life Activities in Adults with ADHD and Their Relationship to Performance on EF Tests. Journal of Psychopathology and Behavioral Assessment, 33, 137-158. doi: 10.1007/s10862-011-9217-x

Barlow, D. H., y Durand, M. (2008). Psicopatología. España: Paraninfo.

Belloso, J. J. (2012). Intervención psicoterapéutica en el trastorno mental grave. Clínica Contemporánea, 3(1), 3-23. http://dx.doi.org/10.5093/cc2012a1

Bender, R. E., Alloy L. B., Sylvia, L. G., Urosevic, S., \& Abramson, L. Y. (2010). Generation of life events in bipolar spectrum disorders: A re-examination and extension of the stress generation theory. Journal of Clinical Psychology. 66(9), 907-926. doi: 10.1002/jclp.20705 
Bombin, I., Cifuentes, A., Climent, G., Luna, P., Cardas, J., Tirapu, J., y Diaz, U. (2014). Validez ecológica y entornos multitareas en la evaluación de las funciones ejecutivas. Revista de Neurología, 59(2), 77-87. Recuperado de http://www.revneurol.com/sec/resumen.php?i=e\&id=2013578

Bramham, J., Murphy, D. G. M., Xenitidis, K., Asherson, P., Hopkin, G., \& Young, S. (2012). Adults with attention deficit hyperactivity disorder: an investigation of age-related differences in behavioural symptoms, neuropsychological function and co-morbidity. Psychological Medicine, 42, 2225-2234. doi: $10.1017 /$ S0033291712000219

Brown, T. E. (2005). Attention Deficit Disorder: The unfocused Mind in Children and Adults. New Heaven: Yale University Press Health \& Wellness.

Caballo, V. E., Salazar, I. C., y Carrobles, J. (2011). Manual de psicopatología y trastornos psicológicos. Madrid: Pirámide.

Chaytor, N., Schmitter-Edgecombe, M., \& Burr, R. (2006). Improving the ecological validity of executive functioning assessment. Archives of Clinical Neuropsychology, 21, 217-227. doi: 10.1016/j.acn.2005.12.002

Chevassus, H., Farret. A., Gagnol, J., Poncon, C., Costa, F., Roux, C.,...Petit, P. (2013). Pyschological an physiological effects of bupropion compared to methylphenidate ater prolonged administration in healthy volunteers. European Journal of Clinical Pharmacology, 69, 779-787. doi: 10.1007/s00228-012-1418$\mathrm{Z}$

Davey, G. (2008). Psychopathology: Research, Assessment and Treatment in Clinical Psychology. United Kingdom: BPS Blackwell.

Doyle, B. B. (2006). Understanding and treating adults with Attention Deficit Hyperactivity Disorder. Washington, DC: American Psychiatric Publishing.

Duda, B. (2011). El coaching para el TDAH. Lima: Asociación Peruana de Déficit de Atención (APDA).

Fernández, A., Fernández, M., Calleja, B., Muñoz, N., y López, S. (2012). Endofenotipos genómicos del trastorno por déficit de atención/hiperactividad. Revista de Neurología, 54(1), 81-87. Recuperado de http://dialnet.unirioja.es/servlet/articulo?codigo $=4241726$.

Fitzgerald, M., Bellgrove, M., \& Gill, M. (2007). Handbook of Attention Deficit Hyperactivity Disorder. England: Wiley. 
Flores, J., Ostrosky F., y Lozano, A (2014). BANFE: Batería Neuropsicológica de Funciones Ejecutivas y Lóbulos Frontales. México: Manual Moderno.

García, A., Tirapú, J., y Roig, T. (2007). Validez ecológica en la exploración de las funciones ejecutivas. Anales de Psicología 23(2), 289-299. Recuperado de http://www.redalyc.org/articulo.oa?id=16723216

García-Blanco, A. C., Sierra, P., y Livianos, L. (2014). Nosología, epidemiologia y etiopatogenia del trastorno bipolar: Ultimas aproximaciones. Psiquiatría Biológica, 21(3), 89-94. http://dx.doi.org/10.1016/j.psiq.2014.07.004

González-Gadea, M., Baez, S., Torralva, T., Castellanos, F., Ratazzi, A., Bein, V., Ibanez, A. (2013). Cognitive variability in adults with ADHD and AS: disentangling the roles of executive functions and social cognition. Research in Developmental Disabilities, 34(2), 817-830. doi: 10.1016/j.ridd.2012.11.009

Grupo de Trabajo de la Guía Práctica Clínica sobre Trastorno Bipolar. (2012). Guía de Práctica Clínica sobre Trastorno Bipolar. Madrid: Asociación Española de Neuropsiquiatría.

Halguin, R., y Krauss, S. (2008). Psicología de la anormalidad. México: Mc Graw Hill. Halmoy, A., Halleland, H., Dramsdahl, M., Bergsholm, P., Bernt, O., \& Haavik, J. (2010). Bipolar Symptoms in Adult Attention-Deficit/Hyperactivity Disorder: A Cross- Sectional Study of 510 clinically diagnosed patients and 417 populationbased controls. Journal of Clinical Psychiatry, 71(1), 48-57. doi: 10.4088/JCP.08m04722ora

Hunsley, J., Elliott, K., \& Therrien, Z. (2014). The efficacy and effectiveness of psychological treatments for mood, anxiety and related disorders. Canadian Psychology, 55(3), 161-176. http://dx.doi.org/10.1037/a0036933

Instituto Nacional de Salud (2012). Prevalencia de vida y edad de inicio de los trastornos psiquiátricos en el Perú urbano: Estudio epidemiológico en ciudades de la costa sierra y selva del Perú. Perú: Ministerio de Salud.

Jarne, A., Talarn, A., Armayones, M., y Horta, E. (2006). Psicopatología. Barcelona: UOC

Klassen, L. J., Katzman, M. A., \& Chokka, P. (2010). Adult ADHD and its comorbidility, with a focus on bipolar disorder. Journal of Affective Disorders, 124, 1-8. doi: 10.1016/j.jad.2009.06.036 
Latalova, K., Prasko, J.,Diveky, T., \& Velartova, H. (2011). Cognitive impairment in bipolar disorder. Biomed Pap Med Fac Univ Palacky Olomouc Czech Repub, 155(1), 19-26. doi: 10.5507/bp.155.2011.003

Lavigne, R., y Romero, J. (2010). El TDAH. Madrid: Pirámide.

Levent, N., Tümkaya, S., Ateşçi, F., Üysüzoğlu, H., Varma, G., \& Oğuzhanoğlu, N. (2014). A Neuropsychological Comparison of Bipolar Disorder and Adult Attention Deficit Hyperactivity Disorder. Turkish Journal of Psychiatry, 25(1), 1 8. Recuperado de http://www.turkpsikiyatri.com/en/default.aspx ?modul= article\&id $=920$

Lezak, M., Howieson, D., \& Loring, D. (2004). Neuropsychological Assessment. New York: Oxford University Press.

Lolich, M., Vásquez, G. H., Álvarez, L. M., y Tamayo, J. M. (2012). Intervenciones psicosociales en el trastorno bipolar: una revisión. Actas Españolas de Psiqiatría, 40(2), 84-92. http://www.actaspsiquiatria.es/repositorio/14/76/ESP/14-76-ESP84-92-211350.pdf

López, C.S. (2011). Trastorno Bipolar y Deterioro Cognitivo (Trabajo de especialización). Universidad de la Plata.

Michelini, G., Kitsune, L., Hosang, M., Asherson, P., McLoughlin, G., \& Kuntsi, J. (2016) Disorder-specific and share neurophysiological impairments of attention and inhibition un women with attention-deficit/hyperactivity disorder and women with bipolar disorder. Psychological Medicine, 46, 493-504. doi: $10.1017 /$ S0033291715001877

Miklowitz, D. J. (2010). Tratamiento coadyuvante para el trastorno bipolar: actualización de las evidencias. Revista de Toxicomanías, 59, 3-17. Recuperado de http://www.cat-barcelona.com/uploads/rets/Ret59_1.pdf

Mora, E., Portella, M.J., Forcada, I., Vieta, E., \& Mur, M. (2013). Persistence of cognitive impairment and its negative impact on psychosocial functioning in lithiumtreated, euthymic bipolar patients: a 6-year follow-up study. Psychological Medicine, 43, 1187-1196. doi: 10.1017/S0033291712001948

Nehra, R., Grover, S., Sharma, S., Sharma, A., \& Sarkar, S. (2014). Neuro-cognitive functioning in unaffected siblings of patients with bipolar disorder: Comparison with bipolar patients and healthy controls. Indian Journal of Psychiatry 56(3), 283-288. doi: 10.4103/0019-5545.140645

Ortuño, F. (2010). Lecciones de Psiquiatría. España: Editorial Medica Panamericana. 
Pachet, A. K., \& Wisniewski, A. M. (2003). The effects of lithium on cognition: an update review. Psychopharmaclogy, 170, 225-234. doi: 19.1007/s00213-003-1592-x

Pérez, C., y Vásquez, C. (2012). Contribución de la neuropsicología al diagnóstico de enfermedades neuropsiquiátricas. Revista Médica Clínica Las Conde, 23(5) 530541. http://www.sciencedirect.com/science/article/pii/S0716864012703474

Polanczyk, G., De Lima, M.S., Horta, B.L., Biederman, J., \& Rohde., L.A. (2007). The worldwide prevalence of ADHD: A systematic review and meta regression analysis. The American Journal of Psychiatry, 164(6), 942-948. Recuperado de http://ajp.psychiatryonline.org/doi/10.1176/ajp.2007.164.6.942

Quintero, J., Balanzá-Martínez, V., Correas, J. y Soler, B. (2013). Trastorno por Déficit de Atención con Hiperactividad (TDAH) en el paciente adulto: visión del clínico. Servicio de Psiquiatria Hospital Universitario Infanta Leonor. Actas Españolas de Psiquiatría, 41(3), 185-195. Recuperado de http://actaspsiquiatria.es/repositorio/15/83/ESP/15-83-ESP-185-195-476628.pdf

Rohlf, H., Jucksch, V., Gawrilow, C., Huss, H., Hein, J., Lehmkuhl, U., \& SalbachAndrae, H. (2012). Set shifting and working memory in adults with attentiondeficit/hyperactivity disorder. Journal of Neural Transmission, 119, 95-106. doi: 10.1007/s00702-011-0660-3

Roselli, M., Matute, E., y Ardila, A. (2010). Neuropsicología del desarrollo infantil. México: Manual Moderno.

Roussos, A. J. (2007). El diseño de caso único en investigación en psicología clínica. Un vínculo entre la investigación y la práctica clínica. Revista Argentina de Clínica Psicológica, 16(3), 261-270. Recuperado de http://www.redalyc.org/pdf/2819/281921790006.pdf

Ruiz, M., Díaz, M., y Villalobos, A. (2012). Manual de Técnicas de Intervención Cognitivo Conductuales. Bilbao: Desclée De Brouwer.

Semrud, M., y Teeter, P. (2011). Neuropsicología infantil. Madrid: Pearson Educación. Sevillá, J., y Pastor, C. (2009). Terapia cognitivo-conductual para el trastorno bipolar. Un manual práctico para el terapeuta. España: Centro de terapia de conducta.

Skirrow,C., y Asherson, P. (2013). Labilidad emocional, comorbilidades y discapacidad en adultos con TDAH. Journal of Affective Disorders, 147(1-3), 80-86. http://dx.doi.org/10.1016/j.jad.2012.10.011 
Solé, B., Martínez, A., y Vieta, E. (2012). Trastorno bipolar y alteraciones cognitivas. Mente y Cerebro, 56, 34-40. Recuperado de http://www.investigacionyciencia.es/ revistas/mente-y-cerebro/numero/56

Stahl, S., \& Mignon, L. (2011). Stahl's Illustrated Attention Deficit Hyperactivity Disorder. New York: Cambridge University Press.

Surman, B. H., Biederman, J., Spencer, T., Miller, C. A., McDermott, K. M., Faraone, S. V. Understanding deficient emotional self-regulation in adults with attention deficit hyperactivity disorder: a controlled study. ADHD Attention Deficit and Hyperactivity Disorders, 5(3), 273-281. doi: 10.1007/s12402-0120100-8

Tirapu, J., Garcia, A., Ríos, M., y Ardila, A. (2012). Neuropsicología de la corteza prefrontal y las funciones ejecutivas. Barcelona: Viguera.

Tirapú, J., y Muñoz, J. (2004). Neurociencia, neuropsicología y psicología clínica: Necesidad de un encuentro. Revista Psicología.com. Recuperado de: http://www.psiquiatria.com/revistas/index.php/psicologiacom/article/viewFile/7 $81 / 755 /$

Torralva, T., Gleichgerrcht, E., Torrente, F., Roca, M., Strejilevich, S. A., Cetkovich, M., Lischinsky, A., \& Manes, F. (2011). Neuropsychological functioning in adult bipolar disorder and ADHD patients: A comparative study. Psychiatry Research, 186, 261-266. doi: 10.1016/j.psychres.2010.08.007

Velásquez, E., Ordoñez, C. (2014). Trastorno por uso de sustancias y trastorno por deficit de atencion e hiperactividad: frecuencia en pacientes varones hospitalizados en un servicio de adicciones. Revista de Neuropsiquiatria, 78 (2). Recuperado de: http://www.scielo.org.pe/scielo.php?pid=S003485972015000200003\&script=sci arttext.

Vidal, Bosch, Nogueira, Casas y Ramos (2012). Tratamiento psicológico del trastorno por déficit de atención con hiperactividad en adultos: revisión sistemática. Actas Españolas de Psiquiatría, 40(3), 147-154. http://www.actaspsiquiatria.es/repositorio/14/77/ESP/14-77-ESP-147-154796079.pdf

Wechsler, D. (2012). WAIS-IV. Escala de Inteligencia de Wechsler para adultos. Madrid: Pearson Educación.

Wechsler, D. (2013). WMS-IV. Escala de Memoria de Wechsler. Madrid: Pearson Educación. 
ANEXOS 


\section{ANEXO 1: Anamnesis}

\section{DATOS DE FILIACIÓN}

1. Nombres y Apellido

2. Sexo

3. Edad

4. Lugar y fecha de nacimiento

5. Tiempo de residencia en Lima

6. Estado civil

7. Grado de instrucción

8. Ocupación actual

9. Religión

10. Idiomas

11. Con quién(es) vive

12. Número de hijos

13. Número de hermanos

14. Dirección

15. Fechas de las entrevistas
: A.A.I

: Masculino

: 49 años

: Buenos Aires, 2 de noviembre de 1965

: Desde las dos semanas de nacido

: Casado

: Superior incompleta (Administración, primer ciclo)

: Rentista (vive de rentas)

: Judía (no practicante), esposa e hijos católicos

: Inglés/ Hebreo/ Castellano

: Esposa e hijos

: 3 hijos

: No conoce

: Surco

: 29/04/2015, 13/05/2015, 22/05/2015, 10/06/2015, 17/06/2015, 23/06/2015, $25 / 06 / 2015$ y $8 / 07 / 2015$.

\section{DESCRIPCIÓN FÍSICA Y CONDUCTUAL DEL PACIENTE}

A es un varón de 49 años de edad y su apariencia guardan relación con dicha edad. $\mathrm{Su}$ estatura se encuentra en un aproximado de 1.95 metros y su contextura es normal promedio. Es de tez blanca, cabello marrón oscuro y ojos marrones. Su vestimenta fue casual, vistió todas las sesiones con jean y casacas y chompas diversas. Asimismo, evidenció un aspecto aseado, en el que se pudo observar y percibir ropa limpia y olores a diversas fragancias. 
Además, se presentó de manera puntual a todas las sesiones y demostró compromiso con la evaluadora puesto que cumplió con las citas acordadas; no obstante, avisó con anticipación las fechas que no estaría en Lima para reprogramar las citas.

A lo largo de las sesiones la actitud demostrada por el evaluado fue amable y colaboradora.

Estas características se pudieron observar en la disposición abierta que tuvo para relatar su historia personal a detalle y la actitud hacia las pruebas asignadas; indicó que recordar algunos hechos le traía buenos recuerdos. "A" mantuvo un contacto visual adecuado con la evaluadora; sin embargo, al relatar su historia personal tendía a mirar la pared contigua cuando trataba de recordar datos específicos y fechas. En la ejecución de las actividades, cuando debía concentrarse para dar un resultado también dirigía la mirada hacia un punto fijo. Además su postura corporal fue relajada y ligeramente encorvada y la mayor parte del tiempo mantuvo las piernas cruzadas y ocasionalmente se reacomodaba en el asiento. Su tono de voz es grueso y con volumen alto, su expresión verbal fue fluida, adecuada en su articulación y contenido y la comprensión se halló conservada tanto para temas sencillos como complejos.

En la evaluación del Test of Variables of Attention (T.O.V.A), al indicarle las instrucciones y el tiempo que demandaría la prueba exclamó “¡Asu tanto tiempo!, me voy a aburrir apretando el botoncito, pero bueno, caballero!"; asimismo, en la batería neuropsicológica de las de funciones ejecutivas y lóbulos frontales (BANFE-2) específicamente en el subtest de e Clasificación de Tarjetas, al ser una prueba en la que no se pueden brindar instrucciones específicas, el evaluado manifestó lo siguiente: "no entiendo de qué se trata esto, trato de hacerlo como me parece pero no me sale, ya me estoy cansando” y al terminó de la prueba: “¡Por fin se acabó esta cosa, ya me había aburrido!". Igualmente en la evaluación del coeficiente intelectual, en el subtest de aritmética indicó: "uy matemáticas, nunca me gustaron, que aburrido pero bueno..."

\section{PROBLEMA ACTUAL}

\subsection{MOTIVO DE CONSULTA:}

El examinado asiste a consulta porque refiere experimentar cansancio y abatimiento para iniciar proyectos laborales, ya que no mantiene un trabajo hace 7 años. Al recordar que no labora o al tener tiempo libre en casa, se le presentan las ideas tales como: "soy 
un bueno para nada", "no tengo fuerzas para volver a comenzar y para creer en mí", "soy un fracaso", "no acabo con lo que empiezo", "no sé qué hacer con mi tiempo libre", "mis hijos no tienen el mejor ejemplo", "ya trabaje de todo hace algunos años, ya no estoy para eso", "no sé qué pasará de acá a unos años", "necesitaría de alguien para comenzar, pero no se quien querrá invertir", "la situación del país cada vez está peor, no sé si será bueno invertir", "no tengo idea por donde comenzar". En esos momentos siente tristeza, frustración y falta de motivación y recurre a fumar un cigarrillo o ver televisión. Esto ocurre aproximadamente dos veces por semana con una intensidad de 7/10, alrededor de hace 6 años. Ante esta situación, incrementa su tristeza y su sentimiento de inutilidad. Cabe resaltar que desde que toma la medicación para el tratamiento de la bipolaridad (Litio, bupropion, benzodiacepinas), estas situaciones aún se siguen repitiendo; sin embargo, presenta mayor energía para realizar actividades del hogar, pero al realizarlas y no obtener los resultados que quisiera, experimenta dificultades para manejar su molestia.

Además, comenta dificultad para expresar ira y rabia, cada vez que sus hijos no lo obedecen, cuando juega con su hijo menor y él pierde, al manejar su vehículo y se interponen en su camino o le tocan la bocina, cuando realiza actividades en su casa como cocinar, pintar, arreglar gasfitería y no obtiene los resultados que él quisiera. En esos momentos experimenta cólera intensa, afirmando: "es como si la sangre me hirviera", "como si viniera un maretazo, pero viene con todo", estas emociones se acompañan de tensión muscular, sudoración e ideas como "mis hijos no hacen las cosas como deberían, no se dejan ayudar" "en lima manejan puros idiotas", cuando arregla elementos de la casa piensa "soy un idiota, un estúpido". En esas situaciones, grita a sus hijos, los critica, si está jugando con alguno de ellos deja de jugar, al conducir, baja del carro a enfrentarse con el otro conductor y en algunas ocasiones ha llegado a los golpes. En la casa al realizar las actividades las tira al suelo o las arroja a la basura. Luego de ello, fuma un cigarro y como consecuencia indica: "me malogra todo el día", y reconoce que su impulsividad e irritabilidad genera conflicto y distanciamiento en la relación con sus tres hijos y esposa, ya que al dirigirse a los demás lo hace de una forma muy directa llegando a herirlos verbalmente, lo cual le genera conflictos en casa. Estas situaciones están presentes desde que el evaluado recuerda, pero hace aproximadamente 5 años indica que tales conductas se han vuelto más recurrentes con una intensidad de 7/10. Por otro lado, indica que su esposa e hijos dicen verlo "mejor", después del tratamiento, pues antes pasaba la mayor parte del tiempo en cama y evitaba conversar con las personas mientras que en la 
actualidad se muestra dispuesto "a todo", afirmando: "tengo más ganas de conversar, hacer cosas, pero no sé qué, algunas veces hago los quehaceres de la casa". En el área social, Adrián refiere que tiene mayores deseos de salir, por ejemplo, todos los miércoles se junta con un grupo de personas aficionados a las motos y con ellos organizan viajes dentro del país.

Además, indica que desde hace aproximadamente 2 años, tiene dificultades en la relación de pareja afirmando "somos buenos padres, pero no esposos". "A" comenta que no comparten actividades que involucren a ambos, la comunicación que existe entre ellos solo se reduce a temas con respecto a sus hijos, por tales razones, Adrián ya le comunicó a su esposa su insatisfacción. Si bien manifiesta esta dificultad, añade, que la relación es muy lineal, no pelean, "yo si quisiera esos altos y bajos, peleas para reconciliarme, es bonito pelear", "Nunca nos peleamos, sí hay discusiones por desacuerdos pero muy rápido lo arreglamos". No obstante, no mantienen relaciones sexuales con frecuencia, el periodo más largo si mantener una relación sexual fue de cuatro meses, "no hay momento para nosotros y en la casa no podemos tener sexo porque están los chicos”. Él considera que sólo son pretextos por parte de su esposa, lo cual le genera una cólera de 7/10. En esas situaciones, en las que la esposa no desea tener relaciones sexuales, el evaluado se ofusca y tiene pensamientos como: "me voy a ir de la casa", "ya no aguanto esta situación", "me quiero divorciar", y lo que hace seguidamente es salir a la calle a tomar una cerveza.

\subsection{DESARROLLO CRONOLÓGICO:}

Con respecto al trastorno bipolar, Adrián indica que a los 19 años en kibutz (En Israel, colonias agrícolas de producción y consumo comunitarias) por 2 semanas aproximadamente durmió 3 horas y trabajaba haciendo "de todo". Además afirma que decidió irse de Perú para vivir solo y "hacerse hombre", comenta que durante esa etapa sintió un ánimo elevado el cual se caracterizó por sentir más energía de la usual sin necesidad de dormir, su horario de trabajo era el siguiente: trabajaba como guardián de 7 pm a 7 am, luego tenia clases de 8 a 1pm, dormía 3 horas y luego se reincorporaba a su trabajo de guardián nuevamente. Además, recuerda que sus pensamientos parecían ser "más rápidos" que lo convencional, pero aun así era productivo en su trabajo. El examinado recalca que aún no había comenzado el consumo de marihuana. 
Ya a los 23 años, en Lima tuvo un "decaimiento" de ánimo que tuvo aproximadamente 2 semanas de duración. Resulta que fue a un evento social en el cual se encontró con una chica con la que habían salido previamente, Adrián al verla en dicho evento se sorprendió y le pidió conversar. Ella se rehusó, tras lo cual él la tomó del brazo y ella empezó a gritar diciendo que le dolía y que le estaba haciendo daño. Adrián le dijo que sólo quería conversar con ella a lo que respondió gritando, diciendo que no quería conversar. El evaluado decidió entonces irse, "salí friqueado" pues nunca había estado involucrado en un "show" semejante; caminó hasta su casa y recuerda con poca claridad pedirle a su madre entre llantos que por favor trajera la chica a la casa pues quería conversar con ella.

Las dos semanas siguientes después del incidente Adrián comenta haber sentido gran tristeza y abatimiento, en el cual su apetito disminuyó y sus ganas de realizar sus actividades disminuyeron notablemente, comenta que las ganas de conducir (su afición) se vio reducida. Afirma que dicho evento tuvo gran repercusión sobre su estado anímico.

Posteriormente, durante sus primeros años de casado, a los 35 años, el examinado reconoce una energía inusual la cual le permitió ser más productivo, pues podía permanecer despierto hasta las 2 am para escribir todo lo que tenía que realizar al día siguiente y luego se levantaba a las 5 de la mañana para ir al gimnasio y al trabajo. También reconoce que sus ideas “iban más rápido” sintiéndose más activo. Mantuvo este ritmo por dos semanas aproximadamente. Durante ese periodo, también reporta haber tenido un apetito voraz y haber estado involucrado en varios proyectos simultáneos, como su empresa constructora y una óptica. También comenta que su esposa se percató de la diferencia en el estado anímico; mas no denotó preocupación puesto que el evaluado era altamente productivo en el área laboral.

En el 2003 quebró la empresa consultora que había iniciado con dos socios más 5 años atrás como resultado de una desunión entre los mismos. Uno de los socios decidió desvincularse tras lo cual instauraron la política de que cada persona que consiga un proyecto, se quedaría con el 10\% de las ganancias que el mismo trajera. En uno de los proyectos, "el único que iba a la obra era yo desde las 6:00 de la mañana hasta las 10:00 de la noche. La obra acabó con una ganancia deficitaria por lo que decidió abandonar la empresa. Manifiesta que esta decisión tuvo un impacto significativo sobre él "fue como un hijo que desaparece o que tiene una enfermedad incurable". Luego de abandonar la empresa, comenzó una búsqueda de empleo fuera del país. Tras tener varios trabajos de corta duración en el extranjero, la relación con sus hijos fue haciéndose progresivamente 
más distante, especialmente con el menor de ellos, que nació en el 2002. "Prácticamente mi hijo menor no me conocía". Por un periodo de 3 meses trabajó en Panamá y Argentina. En este último país, consiguió un trabajo, colegio y casa para su familia. Sin embargo, pasados tres meses le informaron que ya no podían seguir empleándolo y pasó a sustentarse mediante el ingreso económico de las rentas. A partir de ese momento empezó a pasar más tiempo en casa arreglándola "si se quemaba el foco, lo cambiaba, arreglaba el jardín, era un multiusos". Pasado un tiempo su mujer quiso volver a Lima en donde tenía trabajo. Él por su parte, no logró conseguir trabajo "En Perú cuando eres mayor no encuentras trabajo, yo no busco un sueldo alto ni tremendo puesto, solo me interesa estar ocupado".

Cuando finalmente se quedó sin trabajo, el paciente empezó a pasar cada vez más tiempo dentro de casa, se sentía más cómodo dentro de ella. Refiere que debido a que sus hijos tenían amigos con padres que trabajaban, él pensaba: "seguro a mis hijos sí les ha afectado verme echado en la cama sin hacer nada" el, lo cual le causa un malestar significativo. Recuerda que en esa época prefería quedarse en casa viendo televisión y como su esposa prefiere actividades en solitario, dejó de frecuentar a sus amistades. No sentía ganas de ver a sus amigos y se volvió más selectivo con los que frecuentaba; no obstante, atribuye esto a su familia: "a raíz de la familia cambié, yo era parrandero. Ahora todo lo que decida la familia".

Así, su ánimo decayó al punto que quería "no estar presente". Tenía pensamientos como "más valgo muerto que vivo", pensaba que sería mejor que sus hijos tengan un recuerdo de un padre trabajador, que el de él echado como "una momia" en la cama. Además indicó dificultades para conciliar el sueño de manera significativa. Este fue el motivo de consulta que lo llevó a visitar al médico psiquiatra por primera vez a los 48 años. En conversaciones con su esposa, le manifestaba el deseo de irse de la casa "no quiero estar más acá, arréglate tú, ya veo que hago"; ella, en respuesta, lloraba, hasta que en una oportunidad le sugirió acudir al doctor. En esta época, el Adrián afirma que en ocasiones era "contradictorio" pues además de los pensamientos anteriormente expuestos, refiere que a pesar de no querer existir, "me daba cuenta que "todavía hay, todavía existo" "sería un cobarde si no soporto la carga". Igualmente, comenta el abandono de las drogas para esa época.

En la actualidad manifiesta sentir más ganas que antes para realizar las actividades hogareñas, asimismo, su esposa le comenta que ve en él un cambio notable puesto que 
hace algunos años en una etapa, Adrián tendía a permanecer en silencio echado en la cama, sin tener ganas de realizar ninguna actividad. Ahora su familia le dicen que esta "más hablador", que "critica todo como antes"; de igual manera el reconoce sentirse con más ganas de hacer cosas; no obstante, cuando algo no se da en la manera que él quisiera, no controla su molestia y reconoce que puede ocasionar daños con su trato.

En lo referido a su atención, el Adrián relata que sus dificultades atencionales afectaron marcadamente en su niñez; desde el colegio tendía a distraerse con mucha facilidad en las clases, extendiéndose hasta secundaria provocando dos veces la repetición de tercero año y el cambio de colegio en el cual abandonó del quinto año de secundaria antes de finalizar el periodo escolar. Durante toda la etapa escolar, el paciente reporta haber sido "muy movido" en colegio como en casa; asi refiere que al llegar a su casa después del colegio saltaba de techo en techo de las casas jugando con amigos: "nunca estaba en mi casa, mientras mi mamá trabajaba yo jugaba en la calle".

Al ingresar a la universidad también reporta dificultades para prestar atención así como dificultades en la relación con los profesores; estos factores provocaron el abandono del primer ciclo universitario. En la actualidad también presenta dificultades para mantener su atención en actividades que no son de su agrado, por ejemplo las reuniones escolares de sus hijos, el evaluado se rehúsa a asistir por el aburrimiento que experimenta en ese contexto; de igual manera indica que al conversar con gente se distrae rápidamente y puede perder la ilación de la conversación al no ser de su interés "cuando me pierdo y no sé de qué estaban hablando me voy al baño o cambio de tema". Estas características, refiere, han estado presentes durante toda su vida y con el paso de los años se han ido acentuando.

A los 18 años, su conducta impulsiva tuvo repercusiones graves. Un día, mientras realizaba piques ilegales, sufrió un accidente automovilístico. Estando con sus amigos en su auto, un carro se posicionó atrás de ellos estando con las luces delanteras altas. Adrián cuenta que "como siempre alguien que friega y a mí se me fue la mano y le saqué el dedo". Por tal razón, se inició un correteo entre ambos autos; al llegar a una esquina, aceleró y chocó contra otro auto y las consecuencias que sufrió él de este accidente fueron 8 puntos en una oreja, mientras que su acompañante estuvo un mes internado en la clínica.

Estas conductas impulsivas se han visto reflejadas a lo largo de su historias, así refiere haber estado involucrado en más de 30 accidentes automovilísticos, causados en ocasiones por él y en otras por alguien más. Afirma: "me gusta correr y la velocidad, me gusta estar al filo. Siempre, desde chico". Cuando era niño experimentaba la velocidad 
en su bicicleta y al crecer, pasó a buscarla en su auto. Además, ha sufrido varios accidentes en diferentes partes del cuerpo, como tobillos, rodillas, muñecas y dedos. La mayoría de estos accidentes han sido consecuencia de la práctica deportiva.

Adrián comenta que desde pequeño ha sido impulsivo y poco tolerante, características que reconoce que aún se encuentran presentes y le generan dificultades en su hogar. Por ejemplo, cuando juega videojuegos con su hijo menor, Sebastián, y ve que este está ganando, él indica sentir enojo y cólera, exclamando: “¡hasta acá nomás llego, este juego es una porquería! Y tira los controles. El niño en respuesta, erra adrede en el juego para que su padre gane. Sin embargo, éste luego se siente aburrido y decide retirarse. Pasadas unas horas, trata de volver a iniciar una actividad con su hijo, pues reconoce no haberse portado con él adecuadamente.

\subsection{TRATAMIENTO PSICOLÓGICOS Y PSIQUIÁTRICOS PREVIOS:}

En el 2013 acude a consulta psiquiátrica en donde fue diagnosticado con Trastorno Bipolar tipo II y Trastorno por Déficit de Atención e Hiperactividad en el adulto (TDAH). Desde ese momento se encuentra bajo medicación farmacológica. Al mismo tiempo fue derivado a terapia psicológica; sin embargo, el evaluado comenta no haber generado un vínculo con el terapeuta, además afirma que los costos eran muy elevados, por tal motivo abandono la terapia. Luego de unos meses por recomendación del psiquiatra acudió a Felizmente Seguros, ahí describe a su terapeuta como "una chica media argentina española", con la cual se entendían; sin embargo, él señala que esperaba retroalimentación por parte de ella, por lo que afirma "nunca me dice nada, solo escucha toda mi vida" y por consecuencia dejó de asistir a terapia. 


\subsection{OPINIÓN DEL PACIENTE SOBRE SU PROBLEMA:}

El paciente expresa el deseo de disminuir su irritabilidad y de poder desenvolverse con niveles de impulsividad más bajos, manteniendo el control sin que le "hierva la sangre automáticamente”. Quiere además disminuir su frustración pues cuando algo no sale como él espera, echa todo por la borda. Cuando se da cuenta de que esto sucede, trata de controlarlo fumando un cigarro o tomando un café. A pesar de reconocer sus dificultades no logra identificar las causas de la misma, ni tampoco muestra motivación por encontrar sus orígenes pues asegura que estas características lo acompañan desde siempre. Él si desea un cambio; sin embargo, no realiza mayor esfuerzo por encontrar una solución a sus dificultades, esto se ve reflejado en la reducida motivación para asistir a terapia.

\section{HISTORIA PERSONAL}

1. Desarrollo inicial:

No se tiene información acerca del parto pues el evaluado fue adoptado. No obstante, se sabe que su lugar de nacimiento fue Argentina. En aquella época, las personas que no podían concebir hijos, pertenecientes a la colonia Judía en Perú, viajaban a Argentina debido a que había varias personas jóvenes que no tenían los medios económicos para mantener a sus hijos. Cabe resaltar que Adrián se enteró de su adopción a los 37 años de edad; anteriormente, tenía sospechas respecto al tema y preguntó a su madre si éstas eran ciertas. La respuesta que obtuvo fue que "estaba loco y que yo era hijo de su vientre". No tiene información acerca de sus familiares en Argentina, sólo el nombre de la partera que asistió su nacimiento.

Cuando cumplió 5 años de edad, su padre adoptivo fue expulsado de su casa. Esta decisión se desencadenó como resultado de que en una oportunidad, Adrián estaba jugando bajo la lluvia a las 8 de la noche. Cuando su madre llegó del trabajo y lo vio con toda la ropa empapada a tal hora de la noche, tomó las maletas de la empleada doméstica y la despidió. En medio de su enojo, llamó a su esposo, el cual respondió que se encontraba en camino; sin embargo, llegó a la 1 de la madrugada. Ante esto, su madre exclamó “esto no funciona asís”, empacó las cosas del padre adoptivo y nunca más fue 
visto. Su abuela falleció ese mismo año en el que sus padres se separaron, por lo que Adrián creció con su abuelo y su madre.

En su niñez, Adrián comenta haber sido hiperactivo. No hacía tareas escolares y cuando estaba en su casa, solía salir por su ventana para ir a jugar fútbol. Subía al techo de su casa a los 9 años, a los 12 empezó a fumar tabaco y a los 15 empezó a trabajar y a manejar automóviles: a los 13 años ya daba una vuelta a la manzana e espaldas de su madre. Además, hacía “todos” los deportes. Recuerda haberse sentido feliz en esos años.

Con respecto a sus orígenes biológicos, en su adultez viajó a Buenos Aires y fue a la Plaza de Mayo donde están las madres religiosas para averiguar más sobre su pasado. Éstas le informaron que desde el año 1970 no atienden partos y dado que su fecha de nacimiento es 1965, el récord no se encuentra disponible. Posteriormente, decidió publicar su historia en el internet tras lo cual una mujer, también judía y adoptada, se comunicó con él pues ella había tenido la misma partera. Acordaron encontrarse en un centro comercial; al conversar, ella le aconsejó que "no haga mucho lío" pues la partera seguramente tenía una edad avanzada o fallecida. El evaluado afirma que no tiene gran interés en ella pero que le gustaría saber de su historia "de dónde vengo".

Fue a los 15 años que inicialmente sintió la necesidad de aclarar su identidad, la cual se fue mitigando hasta la segunda década de su vida, en la que volvió a urgirle el tener dicho conocimiento. Sin embargo, su madre se negaba a darle información. En una ocasión, relata, su padre le dijo: "Tú no eres adoptado, eres recogido y costaste 15 mil dólares”. Después de esto, fue a los 37 años, cuando ya tenía a sus hijos, que enfrentó a su madre aunque él afirma que "dentro de mí sí sabía”. Cuando finalmente su madre admitió haberlo adoptado, él sintió mucho resentimiento pues el que se le haya ocultado información de dicha índole le causó mucho dolor. Su madre había mantenido esta información secreta siguiendo las instrucciones de un psicólogo. El evaluado se encuentra inscrito en una página de internet dirigida a personas en busca de otras y comenta que si algún día sus padres o algún familiar lo contactan "el día que tenga que ser llegará y si no se da, no importa, porque yo tengo mi propia familia". A la vez, siente que sería "un capítulo en blanco" en su vida. Sus hijos están enterados de la historia y opinan que por lo menos "tuviste a tu madre".

\section{Educación:}




\section{a. Historia escolar}

Asistió al colegio "Leon Pinelo" hasta tercer grado de secundaria y afirma que su recorrido escolar fue "normal", pues no tenía notas altas, pero siempre aprobaba los cursos. En cuanto a la conducta, empieza afirmando que no era revoltoso, situándose en medio de "dos bandos: los intelectuales y los vándalos". Recuerda haber tenido muchos dolores de cabeza para los que le hicieron encefalogramas. En cuanto a la atención, reporta haber experimentado desinterés para algunos cursos; asimismo, refiere haber sido un niño muy activo, siempre se encontraba realizando alguna actividad y gustaba mucho de los deportes.

En secundaria fue cuando empezaron sus dificultades. Tenía peleas con sus amigos, pero eran "absurdas", originadas por "celos, envidia o chicas". Fue en esa época en la que desaprobó el curso de Biología. Afirma haber "sentido" que su profesora lo desaprobó adrede debido a que ésta pensaba que él era "muy vago" y que "podía dar mucho más". Así, tuvo que ir al vacacional para dar un examen. El día anterior al mismo, estudió 4 horas con su madre y obtuvo un 18; su profesora, en respuesta, le preguntó por qué no podía obtener esos resultados así en clase. Adrián respondió diciendo “¿Cómo mi mamá me pudo meter todo un curso en 4 horas?, eso significa que también depende de quién enseñe”. Fue ahí cuando comenzó su “calvario". En tercero de secundaria desaprobó 4 cursos, de los que aprobó 3 en el vacacional. Dentro de esos 3, se encontraba el curso de hebreo, en el que obtuvo un 14 en el examen. A pesar de ello, el director del colegio se negaba a colocar dicha nota en la libreta de estudios alegando que no reflejaba su desempeño en el curso. Él refiere haber pensado que eso era injusto y que además el hebreo era un idioma secundario, fuera de la maya curricular de estudios del Perú. Aun así, su madre accedió a que repitiera el año. Ante esto, Adrián se molestó, tenía pensamiento como "si ella no me apoya, ¿quién lo hará?”. En protesta, comenta no haber estudiado pues "no me parecía justo lo que estaban haciendo conmigo". Como resultado, desaprobó tercero de secundaria por segunda vez. Por otro lado, sus amigos dejaron de jugar con él en el recreo pues ya no pertenecían a la misma promoción; además, varios compañeros fueron expulsados del colegio y no pudieron asistir ni a la fiesta ni al viaje de promoción. Al terminar el año, pidió a su madre un cambio de colegio para poder cursar el cuarto de secundaria; así, la administración del colegio accedió a asignarle una nota aprobatoria con la condición que cambiara de colegio. Relata que en términos generales, no hacía sus tareas; al llegar a casa, almorzaba con su mamá y abuelo después 
de lo cual se quedaba solo en las tardes. En este tiempo del día, se dedicaba a saltar de techo en techo, agarraba su carabina y le disparaba a la gente, montaba bicicleta, iba a la casa de sus amigos, a la costa verde, etc. Nunca se quedaba dentro de casa.

En cuarto de secundaria, entró al Colegio Cristo Redentor lo cual, comenta, "fue un dolor de cabeza" debido al contraste que encontró en él con su otro colegio "Es como irse de Lima a un colegio metido en el cerro, ósea, nada que ver”. Refiere que había diferentes clases sociales, como "un arca de Noé” y que el nivel de exigencia era muy bajo; así, lo aprendido en el Leon Pinelo le sirvió para cuarto y quinto de secundaria. A mediados del último año escolar, Adrián relata que sus amigos tenían planes de viajar al extranjero para estudiar y trabajar, lo que le dio la idea de entrar a una academia pre universitaria. Logró recibir su libreta de calificaciones en el mes de Julio a cambio de dinero. Así, al salir del colegio a mediados de año, entró a la academia de la Universidad San Ignacio de Loyola. Su madre no protestó pues ya tenía todos los documentos con sus notas.

\section{b. Otros estudios realizados}

Tras haber asistido a la academia pre-universitaria de la Universidad San Ignacio de Loyola, se presentó al examen de ingreso a la Universidad de Lima. Relata que "De lechero ingreso" pues debía pasar con un puntaje de 195 y él obtuvo 190; sin embargo, varios ingresantes optaron por no inscribirse a dicha universidad, por lo que logró llegar al punto de corte. Había acordado con su madre que si lograba ingresar a la universidad, ella le daría un carro. Después de una semana de haberlo recibido, Adrián tuvo un accidente automovilístico. Para este entonces, él tenía ya 18 años. Este accidente ocasionó que no pudiera asistir para los exámenes parciales del primer ciclo de universidad.

De todas maneras, Adrián se presentó para sus exámenes finales. Afirma que esa etapa la recuerda con dificultad "me queda un poco borrosa" pues "no sé cómo pasé a segundo ciclo, pero sí jalé algunos cursos”. No llegó a terminar el segundo ciclo de la carrera pues tuvo un conflicto con el profesor de psicología debido a que éste anunció que un tema en particular no iba a ser incluido para el examen, pero si lo fue. Adrián se enfureció “¡Pucha, no hay peor cosa que me mientan!”. Habló con su profesor y le dijo: “¡Tú estás loco! Yo voy a hacer que te boten”. Así, reunió una carta con 20 firmas para dicho propósito, a lo que cuenta que el profesor respondió “A los 19 los voy a aprobar, pero a ti no. ¡Qué mierda!”. Decidió conversar con el decano, le explicó todo y la respuesta del mismo fue "preferimos botar a un alumno que botar a un profesor". Adrián 
respondió diciendo que él no es una persona a la que le gustara estudiar ni estar en un salón de clase, que él es "manual". Luego de esta conversación, estuvo pensando que su madre pagaba una carrera que a él no le gustaba; además, había cursos como cosmología y cultura política que le causaban gran desagrado.

Después de este incidente, empezó a averiguar en la embajada de Israel cómo podía ir a dicho país. A los 19 años logró reunir sus papeles y partió. En Kibutz, Jerusalén, postuló a la universidad, obteniendo un puntaje de 90 en el examen de ingreso. No obstante, no logró ingresar pues el puntaje mínimo necesario era 92. Estuvo ahí por 3 meses.

Antes de volver a Lima, viajó a Los Ángeles para seguir unos cursos de óptica en un instituto de oftalmología. Sin embargo, no quiso quedarse pues no le gustó la ciudad además de parecerle muy costosa. Una vez en Lima asistió de invitado a unos cursos de marketing que duraron dos días. Para tal época, ya tenía 21 años.

\section{Ocupación:}

A los 15 años trabajó para un DJ armando el equipo y consiguiendo contactos. A los 19 años trabajó en Kibutz de gasfitero, vigilante, pelando naranjas, trabajó también con gallinas, cocodrilos, en limpieza y de lavaplatos. Por dos semanas dormía 3 horas al día, hasta que su madre y su primo lo fueron a visitar y le ofrecieron un viaje a Europa. Adrián se rehusó, pero su madre le propuso viajar por dicho continente, luego volver a Lima y si para ese entonces él quería volver a Israel, prometió pagarle el pasaje. No obstante, permaneció en Lima.

Al volver a Lima, trabajó de administrador en una Óptica en el Centro de Lima, negocio de la madre. Luego pasó al local de Chacarilla en donde agregó la venta de relojes, cámaras fotográficas, maletines, billeteras y bicicletas, así como el servicio de revelado. Posteriormente instauró su propio negocio.

Entre el año 1998 y 2003 fundó una empresa constructora con dos socios más. Paralelamente, entre los años 2001 y 2003 abrió una cafetería con 4 de sus amigos junto con sus esposas, la cual fracasó por conflictos internos.

En el 2003 quebró la empresa consultora que había iniciado con dos socios más 5 años atrás como resultado de una desunión entre los mismos. Uno de los socios decidió desvincularse tras lo cual instauraron la política de que cada persona que consiga un proyecto, se quedaría con el $10 \%$ de las ganancias que el mismo trajera. En uno de los 
proyectos, "el único que iba a la obra era yo desde las 6:00 de la mañana hasta las 10:00 de la noche. La obra acabó con una ganancia deficitaria por lo que decidió abandonar la empresa. Manifiesta que esta decisión tuvo un impacto significativo sobre él "como un hijo que desaparece o que tiene una enfermedad incurable".

Luego de abandonar la empresa, comenzó una búsqueda de empleo fuera del país. En el año 2005 viajó a Estados Unidos, fue ayudante de mozo, recepcionista y mozo por 3 meses. Asimismo, por un periodo de también 3 meses trabajó en Panamá como encargado de un almacén y posteriormente, en el 2007, trabajó como archivador en una empresa de etiquetados en el depósito de documentos en Argentina. Viajó a dicho país tras el fallecimiento de su madre y de su suegra. Ambas fallecieron de cáncer con 3 meses de diferencia; afirma que fueron "dos años densos" (2005-2006). Decidieron así viajar a Argentina pues se sentían hastiados de pasar tiempo en clínicas. Ahí vieron "todo lindo, los árboles y el sol, todo brillaba" por lo que decidieron mudarse.

Consiguió un trabajo, colegio y casa para su familia. Sin embargo, pasados cuatro meses le informaron que ya no podían seguir empleándolo y pasó a sustentarse mediante el ingreso económico de rentas de propiedades. A partir de ese momento empezóa pasar más tiempo en casa arreglándola "si se quemaba el foco, lo cambiaba, arreglaba el jardín, era un multiusos". Pasado un tiempo su mujer quiso volver a Lima en donde tenía trabajo. Él por su parte, no logró conseguir trabajo: "En Perú cuando eres mayor no encuentras trabajo, yo no busco un sueldo alto ni tremendo puesto, solo me interesa estar ocupado".

Actualmente se dedica al diseño de muebles de manera ocasional. Lo considera como un hobbie pues ha realizado esto en una sola ocasión para una amiga. Manifiesta que "me gusta ver una idea hecha realidad". Comenta que siempre ha sido muy bueno en dibujo. $\mathrm{Su}$ principal ingreso actual proviene de sus rentas. 
4. Relaciones interpersonales:

a. Amistades

Adrián refiere que durante su adolescencia y juventud tenía "varios amigos por todos lados", tenía bastantes grupos y uno de ellos era el de "los bacanes" con los que causaba "revuelo".

Recuerda dentro de sus anécdotas relacionadas a las relaciones interpersonales en Israel, vivía con un argentino que "no aguantaba mucho" pues un día lo hizo enojar. En ese incidente, le dijo "concha de tu madre" ocasionando que su compañero se asuste y se vaya del cuarto que compartían.

Actualmente no se reúne con sus amistades con la frecuencia de antes, pero si mantiene relación con un grupo de "moteros", una vez a la semana, se juntan en un restaurante para conversar y organizar viajes dentro del país. Refiere también que varios de sus amigos también se encuentran medicados como él: "varios de mis amigos los moteros también toman litio"

\section{b. Relaciones con el sexo opuesto}

El examinado refiere haber tenido un gran número de relaciones sentimentales. A los 19 años manifiesta haber pasado por "una crisis emocional" por mantener una relación con una chica que no era Judía, sino Católica, de nombre Ingrid, ante lo cual su madre se mostraba en desacuerdo. Paralelamente, Adrián había desaprobado cursos en la universidad y su madre le había retirado el carro y la propina. Así, él pasaba la mayor parte del día en la casa de su enamorada, consumía sus alimentos ahí y no se retiraba antes de las doce y media de la noche. Refiere haberla pasado "bien" en aquella época. Cuenta que no necesitaba dinero para tener un buen rato con su novia pues iban al parque o eventualmente tomaban un helado. Fue su primera relación. Poco después partió a Israel.

El evaluado refiere que durante su juventud, entre los 21 y 27 años, no mantuvo una relación de pareja estable y duradera, el máximo tiempo de relación con una mujer fue de 2 meses. Afirma también, que en estos años conoció "chicas de todo tipo, buenas, locas, malísimas, etc." 
Antes de conocer a su esposa, Adrián se encontraba en Miami; cuando su abuelo falleció, Ingrid fue a visitarlo. “La pasamos genial, muy bacán”. La relación, sin embargo, volvió a terminar pues él se regresaba a Lima y ella a España; ni uno de los dos quería mudarse al otro país. Posteriormente se encontraron dos veces más cuando ella visitaba a su madre; además, hace dos o tres años atrás lo llamó y se encontraron. Esto sucedió mientras el evaluado estaba casado con otra mujer. Su esposa no sabe de esto ya que "no entendería, pensaría que no la quiero, que no está bien". Comenta: "pudo haber sido una relación muy bacán, la comunicación era mental, ambos sabíamos lo que pensábamos".

Posteriormente, estando en la playa, avistó a una mujer con la que luego se casaría. Relata que iba con frecuencia a la playa "señoritas", en donde vio a Maritza (su esposa). Al verla, le preguntó a una señora que trabajaba ahí si conocía a "la pelirroja", a lo que respondió afirmativamente. Adrián le dijo que tenía interés en conocerla y la señora le indicó que regresaría el miércoles, pero Maritza no fue aquel día, ni al día siguiente. Entonces, él dejó una nota dirigida a Maritza con la señora que lo había ayudado. Aquella es la época en la que el evaluado tenía una tienda en Chacarilla, en la que un día coincidentemente Maritza entró. En ese momento, Adrián le indicó a la trabajadora que le diera una factura o una boleta en el que apareciera su nombre, teléfono y dirección, pero "la cojuda se olvidó". Entonces, relata, salió de la tienda para ver a donde se iba; la siguió hasta su auto y pensó: "si voltea y sonríe es porque le gusto". Así, pasó caminando a su costado, ella se volteó, rio y se fue. Un tiempo después, él estaba en su carro con una de sus trabajadoras hablando de Maritza a lo que ella decía "si tiene que ser, será". En ese momento, Adrián volteó y vio a Maritza pasar. Manifiesta que no recuerda con claridad, pero que logró conseguir su número de teléfono en la playa y al llegar a su casa después de verla caminando por la calle, empezó a buscarla en las páginas amarillas. Así, la llamó por teléfono y salieron en un par de oportunidades. Sin embargo, a la semana siguiente él debía asistir a una reunión de judíos solteros fuera del país. Posteriormente la llamó por año nuevo, pero ella no estaba en Lima. Había viajado a Trujillo y "no me había contado nada, me tenía sacando chispas". Adrián llegó el 10 de enero a Lima, se encontró con Maritza y ese mismo día iniciaron su relación de enamorados. A los dos días de conocerla le dije para estar y comenzamos a salir. En julio de ese año viajaron a Chile por temas de trabajo, pero al llegar a Lima, tomó la decisión de terminar la relación en respuesta a la presión de su madre. Al poco tiempo, inició una relación con una mujer judía con la que "no pasó ni michi y con las justas le toqué la mano". 
Pasado un tiempo, con sus amigos "juergueros", volvió a encontrarse con Maritza y "no podía creerlo" y decidió retomar la relación. Le pidió disculpas y regresaron con la "condición" de que si en 6 meses todo marchaba correctamente, se casarían. Efectivamente, se casaron, pasado dicho tiempo.

5. Historia psicosexual:

a. Información sobre el sexo

Recibió información acerca del sexo por parte de sus amistades, su madre no se lo mencionaba. Relata que los padres de sus amigos "nos querían estrenar", además, era un orgullo en el colegio decir "me quemé el fin de semana", lo cual indicaba que se había tenido relaciones sexuales con una prostituta. En esa época compraba revistas de pornografía, así como posters de mujeres desnudas detrás del ropero.

\section{b. Historia sexual}

A los 9 años tuvo interés por una niña, veían chistes en toboganes y se visitaban en sus respectivas casas, pero "no hubo ni un beso".

Comenzó a masturbarse a los 12 años. A los 13 años, con cuatro amigos más, fueron a la casa de uno de ellos donde su empleada doméstica, una "vieja, gorda, fea, horrible" les daba sexo oral. No obstante, refiere haberse negado a recibirlo pues "yo era un poco exquisito" salvo por una oportunidad en la que, junto con sus amigos, contrataron a una prostituta. Relata que recuerda a esa experiencia como "bacán” pero no la llegó a repetir; en esa época tenía la idea de tener relaciones sexuales "con una persona igual a mí, de mi misma edad, que me guste".

Después de esa experiencia, no tuvo otra hasta los 18 años. A esa edad, después de mucho tiempo de salir con una muchacha, tuvo sexo con ella y "fue espectacular". Ella fue su primera enamorada y su relación duró dos años; sin embargo, reporta haber sido infiel. Su enamorada de ese entonces se fue de viaje por un mes a Estados Unidos, mientras que la mejor amiga de su novia lo llamó y le pidió que lo acompañara a comprar; él accedió. Al encontrarse, se dieron un beso. Después de esto, Adrián refiere haberse sentido "mal" pero después pensó: "tengo 18 años, no pasa nada". Después de aquello, empezaron a ir al cine o a comer de manera frecuente, mientras su novia estaba de viaje. 
Un día, fue a recoger a esta muchacha (amiga de su novia) del colegio, que era el mismo al que su enamorada asistía. En ese momento, se encontró con Ingrid (su novia) que le preguntó qué hacía ahí, a lo que él respondió con "la cagué". Terminaron la relación pues afirma haberse sentido más atraído por la amiga de Ingrid en ese momento.

No obstante, en una oportunidad se encontró con ella (Ingrid) en un parque y le dijo que necesitaba 10 minutos de su tiempo y que no pedía ser perdonado. Así, se amistaron y empezaron a salir nuevamente. Esta relación terminó con el viaje que Adrián hizo a Israel a los 19 años. Al regreso, Ingrid se mudó a España.

Entre los 21 y 27 años, el examinado comenta haber frecuentado a varias mujeres por periodos de tiempo de aproximadamente 2 meses y que a su vez mantenía relaciones sexuales con ellas afirmando: "por mi carro han pasado pelos de todos los colores". No hubo una relación formal en ese periodo, relata que "habían experiencias de todo tipo, buenas, locas, malísimas”. A los 27 años conoció a Maritza (su esposa) y el paciente comenta que su vida sexual en ese entonces era "muy divertida" tenía relaciones sexuales en la calle, playa, en el carro y en hostales.

Actualmente, en contraste, su esposa no quiere tener relaciones sexuales. Manifiesta fastidio por la falta de motivación por parte de su esposa respecto al área sexual, "no sé por qué”. Cuenta que al casarse, tuvo a sus hijos y "misión cumplida”. Su esposa se niega tener sexo por que en la casa están presentes sus hijos; él reitera que "hay mil maneras de hacerlo, lo tuyo son pretextos". Ha llegado a irse de la casa debido a que no tenían relaciones sexuales durante tres meses y ella se molestó. Le dijo "si tanto lo quieres hacer, búscalo en la calle”.

El marzo del 2014, él sugirió a su esposa darse una oportunidad e ir a Nueva York los dos solos. En tal viaje relata que tuvieron "una noche de sexo en el hotel" pero el resto de días estuvieron en la casa de la tía de su esposa.

\section{Educación hogareña y religión:}

Adrián refiere habérsele inculcado en su familia la honestidad y respeto a su apellido. Además, un aspecto importante es no tener deudas "no puedo deber un sol a nadie, no duermo. Mis servicios los pago antes de tiempo. Nunca pido ayuda, si es que necesito pagar un servicio o comer, primero me muero de hambre antes de pedir plata o un favor". Cuenta que cuando sus hijos eran más pequeños en ocasiones le interrumpían el servicio de luz por dejar de pagar por varios meses. Sin embargo, él se las agenciaba para 
conseguir dinero. Nunca faltó comida ni leche para ellos. Sólo una vez, relata, pidió ayuda para trabajar en Argentina. Usualmente no le importa qué trabajo sea "con tal de hacer algo".

En cuanto a su religión comenta que "a veces creo, a veces no". El tema religioso "fue muy liviano" en casa. Su familia pertenece a la comunidad Judía pero a él se le tenía permitido consumir jamón en el colegio, comer chifa con chancho, etc. Su abuelo era el miembro de la familia que le daba más importancia a la religión, hacía rezos de tres horas diarias. En las reuniones religiosas, él nunca fue llamado a leer el "libro sagrado", mientras que todos sus primos sí. Este hecho fue uno de los factores que lo hicieron dudar acerca de su procedencia; la razón por la que no era llamado es que no se le consideraba como hijo "legítimo", no se sabía el vientre de dónde provenía.

Opina que existen varias contradicciones en las enseñanzas religiosas, y basta con que se siga la voluntad de Dios, el cual desea que se haga el bien "procura que tu familia viva bien y feliz, no te metas en los problemas de otro y punto". No obstante, en presencia de su abuelo, el seguimiento de las reglas religiosas era más riguroso. Actualmente afirma que cree en Dios en "ciertos momentos, en otro no. No hay religión, mi comunicación es directa con él".

7. Historia de la recreación y de la vida social:

El examinado recuerda que en la niñez jugaba con sus amigos del barrio, recuerda esas épocas como "bonitas", puesto que después del colegio se juntaba con ellos para jugar futbol, salar de techo en techo, dispara con carabina, etc. Recuerda también haberse peleado con algunos amigos pero califica esas peleas como parte de la infancia. En la adolescencia y juventud, también mantenía sus amistades de la infancia, pero ahora mas frecuentaba a los amigos del colegio, con los que iban a fiestas, reuniones y también realizaban piques ilegales. En la etapa d la adultez Adrián indica que se dedica a los temas hogareños más que a la vida social; sin embargo, pertenece a un grupo de personas aficionadas a las motos, con los cuales se reúnen una vez por semana en un restaurante conocido. A partir de ello, se programó un viaje en moto hacia Pacasmayo.

\section{Hábitos:}


El evaluado refiere fumar cigarros de tabaco con regularidad, aunque en ocasiones suspende su consumo por dos o tres meses, para luego retomarlo. "Fumo cuando me provoca". Ha consumido cocaína, pasta básica, hachís y sobre todo marihuana. Hubo una época en la que tenía una planta de la misma en su domicilio. Actualmente manifiesta tener mayores deseos de fumarla para tener un momento consigo mismo, por ejemplo viendo una película.

La primera droga que consumió fue la marihuana a los 19 años. Lo hacía con regularidad, los fines de semana con sus amistades, comenta que lo hacía viendo una película y que después iban a comer y luego dormir, lo describe como "la mejor sensación". Su consumo se extendió hasta los 32 años y la abandonó cuando tuvo a su primer hijo "tenía que seguir el ritmo de mis hijos". Afirma que si bien su esposa no gusta del consumo de marihuana, no tenía problema con que él la consumiera. Desde los 20 años hasta los 21 inició consumo de cocaína mantuvo una frecuencia de una vez por semana y también lo realizaba con amigos, afirma no haber tenido dificultades para dejarla. En este periodo también probó pasta básica "no me gusto" y el hachís. Con el hachís, explica, está contenido en un pomo dentro del cual se olfatea y "te vas para atrás". Esta última droga es marihuana "repotenciada por 10 veces"; la diferencia es que "la marihuana tiene un pico alto de ahí muere; el hachís en cambo, tiene varios picos y su duración es mayor. .

Actualmente, considera que sus hábitos son buenos; en su hogar se promueve el orden y limpieza, se preocupa por el estado de sus vehículos (carro y moto) y disfruta de la cocina, así como de ver películas y manejar automóviles. Durante la semana él es el encargado de arreglar los artefactos defectuosos, realizar los pagos, recoger a sus hijos del colegio o academia cuando Maritza no puede y además como rutina, una vez por semana se junta con amigos: "los moteros". Adrián afirma: "Me gusta correr y la velocidad, me gusta estar al filo. Siempre, desde chico". Cuando era niño experimentaba la velocidad en su bicicleta y al crecer, pasó a buscarla en su auto. Cuenta que tiene un "mundo paralelo" en su automóvil, "manejaría cualquier cosa". Al preguntársele por la práctica de deportes extremos, reporta haber corrido tabla por un tiempo.

9. Enfermedades y accidentes: 
Relata que a los 5 años de edad, la empleada doméstica le cerró la puerta en el dedo adrede "Me dejaron solo con la empleada y ella vivía en el segundo piso. Yo subí porque tenía miedo, era chico y ella pensó que subía para verla calata y me cerró la puerta". No abrió la puerta por más que su dedo estaba colgando "por eso tengo doble uña". Después de eso, hirvió agua, puso sal a la herida y la vendó "desde chiquito sabía cómo currarme raspones y heridas". Cuando su madre llegó y vio su herida, a pesar de que él le dijo que todo estaba bien, despidieron a la empleada.

Aproximadamente a los 7 años de edad, recuerda que frente a su casa había un pampón en el que "nos enfrentábamos a piedrazos con otros vecinos". En una oportunidad, una piedra cayó en su cabeza y le hizo una herida para la que "sólo usé algodón y un parche".

A los 15 años se le diagnosticó Mononucleosis Hepática, cuya ocurrencia le impide donar sangre hasta el día de hoy. Ha sufrido de varios accidentes en diferentes partes del cuerpo, como tobillos, rodillas, muñecas y dedos. La mayoría de estos accidentes han sido consecuencia de la práctica deportiva; por ejemplo, jugando fútbol se rompió un ligamento de la rodilla y practicando el voleibol tuvo un accidente que ameritó una operación pues se vio impedido de caminar.

Además, hace poco más de 20 años se dañó la mano derecha tras dar un golpe al parabrisas de un carro con el puño. En esta oportunidad, estaba manejando y un microbús no lo dejó pasar "te exaltas y te pones rabioso porque no comprendes como gente así maneja en este país y tú quieres hacer las cosas bien o como en otro lado". En esta oportunidad, cuenta que "mi cólera estalló" y bajó de su vehículo a increpar al chofer. Éste utilizó gas pimienta y en respuesta, Adrián golpeó y rompió el parabrisas del microbús. Tuvo que llamar a la compañía de seguros pues el chofer también había roto el parabrisas de su auto. Finalmente, cada uno arregló sus daños respectivos.

10. Movilidad e instalación:

A los 19 años Adrián viajó a Israel para trabajar en Kibutz (colonia agrícola de producción y consumo comunitarios), por un periodo de 3 meses. Luego a los 41 años se dirigió a Estados Unidos, también por 3 meses para buscar trabajo, se desempeñó como mozo, recepcionista y en ese mismo año se traslada a Panamá para trabajar en un almacén. Luego, a los 43 años viaja a Argentina para buscar trabajo y labora como archivador de 
una empresa, ahí trabajo 4 meses aproximadamente y decide trasladar a su familia también a Argentina y viven ahí alrededor de 1 año.

10. Delincuencia, récord policial y judicial:

No tiene un record policial, pero refiere haber estado involucrado en más de 30 accidentes automovilísticos. Han sido causados en ocasiones por él y en otras por alguien más. Afirma que "me gusta correr y la velocidad, me gusta estar al filo. Siempre, desde chico". Por tal razón manifiesta haber sido partícipe de varios accidentes.

\section{Personalidad:}

El examinado refiere que en la infancia era un niño alegre con mucha energía, siempre estaba realizando algún deporte o actividad. Se califica como un niño distraído en el colegio, le costaba mantener su atención a las clases. Se molestaba rápidamente cuando alguien lo atacaba o le hacían burlas, pero si eso no ocurría tendía mantener buena relación con sus amistades.

En la adolescencia también se consideraba alegre y extrovertido, sobretodo impulsivo, siempre estaba realizando alguna actividad, como un deporte o manejando su auto a grandes velocidades; él afirma que disfrutaba de la velocidad y la sensación de "estar al filo". También reporta oportunidades en la que ha reaccionado de manera agresiva por discusiones con amigos y confrontaciones con otros conductores. Además, en esta etapa en la juventud, comenzó a experimentar estados anímicos elevados y depresivos, los cuales estuvieron aproximadamente dos semanas presentes.

En la adultez, la impulsividad, la baja tolerancia a la frustración y la irritabilidad, fueron características que han perdurado y que a su vez han tenido diversas repercusiones sobre su funcionamiento diario, al igual que sus oscilaciones en el estado anímico. Por ejemplo, al estar en la cocina preparando panqueques y uno se le pega a la sartén comenta: "lo tiro con sartén y todo por cólera". Dice ser renegón cuando los demás no siguen lo que él dice o no realizan las cosas a su manera. Si es que las cosas le salen mal "me enerva, no se dejan enseñar". Esto le sucede con sus hijos, manifiesta haberle gustado tener un padre que le explicara cómo son las cosas "ellos no quiere nada conmigo, no me hacen caso". Se describe como una persona alegre en ocasiones pero cuando las cosas no resultan como él quiere, siente mucha rabia. 


\section{HISTORIA MARITAL O DEL COMPROMISO ACTUAL}

\section{CÓNYUGE}

a. Datos de Filiación

1. Nombre y apellidos: M.T.O.H

2. Sexo: Femenino

3. Edad: 46 años

4. Lugar y fecha de nacimiento: Lima, Perú - 22 de septiembre de 1967

5. Tiempo de residencia en Lima: Toda su vida.

6. Estado civil: Casada

7. Grado de instrucción: Técnico

8. Ocupación actual (centro de trabajo y cargo): Colegio Jorge Washington. Se encarga del área administrativa. Es un negocio familiar llevado por Maritza y su hermana.

9. Religión: Católica

\section{b. Características personales}

Maritza es una mujer pelirroja de tez blanca. Sufre de cáncer a la piel desde el año 2002 pero gracias a que sigue un tratamiento farmacológico, lo mantiene bajo control. Esta condición afecta de manera considerable su vida diaria ya que no puede permanecer bajo el sol por un tiempo prolongado y tiende a la formación de yagas en el pecho, cara y brazos que deben ser cauterizadas y la han obligado a guardar descanso, además de generar gran preocupación en su familia. La enfermedad se generó a raíz de una excesiva exposición al sol; además, sus embarazos contribuyeron a que sus complicaciones se agravaran.

Esta enfermedad afecta la dinámica familiar pues al ir a la playa les es difícil compartir momentos juntos y deben ir a playas en donde la intensidad de los rayos solares sea menor. Además, cuando las yagas aparecen, no pueden tener relaciones sexuales. Adrián señala que en ocasiones no sabe si su mujer no quiere tener relaciones sexuales por sus heridas o porque realmente no lo desea. 
En cuanto a su personalidad, la describe como "sumamente buena, dedicada a ayudar a los demás". Refiere que cuando alguien de la familia tiene dificultades, acuden a ella. Es introvertida, "le falta demostrar sus sentimientos, sean buenos o malos". Se levanta y acuesta muy temprano pues inicia sus tareas sin preámbulo y al final del día llega muy cansada después del trabajo. Es una mujer sencilla e inocente, dedicada a sus hijos. Él refiere que es una excelente madre.

El paciente relata que cuando ésta bebe alcohol, su actitud cambia y "se vuelve de 18 años, se pone alegre", pasa de un estado tensional a un estado alegre. Afirma que es quizás la persona que a él le gustaría que sea siempre. Esto ocurre cuando viajan o tienen alguna celebración como navidad o año nuevo.

Las fortalezas de Maritza radican en su rol de madre, todas sus actividades van dirigidas al bienestar de sus hijos, no es renegona, criticona o chismosa.

\section{c. Relación entre los cónyuges}

Actualmente describe su relación como lineal, "yo si quisiera esos altos y bajos, peleas para reconciliarme. Es bonito pelear. Con Maritza es muy muerto, no pasa nada. Pero Maritza tiene el diablo al lado porque yo soy movido, soy inquieto, necesito movimiento, por eso me compre mi moto, necesito salir, airearme, estar con gente". "Nunca nos peleamos, sí hay discusiones por desacuerdos pero muy rápido lo arreglamos". No obstante, en una oportunidad se fue de la casa por unas horas debido a que ella se había negado a tener relaciones sexuales por tres meses.

En aquella ocasión salió de casa muy molesto "porque a veces me molesta que la línea este ahí horizontal y ahí en el sexo ella no tenga motivación, no sé por qué". Considera que para ella, el casarse y tener hijos constituye una "misión cumplida" y a él sólo lo considera como el padre de sus hijos, su marido "pero ahí nomás". Comenta que están pasando por una etapa difícil pues, a pesar de no pelearse, la comunicación que tienen es exclusivamente para el bienestar de sus hijos. "No podemos ir a tomar un café, ir al cine, no hay momento para nosotros y en la casa no podemos tener sexo porque están los chicos". Él considera que sólo son pretextos por parte de Maritza.

Al salir de la casa, ella se molestó y le dijo "si tanto lo quieres hacer, búscalo en la calle" así que él fue a un bar a tomar una cerveza, aunque afirma no haber seguido sus 
instrucciones. Adrián dice que no comparten la misma manera de ver la vida. "Ella en la época de enamorados era diferente, era como yo quería. Ahí si era a la hora que tú quieras, como tú quieras, donde tú quieras. En su casa, con su mama al lado. ¡Entonces que no me venga que es por los hijos! Le pongo tapones a los hijos, una pastilla para que se queden dormidos, le pongo un bozal, almohadas en la puerta”. Refiere que siente que ella no está enamorada "quizá me quiera, pero no está enamorada. Igualito le dije yo, te quiero, pero no te amo". Esto se lo dijo hace poco y ella le respondió diciendo que está segura de que él la ama. Afirma que se lo dijo "cruelmente porque no aguanto". Esto lo ha conversado con su esposa y dice que "aguanta" por sus hijos pero alega que cuando éstos se independicen, él se irá también. "Ayer le arregle su ropero porque me provoca, porque si la quiero y quisiera que cambie pero no quiere cambiar". No quiere pasar el resto de su vida así, manifiesta querer gozarla antes de que lleguen los años en los que no pueda valerse por sí mismo.

Relata que el Marzo pasado, después de no haber tenido sexo por 5 meses, le propuso ir a Nueva York los dos solos. No obstante, tuvieron sólo una noche de relaciones sexuales lo cual no lo "llena". Ella duerme a las 8:30 de la noche y se levanta a las 5:30, por lo que durante la semana no tienen tiempo de intimidad y el fin de semana tienen a sus hijos en casa. Afirma haber estado contando los meses "porque si llegaba al año, ¡chau!".

Refiere que "la casa parece un ambiente normal y feliz", a pesar de que él no está feliz pues Maritza quiere hacer parecer que sí: "Si discutimos, no pasada nada, que si me voy a de la casa, todo está bien. No es compañera, es mi esposa, pero no es mi amiga. Hay cosas que quiero hacer pero no las hago, como ir al cine, salir a comer a la calle, caminar, charlar." Todo comenzó cuando nació Natalia, su hija mayor y empezaron a dedicarse a sus hijos. "Yo estaba bien con eso, pero ya crecieron", comenta que cuando sus hijos se independicen, en unos 10 años, va a quedar un vacío que no podrá ser llenado. Califica la intensidad del problema en una escala de 0 a 10, como 8-9. Es un conflicto que ha ido incrementando a lo largo del tiempo, desde hace dos años atrás.

\section{HIJOS}

a. Datos de filiación: 
1. Nombre y apellidos: N.A.O

2. Sexo: Femenino

3. Edad: 18 años

4. Lugar y fecha de nacimiento: Lima, Perú - 19 de febrero de 1996

5. Tiempo de residencia en lima: Toda su vida

6. Estado civil: Soltera

7. Grado de instrucción: Universitaria en curso

8. Ocupación actual: Estudio de Diseño de Interiores.

9. Religión: Católica no practicante

\section{b. Características personales}

Adrián describe a su hija diciendo "mi niña flota en una nube, pero a veces toca tierra", y ve la vida como si no hubiese nada de qué preocuparse. Relata que de niña tuvo berrinches frente a los que recurrió meterla bajo el agua de la ducha "con ropa y todo". Actualmente, es una joven alegre y mandona "le gusta que los demás hagan el trabajo". Gusta de las fiestas y relaciones interpersonales; actualmente tiene pareja. Su enamorado es universitario y "es número uno". Adrián refiere que esto ha hecho que Natalia sea más responsable; no obstante, al principio de la relación él tenía miedo de que "la usen y luego la boten" pues ella tenía 17 años y su novio 21 cuando iniciaron la relación. Finalmente "resultó un chico de buena familia, ella lo trata de la forma que quiere y ella es la que lleva los pantalones por más sonsa que se haga. Ambos se complementan". Relata que en una oportunidad se aproximó a ella y a su novio que estaban viendo televisión en casa esperando encontrarlos abrazados, uno encima del otro y se sorprendió al verlos "matándose de risa". Eso le gustó y comenta que cree que no han tenido relaciones sexuales. Sin embargo, afirma que "yo soy el que tiene que poner el pare. No quisiera que se interrumpa su vida académica y que salga embarazada".

En cuanto al aspecto académico, su rendimiento es promedio y nunca ha presentado problemas aunque sí ha tenido profesores de matemática.

c. Relación del paciente con su hija: 
El examinado refiere que la relación con su hija es "buena"; sin embargo, hay oportunidades en las que ha ofendido a su hija por no dirigirse adecuadamente a ella o al ver a su padre involucrado en altercados en la calle. Así por ejemplo en una oportunidad, Adrián , debía recoger a su hija de un centro comercial, pero se generó un "malentendido" y le dijo “oye cojuda de mierda ¿dónde estás?” tras lo cual empezaron a discutir por teléfono. En otra oportunidad, el evaluado al ir conduciendo su vehículo con su hija de copiloto, un taxista rozó su auto y seguidamente el evaluado bajó del auto a enfrentarse al otro conductor agarrándolo de la camisa para tirarle un puñete; sin embargo, al voltear vio la cara de susto de su hija y decidió parar la pelea. Adrián refiere que en esa oportunidad su hija se quedó callada y éste le pidió disculpas.

Por otro lado, los métodos disciplinarios que utiliza son regaños con un alza en el tono de voz. Nunca ha recurrido a golpes.

d. Relación del cónyuge con su hija:

Es una muy buena relación pues comparten cosas como ropa y temas de peluquería. "Mi hija la friega, son como amigas". Él opina que a su esposa le falta establecer más reglas "falta un poco de madre" en la relación.

e. Relación entre los hermanos:

La relación que tiene Natalia con su hermano Iván es muy buena, conversan y se mandan fotos por el celular. Cuando era más pequeña, ella tendía a "mandonearlo" pero actualmente son muy unidos.

La relación que guarda con Sebastián es también buena e inclusive, el enamorado de Natalia le hace invitaciones a su casa para comer y a veces para ir al cine. "La familia de él muere por Sebastián".

a. Datos de filiación:

1. Nombre y apellidos: I.A.O

2. Sexo: Masculino

3. Edad: 17 años

4. Lugar y fecha de nacimiento: Lima, Perú - 20 de julio de 1997 
5. Tiempo de residencia en lima: Toda su vida

6. Estado civil: Soltero

7. Grado de instrucción: Secundaria Completa

8. Ocupación actual (centro de estudio/trabajo y grado/cargo): Estudiante

9. Religión: Católica no practicante

b. Características personales

Cuando era niño lo describe como tranquilo y distraído "recontra distraído en la forma de caminar, pero a la vez, deportista avezado". Cuenta que cuando Iván tenía 3 años de edad subió a un columpio que colgaba a 3.20 metros del piso desde el cual dio un salto mortal. Nunca ha tenido miedo frente a deportes extremos como el skateboard por ejemplo, aprendió a montar bicicleta a los 3 años. "Siempre lo he visto como un niño con cualidades superiores, mucha destreza, pero cuando camina se estrella contra el poste". De niño pasaba mucho tiempo con su hermana mayor jugando en el parque o en la computadora.

Con respecto a su personalidad, lo describe en la infancia como un chico muy amoroso “jugábamos en la cama con Natalia, la pasábamos bien”. Sin embargo, a medida que fue creciendo, alrededor de los 14 o 15 años, sus intereses fueron cambiando y el tiempo que invertía en su familia fue disminuyendo poco a poco, prefiriendo frecuentar a sus amigos. Asimismo, "poco a poco iba contestando de mala manera". Adrián refiere que frente a esta situación prefirió apartarse debido a que sentía que la comunicación entre él y su hijo era inexistente "sentía que había una pared, porque lo que yo le decía parecía que le molestaba y a mí también". Ambos tienen puntos de vista diferentes; además, en esa época estuvo viajando y fue todo un año en el que estuvo "ausente". A los 16 años Iván empezó a salir de casa y "casi ya no había relación”.

En lo referido al consumo de drogas, ha probado "happy brownies", experiencia sobre la que conversaron e intercambiaron experiencias. Iván le comentó que "no sintió nada" y él dijo a él y a sus demás hijos que "lo probamos en la casa". Afirma que sus hijos están informados respecto al tema de las drogas; a pesar de ello, cada vez que su hijo llega a su casa lo revisa para ver a que huele: nunca ha detectado un olor diferente al alcohol.

Con respecto al área académica "nunca vi a Iván agarrar una tarea”. Lo consideraba súper inteligente pero "después de los resultados de la prueba de inteligencia me di cuenta que salió promedio nomás”. Es un joven que no suele estudiar ni hacer tareas, pero sus 
notas son de alrededor 15 puntos. Por otro lado, ha tenido problemas de conducta por su “carácter explosivo". Terminó la secundaria con matrícula condicional debido a varios incidentes.

Primero, un amigo suyo dijo una lisura a un profesor y él "sacó cara por el amigo", por lo que recibió una penalidad. El segundo incidente fue en la cancha del colegio. Iván estaba corriendo mientras que una amiga lo llamaba, al llegar a la meta él voltea y le dice: “i¿Qué mierda quieres?!”. El vigilante vio la escena y le indicó que en el establecimiento no estaba permitido decir lisuras, a lo que Iván responde con: “¡¿Dónde está el letrero que diga que no se pueden decir lisuras?!”. Llamaron a Adrián pues el colegio tenía la intención de suspenderlo. Al hablar con el tutor de su hijo, éste le dijo que las circunstancias de la ocurrencia justificaban la reacción de Iván, además, indicó que el vigilante no estaba en lugar de llamarle la atención pues "para eso están los profesores". El asunto quedó como una llamada de atención.

Estas "explosiones" también se han dado en el campo deportivo. En una oportunidad casi se pelea con un joven pues éste le tiró un puñete de casualidad; cuando las actividades que realiza no resultan de manera correcta se dice a sí mismo "no me sale nada bien, soy un bruto, un estúpido" y pasa a desechar su trabajo al tacho de basura o romperlo debido a que simplemente una línea no estaba derecha. Al ofrecérsele ayuda, la rechaza.

Iván está bajo un tratamiento farmacológico debido a un TDAH o trastorno bipolar (el paciente no recuerda; sin embargo se confirmó con la historia clínica). Adrián afirma que ha habido una mejora con la medicación, "ya no está tan explosivo"; demás, hay muestras de cariño con la familia que antes no había.

b. Relación del paciente con su hijo:

Refiere que intenta "enseñarle cosas" a su hijo, pero que él no lo escucha. "Conmigo se pica cuando le doy un consejo, lo trato de ayudar y me bota y me voy". No suele ir a los eventos del colegio pues se aburre con facilidad: Adrián dice que Iván "tiene que aprender a que si no quiero, no quiero". Por otro lado, se esfuerza en inculcar que lave sus platos pero él siempre "se olvida". Refiere que en oportunidades no lo saluda y sólo quiere dinero; además, refiere que su esposa es muy permisiva y lo desautoriza frente a su hijo, quedando ella como la "buena" y él como "el malo".

A pesar de sus diferencias, en una oportunidad llegó borracho y él reaccionó dándole una "Sal de Andrews", le indicó que se asee y vaya a dormir. Actualmente ya no esconde 
que fuma "fuma cigarro delante de mí". A pesar de que pasa más tiempo con sus amigos, él afirma que entiende que es parte de su etapa. Por otro lado, le da consejos con respecto al trato del sexo opuesto; cuando su esposa le sugiere salir con una chica que a Iván le parece poco atractiva, él le sugiere conocerla de todas maneras pero afirma que "si sólo se la quiere agarrar, que sea bonita".

c. Relación del cónyuge con su hijo:

Es buena, "Iván necesita mucho de ella", hay una comunicación estrecha entre ambos, mientras que refiere que con él, sus hijos son más "banales" pues acuden a él para pedirle dinero, para que los recoja o para ver una película. En términos generales, la relación entre Iván y su madre es buena aunque en ocasiones "lo saca de quicio" pues le hace preguntas como “¿Por qué no sales con tal chica si está bonita?” Y él responde con que ésta llega de granos, se molesta y se va.

d. Relación entre los hermanos:

Como ya se mencionó, la relación que tiene con Natalia es muy buena. Por otro lado, en un principio, la relación entre Iván y Sebastián no era buena. Sebastián trataba de acercarse a su hermano, pero éste "lo mandaba a rodar porque era muy meloso, se pegaba como chicle y te da ganas de asesinarlo".

Hace un año, la relación empezó a mejorar porque Sebastián fue cambiando su manera de ser. El paciente refiere que ahora es Iván el que se siente apartado y el que busca compañía "porque por ejemplo, le dice a Sebastián para ver una película". 
a. Datos de filiación:

1. Nombre y apellidos: S.A.O

2. Sexo: Masculino

3. Edad: 12 años

4. Lugar y fecha de nacimiento: Lima, Perú - 22 de noviembre del 2002

5. Tiempo de residencia en lima: Toda su vida

6. Estado civil: Soltero

7. Grado de instrucción: Primero de secundaria

8. Ocupación actual (centro de estudio/trabajo y grado/cargo): Estudiante

9. Religión: Católica no practicante

\section{b. Características personales}

Sebastián es un niño cariñoso e inquieto. Es obediente y el más demostrativo de afecto, es un chico alegre, "nunca lo ves molesto". "Es el payaso de la casa, nos alegra la vida a todos". Actualmente pasa su tiempo libre jugando a través de la computadora con sus amigos. Él siempre se ha comunicado con gente mayor, sus abuelos, hermanos mayores así como con chicos menores que él "es un comunicador nato". De grande quiere ser actor; además, gusta del baile y la música.

Adrián describe a su hijo como un niño muy "halagador". En una oportunidad silbó a la profesora de educación física. Ésta se molestó y preguntó por qué había hecho esto a lo que Sebastián respondió: "Porque estás muy bonita”. Así trata a todas sus profesoras.

c. Relación del paciente con su hijo:

El examinado indica que por momentos se siente muy irritado por su hijo pues es muy demandante, "estaba ocupado y él se te paga como lapa y tenía que decirle que espere unos minutos". Pasados unos minutos, reclamaba. Manifiesta haber tenido "ganas de asesinarlo" en estos incidentes. Además, cuando juegan algún videojuego juntos y Sebastián está ganando, Adrián indica sentir enojo y exclama cosas como “¡hasta acá nomás llego, este juego es una porquería! Y tira los controles. El niño en respuesta erra adrede en el juego para que su padre gane. Sin embargo, éste luego se siente aburrido y 
decide retirarse. Pasadas unas horas, trata de volver a iniciar una actividad con su hijo, después de que la cólera pasó.

d. Relación del cónyuge con su hijo:

Tienen una relación muy amorosa "Para Sebastián es su enamorada". Refiere que se sorprende de las cosas que Sebastián dice, como "qué bonita estás", "eres la mamá más bonita" y "todo va a salir bien".

\section{HISTORIA FAMILIAR}

El examinado se enteró de su adopción a los 37 años de edad tras haber tenido sospechas por varios años.

\section{PADRES}

\subsection{Padre}

a. Datos de filiación:

1. Nombre y apellidos: N.A.Y

2. Sexo: Masculino

3. Edad: 85 años

4. Lugar y fecha de nacimiento: Rumania, 20 de marzo de 1928

5. Tiempo de residencia en lima: Vivió en Huacho hasta los 3 años

6. Estado civil: Divorciado

7. Grado de instrucción: Superior (Odontólogo - nunca ejerció)

8. Ocupación actual: Retirado

9. Religión: judía

b. Características personales

Adrián describe a su padre adoptivo como una persona egocéntrica y egoísta, lo considera como una persona poco tolerante "no aguanta a la gente" e indica que era económicamente dependiente de su madre hasta que se divorciaron. No lo conoce bien 
pues vivió con él hasta los 5 años y sus encuentros han sido muy puntuales. Por ejemplo, en los cumpleaños de sus hijos “comía y se iba”. Nunca mostró interés en acercarse a él.

Su padre formó otra familia y tuvo una hija. Un día lo llamó por teléfono para pedirle ayuda para acercarse a su hija; el examinado señala: "yo no tuve ningún inconveniente y lo apoyé”. Así, fueron al colegio de la niña a buscarla, pero la madre de ésta indicó que su padre no podía acercarse. Él entonces fue como su hermano, pero tampoco le permitieron verla. Finalmente ella lo llamó y lograron un acercamiento entre ellos y su padre. No obstante, él la abandonó. Su hermana vive ahora en Estados Unidos y no usa el apellido de su padre. "El distanciamiento que tuvo con su hija fue porque él es una persona que no le gusta compartir, es alguien que le gusta estar solo". Actualmente vive solo con una empleada doméstica.

c. Relación del paciente con su padre

No tiene ni un tipo de relación con su padre, dejaron de convivir cuando Adrián tenía 5 años de edad y en la actualidad no se ven hace un par de años.

\section{2. Madre}

a. Datos de filiación:

1. Nombre y apellidos: R.I.S

2. Sexo: Femenino

3. Edad: Falleció a los 75 años.

4. Lugar y fecha de nacimiento: 23 de Octubre de 1930

5. Tiempo de residencia en lima: No recuerda

6. Estado civil: Divorciada

7. Grado de instrucción: Desconocido

8. Ocupación actual (centro de trabajo y cargo): -

9. Religión: judía

b. Características personales 
Fue una mujer cariñosa, inteligente, trabajadora, responsable, alegre, emprendedora y tenaz. Sin embargo, a la vez, la percibía como sobreprotectora y manipuladora "movía las piezas de ajedrez hacia su conveniencia" Refiere que de niño lo trataba de manipulaba con regalos y que la percibía como la jefa de la familia.

c. Relación del paciente con su madre

De adulto tenía conflictos con ella referidos a sus relaciones amorosas "con las enamoradas, ninguna le parecía, todas eran putas o brujas, menos las judías”. Además, debido a que su relación con ella era estrecha y compartían bastante tiempo juntos en viajes y de manera diaria, su opinión tenía una gran influencia. Él cedía a lo que su madre dijera pues "ella hacía mucho esfuerzo por mí, me ha mantenido, me ha criado y ha dado todo por mí". Su obediencia para él era "como un agradecimiento".

\subsection{Relación entre los padres}

Cuando Adrián tenía 5 años, su madre tomó la decisión de divorciarse de su padre y lo expulsó de la casa. A partir de su divorcio la relación entre ambos fue interrumpida de manera definitiva.

\section{ANTECEDENTES PSIQUIÁTRICOS EN LA FAMILIA}

No se sabe.

\section{PERSONAS SIGNIFICATIVAS INTEGRADAS AL GRUPO FAMILIAR}

Su abuelo materno era como un padre y amigo para él. De niño vivió en su casa por 3 meses mientras su madre se divorciaba. Una vez terminado el proceso, él pasó a vivir el resto de su vida en su casa. "Era una relación muy bacán, éramos amigos, salíamos juntos siempre" Relata que de él aprendió a afeitarse y a "ser hombre"; tomaban leche juntos por más que a su abuelo no le gustara. Además, cuando Adrián tenía salidas nocturnas de las que llegaba a casa a las tres de la mañana, su abuelo lo esperaba despierto. 
Por otro lado, éste tenía el hábito de tirar las puertas, el cual fue adoptado por Adrián ; del mismo modo, de él aprendió a decir insultos. En ocasiones se peleaban "a muerte" y se insultaban mutuamente. Sin embargo, luego de cada pelea se abrazaban. Afirma que en casa había peleas constantes ya que su abuelo, su madre y él mismo compartían el signo zodiacal de Escorpio. Así, cuando su abuelo discutía con su madre, Adrián la defendía o cuando el paciente discutía con ella, su abuelo abogaba por él. A pesar de ello "había mucho amor entre los tres".

Cuando su abuelo fue diagnosticado con cáncer al pulmón debido a que fumaba constantemente y fue internado en la clínica por dos años, fue a Adrián al que llamó primero. Lo iba a visitar regularmente y era él el que lo sacaba a caminar. El día de su muerte, el evaluado partía a un viaje a Miami. Decidió irse a pesar de las circunstancias pues no deseaba afrontar el tema, "me daba mucha pena". Las últimas palabras de su abuelo fueron "Adrián"; afirma sentir dolor por no estar presente, pero a la vez, la pena no fue tan grande pues no lo sintió de manera directa. Actualmente visita el cementerio para "conversar con ellos" (su abuelo y madre). 


\section{ANEXO 2: Instrumentos utilizados}

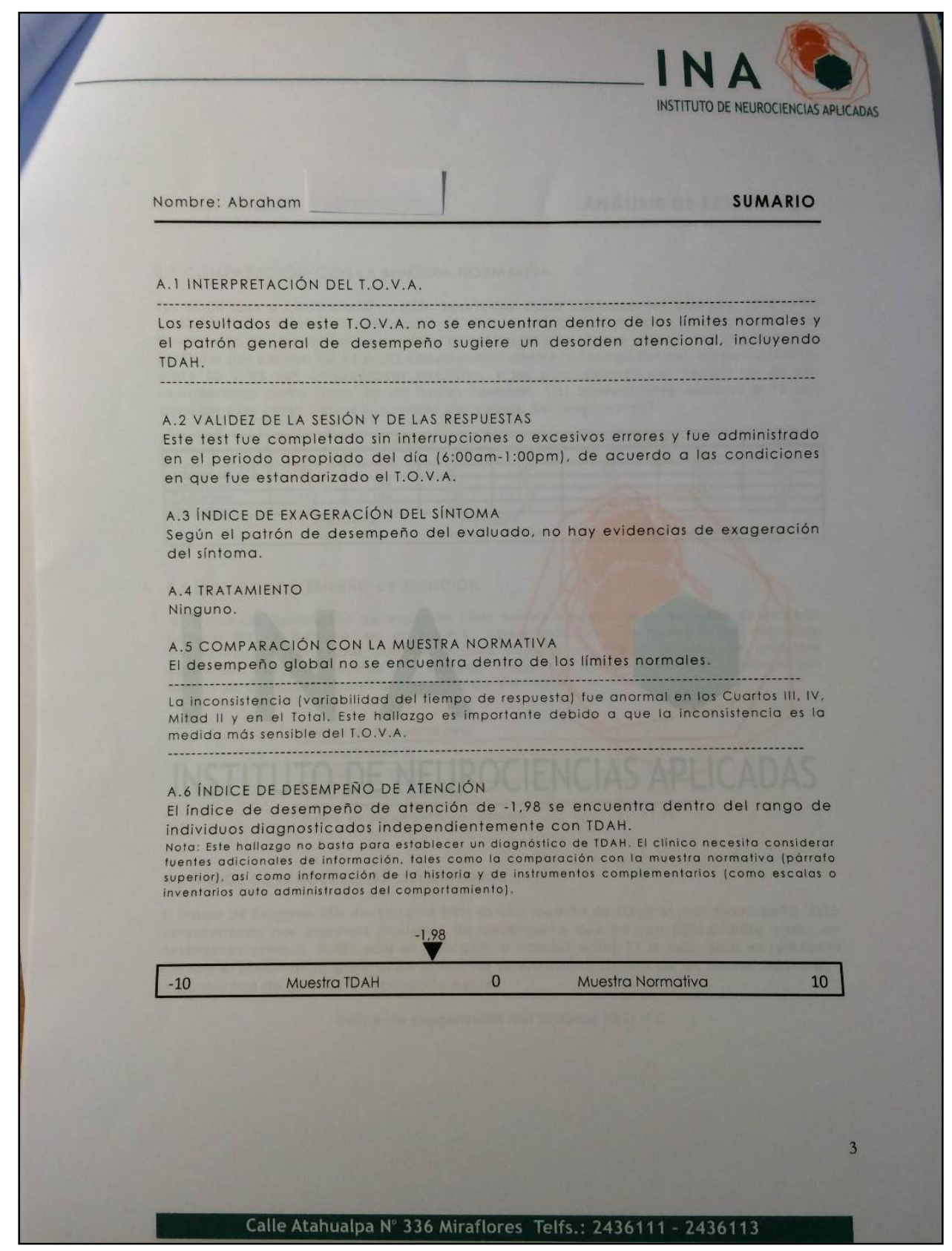

Figura 3. Informe del Test de Variables de Atención T.O.V.A 


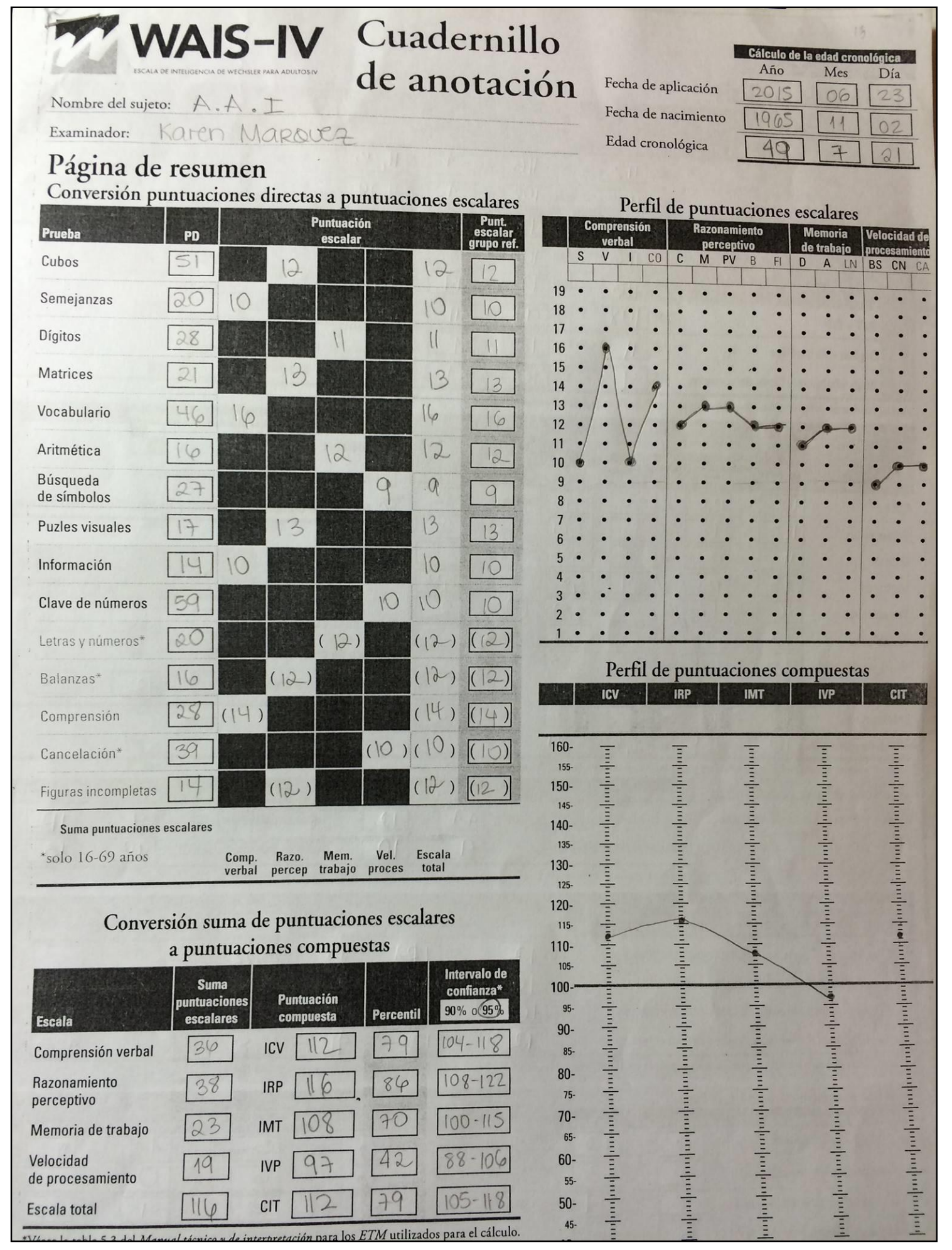

Figura 4: Perfil de puntuaciones y resultados del WAIS-IV. 


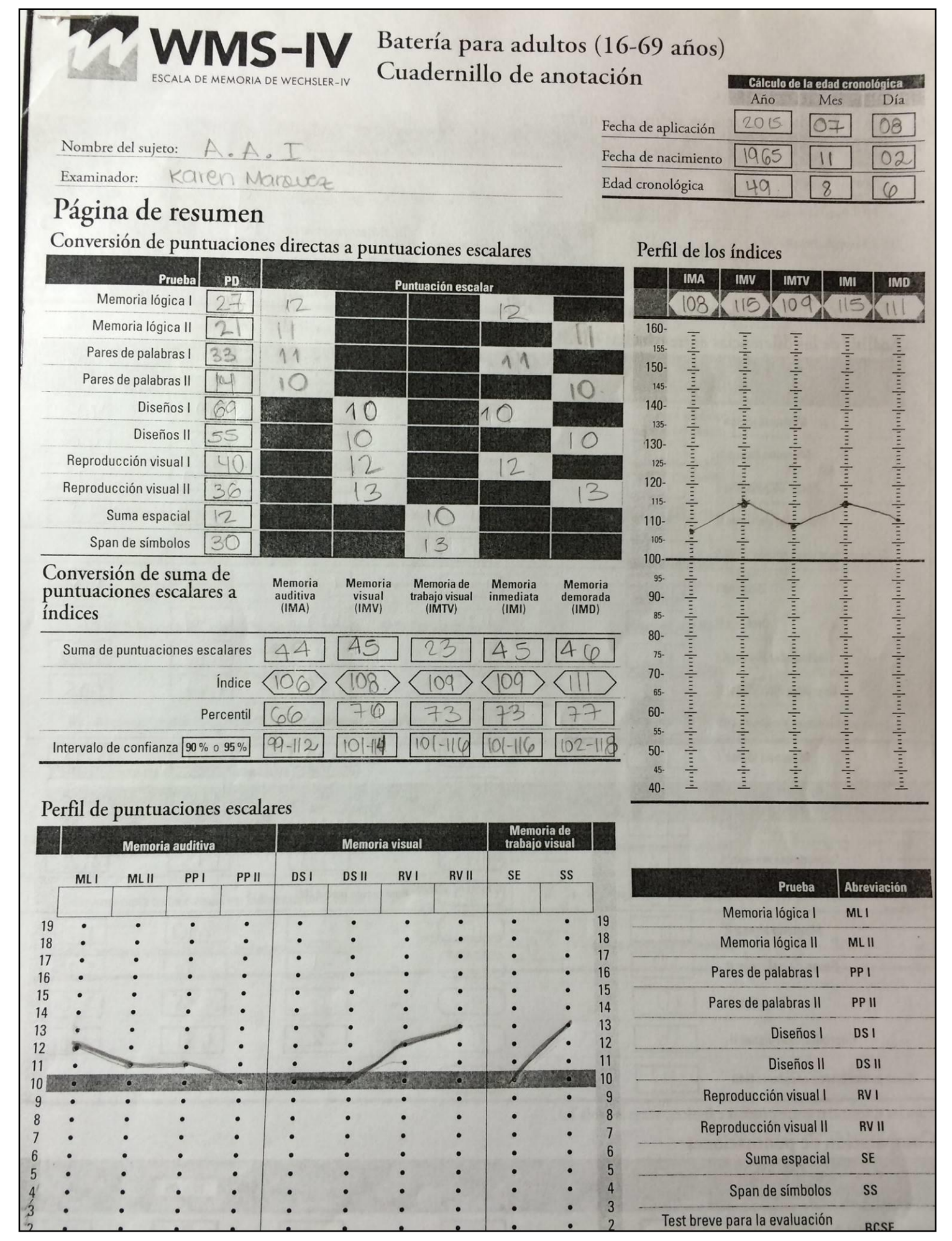

Figura 5: Perfil de puntuaciones y resultados del WMS-IV. 


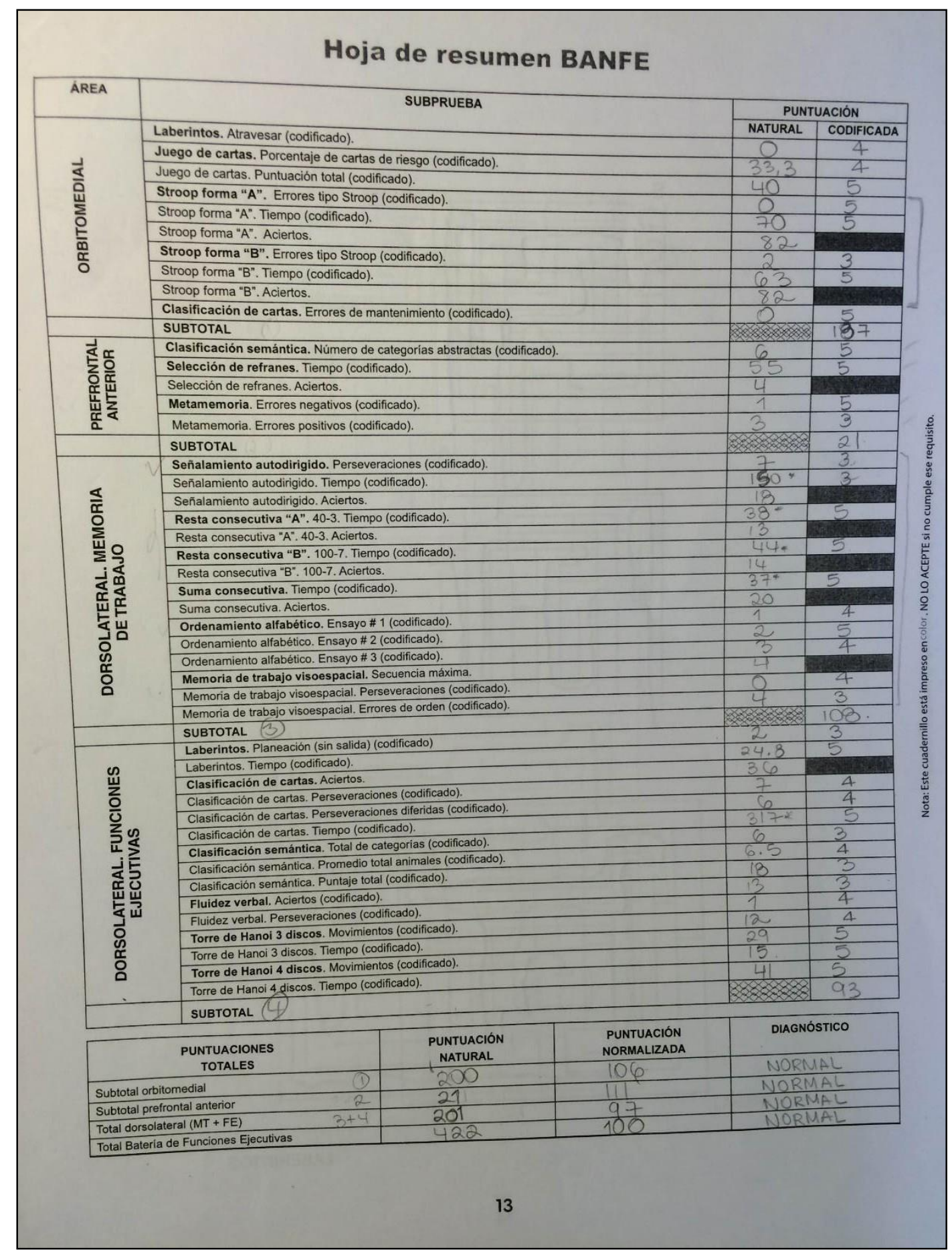

Figura 6: Perfil de puntuaciones y resultados del BANFE-2 


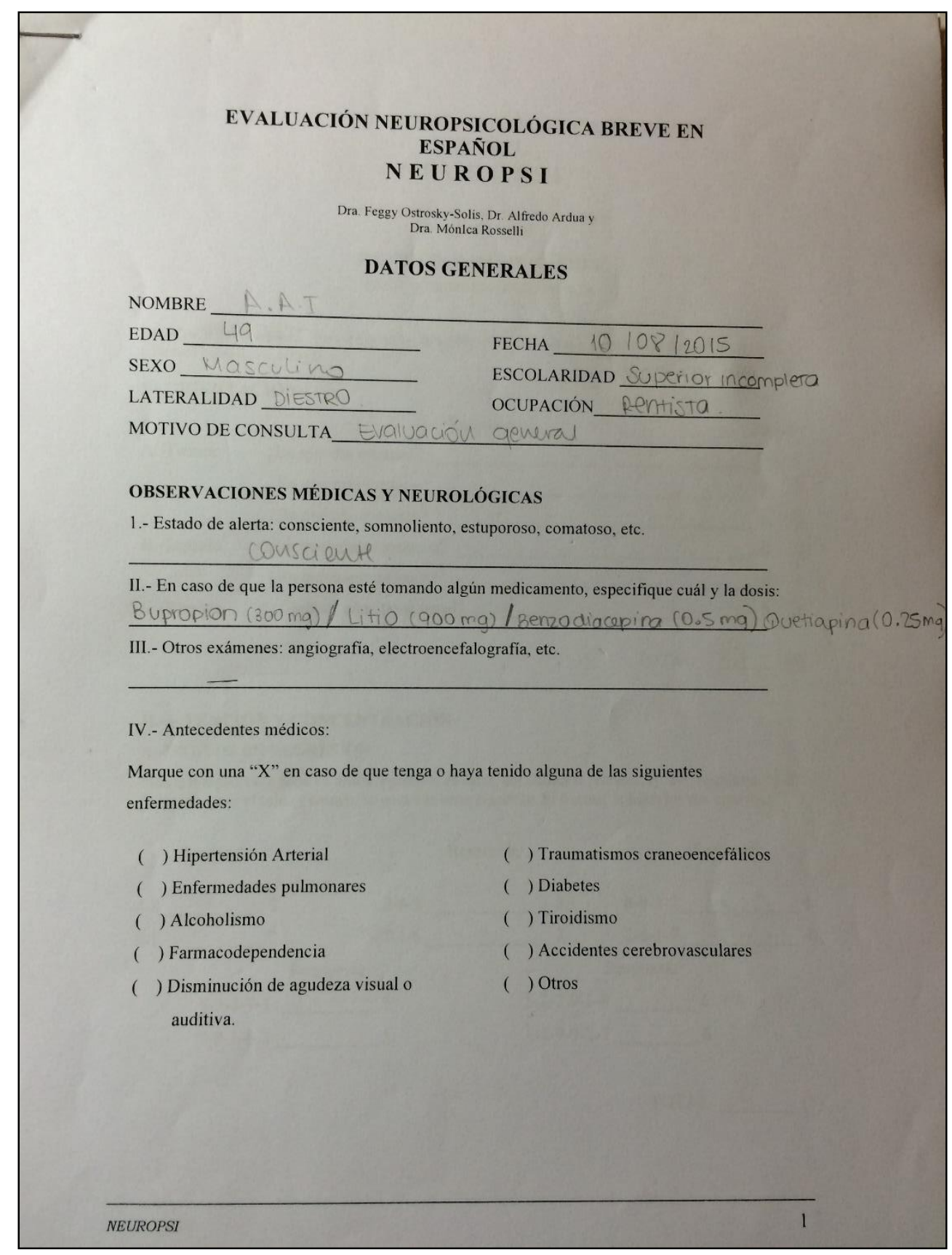

Figura 7: NEUROPSI 


\section{ANEXO 3: Modelo de Anamnesis}

\section{HISTORIA CLIINICA}

\section{DATOS DE FILIACIÓN}

1. Nombres y apellidos

2. Sexo

3. Edad

4. Lugar y fecha de nacimiento

5. Tiempo de residencia en Lima

6. Estado civil

7. Grado de instrucción

8. Ocupación actual

a. Centro de estudios: Grado:

b. Centro de trabajo: Cargo:

9. Religión

10. Con quién vive

11. Número de hermanos/Número de hijos

12. Posición ordinal

13. Lugar de residencia

14. Teléfono

15. Lugar de la entrevista

16. Fecha de la primera entrevista

17. Terapeuta

18. Supervisor

\section{PROBLEMA ACTUAL}

1. Exprese con sus propias palabras la nafuraleza y la duración de su (s) problemas (s) principal (s).

2. En la siguiente escala, evalúe la gravedad del (los) problema (s) señalando (s) anteriormente:

$\begin{array}{llll}1 & 2 & 3 & 4\end{array}$

5

$1=$ levemente perturbador

$2=$ moderadamente grave

$3=$ muy grave

$4=$ sumamente grave

$5=$ totalmente grave

3. Subraye cualquiera de las siguientes palabras que sea aplicable a su caso (puede marcar más de una): 
- dolores de cabeza

- desmayos

- falta de apetito

- problemas digestivos

- depresión

- no puedo entablar amistades

- no puedo conservar un trabajo

- problemas de sueño

- tomar pastillas (indique)

- ansiedad

- pesadillas

- pánico

- conmociones

- problemas de memoria

- problemas sexuales

- incapacidad de tomar una decisión

- consumo drogas (indique)

-excesiva ambición

- otros...
- ideas de suicidio

- dificultades de concentración

- sentimientos de inferioridad

- mareos

- palpitaciones

- fatiga

- tensión

- "nervios"

- evito salir de mi casa

- problemas financieros 
4. Haga una breve reseña de la historia y del desarrollo de su (s) problema (s) desde su origen hasta el presente (indicio, situación, frecuencia, intensidad $(0-$ 10), duración, cambios conductuales y reacción del medio ambiente ante ellos)

5. Señale brevemente a quién ha consultado acerca de su (s) problemas (s) actual (es).

6. Que opina Ud. Sobre su (s) problema (s) actual (es)?

\section{HISTORIA PERSONAL}

Desarrolle brevemente los siguientes puntos:

\section{A. DESARROLLO INICIAL}

1. Edad de los padres cuando Ud. nació.

2. Condición de su madre durante el embarazo.

3. Actitud de su padre y de su madre hacia su llegada.

4. Lugar del alumbramiento / parto.

5. Naturaleza del parto (duración del embarazo, dificultades).

6. Peso y tamaño al nacer: otros datos relevantes.

7. Nutrición general y dificultades en la alimentación.

8. Edad de inicio de: la marcha, las primeras palabras y el control de esfínteres (pedir ir al baño).

9. Persona a cargo de su cuidado durante su niñez (si fuera otra distinta a sus padres, indique la razón).

- Subraye cualquiera de las siguientes situaciones que haya tenido lugar durante su niñez:emor nocturno

- chuparse el dedo

- orinarse en la cama

- tartamudez

- temores en general

- comerse las uñas

- sonambulismo

- rabietas

- otros:

10. Tipo de juegos preferidos durante su niñez. 
11. Dé una impresión sobre la atmósfera que reinaba en su hogar cuando Ud. era niño.

12. En términos generales, como considera que fue su niñez?

\section{B. EDUCACIÓN}

\section{a. Historia escolar}

1. Edad y año de ingreso al nido / jardín de infantes

2. Indique cómo se sintió en el nido, la relación con sus compañeros y profesores y mencione algún recuerdo significativo de esta etapa.

3. Edad y año de ingreso al colegio.

4. Nombre y tipo (mixto, sólo mujeres / hombres; estatal, particular; laico, religioso) del (los) colegio (s) donde ha cursado sus estudios escolares. Si fuera más de uno, indique las razones de su traslado y el (los) año (s).

5. De una impresión general de sus primeros días de clase.

6. Haga una reseña de su historia escolar, en base a los siguientes datos:

- Relación con sus compañeros y/o compañeras

- Relación con sus profesores y/o profesoras

- Nota promedio de todos los años escolares y ubicación en el cuadro de méritos de su salón.

- Monto de esfuerzo en sus estudios (haga una diferenciación por años si es relevante)

- Cursos preferidos y aquellos que le gustaban menos

- Cursos en los que le fue mejor o peor

- Grado de participación académica en clases

- Grado de participación en las actividades, juegos y actuaciones

- Años repetidos; indique el motivo y las consecuencias

- Conducta (buena - regular - mala; tipo de problemas)

- Dificultades de aprendizaje (falta de atención, de concentración, etc.) 
7. Asistía regularmente a clases? Si su respuesta es NO, indique los motivos.

8. Se sentía integrado (a) a su grupo de compañeros? Por qué?

\section{b. Otros estudios realizados}

1. Debido a dificultades en el aprendizaje y/ o de conducta, realizó estudios en algún centro especial? Si su respuesta es SI, especifique el nombre de la institución y el (los) año (s) que asistió.

2. Ha realizado algún tipo de estudios paralelo o posterior al colegio? Indique cuáles y en que años.

3. Estudia o estudió alguna carrera técnica y/o universitaria? Indique cuáles, dónde y los años de estudio.

4. Haga una breve reseña de sus estudios profesionales o técnicos, siguiendo los mismos lineamientos que para la pregunta 6 , del apartado anterior.

\section{RELACIONES INTERPERSONALES}

a. Amistades (desde la adolescencia)

1. Le resulta fácil establecer y conservar amistades? Por qué?

2. Tiene algún amigo muy cercano o íntimo al que Ud. pueda contar información muy personal?

3. Considera Ud. que es una persona amiguera y que cuanta con muchos amigos, o es mas bien una persona "de pocos amigos".

4. Qué tipo de actividades suele compartir con sus amigos?

5. Cómo se siente cuando se encuentra con sus amigos? 
6. Realice una evaluación de cómo se han ido desarrollando sus relaciones interpersonales.

b. Relación con el sexo opuesto

1. Cantidad de enamorados (as) y edad en que los (las) tuvo.

2. Realice una breve reseña de la (s) relación (es) mas significativas que tuvo, especialmente de la primera, indicando el motivo de la (s) ruptura (s).

3. Realice una evaluación de lo que significa para Ud. una relación de pareja.

4. Si Ud. tiene enamorado (a) actualmente, conteste a lo siguiente: (no contestar si Ud. es casado)

- edad de su pareja

- ocupación

- descripción física y características de personalidad

- cómo se conocieron

- grado de satisfacción actual con su relación

- aspectos que le agradan y que le desagradan de él (ella)

\section{SEXUALIDAD}

a. Información sobre el sexo

1. Hubo instrucción sexual o conversaciones sobre el tema en su casa?

2. Actitud de sus padres en relación al sexo.

3. Cuándo y cómo adquirió sus primeros conocimientos sobre el sexo (padre, madre, hermanos, familiares, amigos, colegio, películas, libros, revistas, religiosos)?

4. Considera que la información que tiene sobre el sexo es suficiente y adecuada? Indique por qué.

5. Considera que la educación sexual es importante?

b. Historia sexual

5. Cuándo tomó Ud. conciencia de sus propios impulsos sexuales? 
6. Alguna vez se sintió angustiado o culpable por realizar algún tipo de actividad sexual? En caso afirmativo, especifique.

7. Que opina Ud. sobre la masturbación?

8. Se ha masturbado Ud. alguna vez? Cuando fue la primera vez que se masturbo? Cómo se sintió?

9. Con cuánta frecuencia se masturba Ud. actualmente?

10. Que recuerdos tiene acerca de los cambios que se dieron en su cuerpo durante la pubertad? Cómo se sintió?

11. A qué edad tuvo su primera regla? Cómo se sintió? Cuál fue la reacción de su medio ambiente?

12. Su regla es: Regular? SI $\mathrm{NO}$

13. Frcuencia (cada cuántos días)

14. Duración

15. Padece de dolores? SI $\mathrm{NO}$ Antes

16. Durante

17. Le afecta la regla el estado de ánimo? Cómo así?

18. Ha tenido relaciones sexuales? Si las tuvo, especifique a que edad tuvo su primera relación sexual, y cómo se sintió.

19. Mantiene Ud. actualmente relaciones sexuales? Con quién (es)? Son satisfactorias? Especifique.

20. Presenta algún problema en sus relaciones sexuales? Especifique.

21. Alguna vez ha tenido prácticas y/o intereses sexuales fuera de lo común? Especifique.

\section{E. EDUCACIÓN Y ACTITUDES RELIGIOSAS}

1. De qué forma lo castigaban sus padres o la (s) persona (s) a su cargo cuando era pequeño?

2. Y de que forma lo premiaban? 
3. Recuerda Ud. cómo se sentía cuando era premiado o castigado?

4. Considera Ud. que había una coherencia entre lo que sus padres le decían y lo que hacían?

5. Describe en pocas palabras su formación y participación religiosa.

\section{F. HISTORIA DEL TRABAJO}

1. Se mantiene Ud. solo o depende económicamente de alguien?

2. Qué tipo de trabajo desempeño en el pasado? Mencione por cuánto tiempo trabajó, su grado de satisfacción con el trabajo, en qué empleaba su sueldo, cómo se llevaba con sus compañeros y con sus jefes.

3. Qué tipo de trabajo desempeña Ud. actualmente? Mencione desde cuándo lo hace y los puntos anteriores.

4. Que trabajo le gustaría desempeñar en un futuro?

\section{G. HISTORIA DE LA RECREACIÓN}

1. En que ocupa su tiempo libre?

2. Existen actividades que le gustaría realizar y que no lo hace actualmente? Por qué? Cuáles son?

3. Le gustan los deportes? Practica actualmente alguno? Cuál (es)?

\section{H. HÁBITOS}

\section{ENFERMEDADES Y ACCIDENTES}

1. En general, cuál fue su estado de salud durante su infancia. Enumere las enfermedades que tuvo y la edad que tenía (reacción de padres u otros).

2. Mencione cuál es su estado se salud desde la adolescencia hasta la actualidad. Enumere las enfermedades que tuvo y la edad que tenía, así como algún dato que considere significativo (reacción padres u otros).

3. Ha tenido intervenciones quirúrgicas? Enumérelas, indique razón y especifique la edad.

4. Ha tenido algún accidente? Especifique la edad y las consecuencias. 


\section{J. MOVILIDAD E INSTALACIÓN}

1. Ha cambiado de residencia alguna vez? Especifique: motivo del cambio, fecha, lugar, tiempo de permanencia en cada lugar, con quién (es) vivía.

2. Cómo se ha sentido al cambiar de residencia?

3. Hable de algo acerca de su adaptación al nuevo ambiente / medio.

\section{K. RÉCORD POLICIAL / JUDICIAL}

1. Ha tenido algún problema con la justicia? En que año? Coméntenos al respecto (motivo, cómo se resolvió el problema, etc.)

\section{HISTORIA MARITAL O DEL COMPROMISO ACTUAL}

\section{HISTORIA FAMILIAR}

\section{A. PADRES}

1. Padre

a. Datos de filiación

1. Nombres y apellidos

2. Edad

3. Lugar y fecha de nacimiento

4. Tiempo de residencia en Lima

5. Estado civil

6. Grado de instrucción

7. Ocupación actual

8. Religión

9. Idiomas

b. Características personales

1. Describa la personalidad de su padre (pasada y presente)

c. Relación del paciente con su padre

1. Cómo calificaría la relación con su padre?

2. Cómo le gustaría que fuera?

2. Madre

a. Datos de filiación

1. Nombres y apellidos

2. Edad

3. Lugar y fecha de nacimiento

4. Tiempo de residencia en Lima

5. Estado civil 
6. Grado de instrucción

7. Ocupación actual

8. Religión

9. Idiomas

b. Características personales

Describa la personalidad de su padre (pasada y presente)

c. Relación del paciente con su madre

3. Relación entre los Padres

1. Describa brevemente la relación pasada y presente entre sus padres.

B. HERMANOS (para cada uno de ellos)

a. Datos de filiación (igual que la de los hijos)

b. Características personales

1. Describa brevemente las características de personalidad de cada uno de sus hermanos.

c. Relación del paciente con su (s) hermanos

1. Cómo calificaría la relación del pasada y actual que lleva con cada uno de sus hermanos y con ellos en general?

d. Relación de los padres con su (s) hermano (s)

1. Cómo calificaría la relación pasada y actual de sus padres con cada uno de sus hermanos y con ellos en general?

e. Relación entre los hermanos

1. Cómo se llevan sus hermanos entre sí? (alianzas, rivalidades, competencias)

C. ANTECEDENTES MEDICOS PSIOUIATRICOS DE LA FAMILIA

1. Hubo o hay algún caso de enfermedad en su familia que merezca ser mencionado?

2. Algún miembro de su familia sufre de alcoholismo, epilepsia o algún otro problema que pueda considerarse un "trastorno mental"? Especifique.

\section{PERSONAS SIGNIFICATIVAS INTEGRADAS AL GRUPO FAMILIAR}

1. Existe alguna persona que viva con Ud. o esté vinculada a su grupo familiar (tío, primo, abuelos, etc.)

2. Cómo es su relación actual con esa (s) persona (s)? 


\section{ANEXO 4: Consentimiento informado}

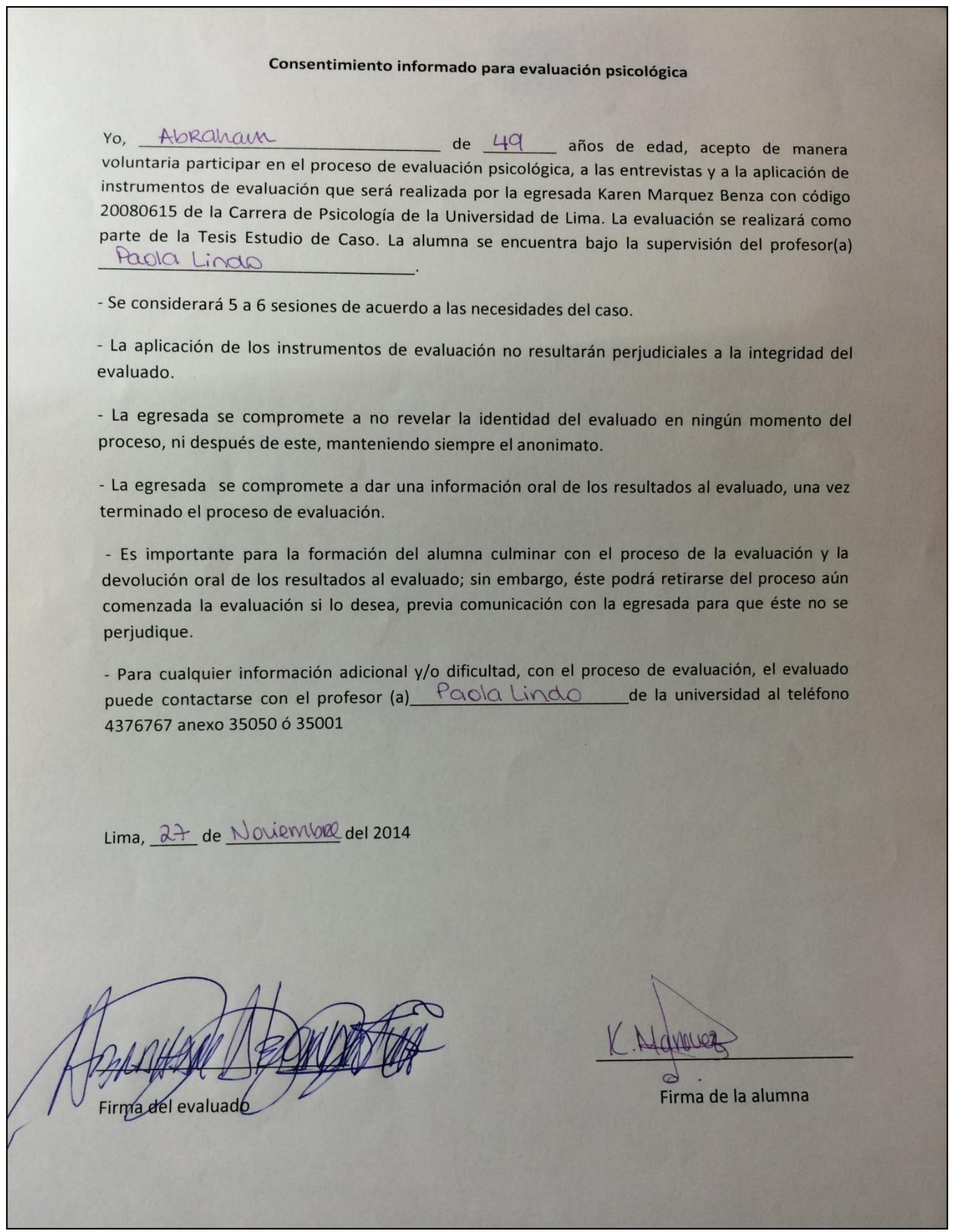




\section{ANEXO 5: Plan terapéutico para la depresión}

\begin{tabular}{|c|c|c|c|}
\hline Síntomas & & Objetivos & Técnicas \\
\hline Cognitivos & $\begin{array}{l}\text { - Sobre sí mismo: Soy un bueno para } \\
\text { nada", "no tengo fuerzas para volver a } \\
\text { comenzar y para creer en mí" "soy un } \\
\text { fracaso", "ya trabaje de todo hace algunos } \\
\text { años, ya no estoy para eso"" } \\
\text { - Sobre los demás: "mis hijos no tienen el } \\
\text { mejor ejemplo" "mi esposa no es } \\
\text { compañera ni amiga" "la casa parece un } \\
\text { ambiente normal y feliz" } \\
\text { - Sobre el futuro: "la situación del país } \\
\text { cada vez está peor, no sé si será bueno } \\
\text { invertir", "no sé qué pasará de acá a unos } \\
\text { años" }\end{array}$ & $\begin{array}{l}\text { 1. Identificar ante qué situaciones, personas o } \\
\text { conductas, el estado emocional se ve alterado, } \\
\text { así como las cogniciones que surgen de las } \\
\text { mismas. } \\
\text { 2. Identificar pensamientos automáticos, } \\
\text { creencias subyacentes. Alcanzar nuevas } \\
\text { perspectivas que desafíen las creencias } \\
\text { disfuncionales } \\
\text { 3. Modificar los sesgos cognitivos de los estilos } \\
\text { de atribución } \\
\text { 4. Generar mayor conocimiento de sus síntomas } \\
\text { y consecuencias }\end{array}$ & $\begin{array}{l}\text { 1. Autorregistros } \\
\text { 2. Descubrimiento } \\
\text { guiado (Dialogo } \\
\text { Socrático) } \\
\text { 3. Técnicas de } \\
\text { retribución }\end{array}$ \\
\hline Conductuales & $\begin{array}{l}\text { - Recurre a fumar un cigarrillo o a ver } \\
\text { televisión } \\
\text { - Inactividad en el área laboral } \\
\text { - Discute con hijos y esposa }\end{array}$ & $\begin{array}{l}\text { 1. Aumentar la percepción de la capacidad para } \\
\text { controlar el tiempo y realizar actividades. } \\
\text { Cambiar la creencia de inutilidad }\end{array}$ & $\begin{array}{l}\text { 1. Programa de } \\
\text { actividades }\end{array}$ \\
\hline Emocionales & $\begin{array}{l}\text { - Tristeza } \\
\text { - Frustración } \\
\text { - Falta de motivación para emprender } \\
\text { proyectos laborales } \\
\text { - Sentimientos de inutilidad } \\
\text { - Sentimientos de culpa }\end{array}$ & $\begin{array}{l}\text { 1. Aliviar sentimientos de tristeza } \\
\text { 2. Reducir sentimientos de culpa }\end{array}$ & $\begin{array}{l}\text { 1. Técnica de la } \\
\text { distracción externa } \\
\text { 2. Análisis de la } \\
\text { responsabilidad }\end{array}$ \\
\hline Fisiológicos & - Cansancio- Abatimiento & Elevar el nivel de energía & Medicación \\
\hline
\end{tabular}




\section{ANEXO 6: Plan terapéutico para el TDAH}

\begin{tabular}{|c|c|c|c|}
\hline Síntomas & & Objetivos & Técnicas \\
\hline Cognitivos & $\begin{array}{l}\text { - Sobre sí mismo: "no acabo con lo } \\
\text { que empiezo" "no sé qué hacer con } \\
\text { mi tiempo libre", "no tengo idea por } \\
\text { donde comenzar" "como si la sangre } \\
\text { me hirviera", "como si viniera un } \\
\text { maretazo, pero viene con todo" } \\
\text { - Sobre los demás: "mis hijos no } \\
\text { hacen las cosas como deberían, no se } \\
\text { dejan ayudar" "en lima manejan } \\
\text { puros idiotas", "me malogra todo el } \\
\text { día" }\end{array}$ & $\begin{array}{l}\text { 1. Identificar ante qué situaciones, } \\
\text { personas o conductas, el estado } \\
\text { emocional se ve alterado, así como las } \\
\text { cogniciones que surgen de las mismas. } \\
\text { 2. Identificar pensamientos automáticos, } \\
\text { creencias subyacentes. } \\
\text { 3. Alcanzar nuevas perspectivas que } \\
\text { desafíen las creencias disfuncionales } \\
\text { 4. Análisis del costo beneficio } \\
\text { 5. Encontrar interpretaciones y } \\
\text { explicaciones alternativas ante los } \\
\text { problemas } \\
\text { 6. Mayor conocimiento de sus síntomas } \\
\text { y consecuencias }\end{array}$ & $\begin{array}{l}\text { 1. Autorregistros } \\
\text { 2. Descubrimiento guiado (Dialogo } \\
\text { Socrático) } \\
\text { 3. Evaluar las ventajas y desventajas } \\
\text { de las cogniciones, conductas y } \\
\text { emociones } \\
\text { 4. Técnica de conceptualización } \\
\text { alternativa }\end{array}$ \\
\hline Conductuales & $\begin{array}{l}\text { - Grita a sus hijos } \\
\text { - Los critica si está jugando con } \\
\text { alguno de ellos deja de jugar } \\
\text { - Baja del carro a enfrentarse con el } \\
\text { otro conductor y en algunas } \\
\text { ocasiones ha llegado a los golpes, } \\
\text { - En la casa al realizar las actividades } \\
\text { las tira al suelo o a la basura. } \\
\text { - Realiza viajes riesgosos en moto }\end{array}$ & $\begin{array}{l}\text { 1. Aprender a actuar ante las situaciones } \\
\text { demandantes } \\
\text { 2. Aumentar la capacidad del individuo } \\
\text { para identificar soluciones eficaces } \\
\text { para afrontar situaciones demandantes } \\
\text { 3. Mejorar la calidad de las relaciones } \\
\text { interpersonales, de comunicación y } \\
\text { relacionales }\end{array}$ & $\begin{array}{l}\text { 1. Juego de roles } \\
\text { 2. Técnicas de solución de problemas } \\
\text { 3. Entrenamiento en Habilidades } \\
\text { Sociales }\end{array}$ \\
\hline Emocionales & $\begin{array}{l}\text { - Cólera } \\
\text { - Rabia } \\
\text { - Irritabilidad }\end{array}$ & $\begin{array}{l}\text { 1. Aprender a reconocer y a discriminar } \\
\text { un estado emocional evaluar sus } \\
\text { recursos y estrategias para hacer frente } \\
\text { a dicha situación y poner en marcha }\end{array}$ & $\begin{array}{l}\text { 1. Técnica de entrenamiento en la } \\
\text { regulación emocional } \\
\text { 2. Inoculación del estrés } \\
\text { 3. Entrenamiento en } \\
\text { autoinstrucciones }\end{array}$ \\
\hline
\end{tabular}




\begin{tabular}{|l|l|l|l|}
\hline \multirow{5}{*}{} & & $\begin{array}{l}\text { un plan que lo ayude a inhibir la } \\
\text { conducta impulsiva. } \\
\text { 2. Reducción de autoverbalizaciones, } \\
\text { imágenes y emociones que afecten el } \\
\text { funcionamiento adecuado. } \\
\text { 3. Generar el mayor número de } \\
\text { autoinstrucciones adaptativas para } \\
\text { guiar con éxito su conducta }\end{array}$ & \\
\hline Fisiológicos & $\begin{array}{l}\text { 1. Reducir el estado de activación } \\
\text { fisiológica, y que por ende influyen en } \\
\text { los procesos emocionales, cognitivos y } \\
\text { conductuales }\end{array}$ & 1. Técnicas de relajación \\
\hline
\end{tabular}

